\title{
UNE CONCENTRATION DE VESTIGES CARACTÉRISTIQUES DU BEURONIEN À SEGMENTS : LE GISEMENT DE WARLUIS I (OISE)
}

\author{
Thierry DUCROCQ, Anne BRIDAULT, Nicolas CAYOL \& Sylvie COUTARD
}

\section{INTRODUCTION}

Des opérations d'archéologie préventive sur une carrière de graviers de la SA Chouvet ont permis d'étudier plusieurs gisements du Paléolithique final et du Mésolithique inscrits dans la plaine alluviale tourbeuse du Thérain.

La première fouille a concerné le gisement mésolithique de Warluis I (= Méso 1) à la fin de l'année 2000. Les moyens consacrés à l'approche sur le terrain ont été nettement trop restreints à cause d'un projet initial réduit mais surtout en raison d'une surprenante pluviométrie continue, prémices des inondations spectaculaires qui allaient affecter les vallées tourbeuses picardes au début de 2001 (fig 1). La fouille manuelle, suivi d'un tamisage en laboratoire, a été de ce fait limitée à $27 \mathrm{~m}^{2}$. Par ailleurs, près de $150 \mathrm{~m}^{2}$ ont été traités à la pelle mécanique.

Bien que ces faits restreignent la documentation, le site I livre des informations de qualité avec sa riche industrie lithique, ses nombreux restes fauniques et une datation absolue de noisettes carbonisées bien associées au reste du mobilier. Ainsi, il est possible d'aborder de nombreuses questions comme :

- les processus taphonomiques de constitution du gisement ;

- l'insertion environnementale ;

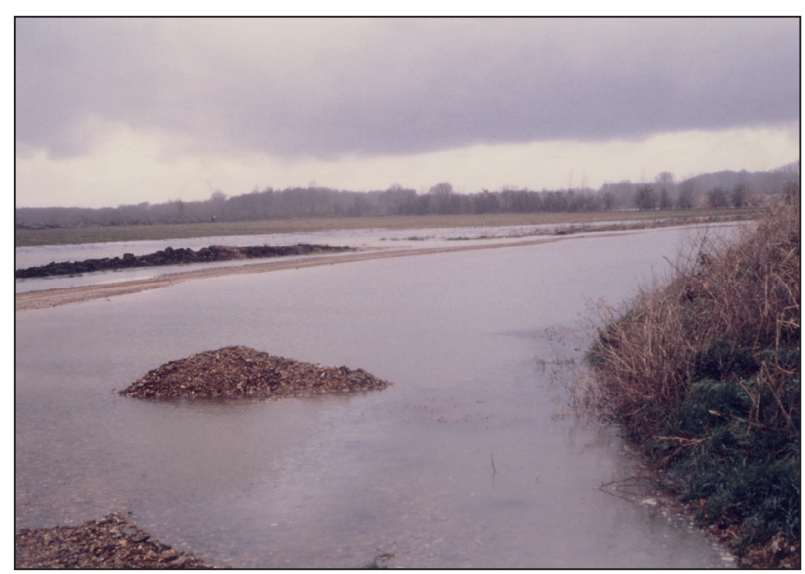

Fig. 1 - L'inondation de la vallée du Thérain a considérablement gêné la fouille du site I (le crédit des illustrations est à porter aux auteurs sauf dans certains cas signalés).
- l'identification techno-typologique de l'industrie lithique ;

- l'insertion chronoculturelle ;

- l'exploitation des ressources ;

- la caractérisation fonctionnelle du site.

Le présent travail s'appuie en partie sur des données déjà communiquées dans un rapport de fouilles (Ducroce et al. 2003). L'approche archéozoologique, les aspects géoarchéologiques et l'étude fonctionnelle des silex taillés sont respectivement traités par A. Bridault, S. Coutard et N. Cayol. L'analyse typo-technologique de l'industrie et la direction de l'ensemble est assurée par T. Ducrocq. En outre, cette publication s'inscrit dans un projet de diffusion progressive de la totalité de la documentation. Ainsi, après une présentation préliminaire de l'ensemble du site (Ducroce et al. 2008), une approche synthétique du cadre naturel a été proposée (COUTARD et al. 2010), suivie de l'étude de petites concentrations assez singulières (Warluis VI et IX ; Ducroce 2010).

\section{LOCALISATION EN UN LIEU PARTICULIÈREMENT ATTRACTIF}

Situé à quelques kilomètres au sud-est de Beauvais (fig. 2), le gisement s'inscrit dans la vallée tourbeuse du Thérain. Cet affluent de l'Oise s'écoule vers le sud en empruntant un axe synclinal parallèle au Pays de Bray. Au niveau de la carrière, la rive droite est façonnée dans les formations tertiaires tandis que la rive gauche est au contact du plateau crayeux, parsemé de quelques buttes témoins. Quelques kilomètres en aval, l'ensemble de la vallée s'inscrit entièrement dans les formations tertiaires. Les terrains tertiaires sont principalement des sables, des argiles et des calcaires (Thanétien, Yprésien, Lutétien). Des terrasses alluviales (Fy) sont en outre cartographiées principalement en rive gauche. Ainsi, il semble que le substrat de la vallée au niveau du site soit constitué de sables tertiaires (e2 : Sables de Bracheux) (BLONDEAu et al. 1970). Sur la rive gauche, le Ru de Laversines rejoint actuellement le cours du Thérain à moins d'un kilomètre en amont du site. Il peut correspondre au paléochenal observé à proximité immédiate du site I. 


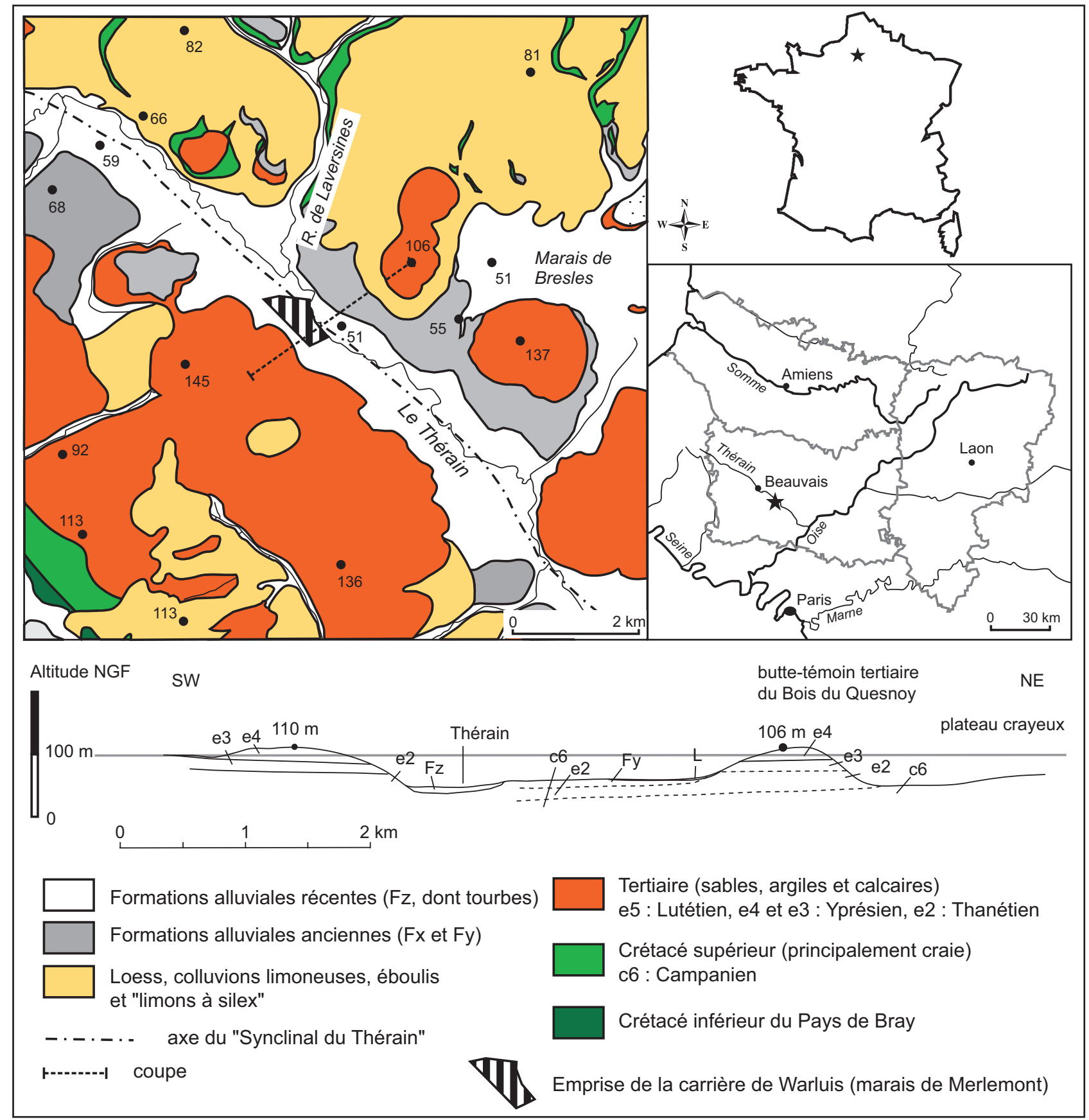

Fig. 2 - Insertion du site dans son cadre géographique et géologique.

Les cours d'eau, le relief varié avec une combinaison de versants raides et peu escarpés, ainsi que l'alternance de sols limoneux, argileux, sableux et crayeux ont probablement produit un paysage en mosaïque avec des ressources végétales et animales variées.

Un autre attrait de ce secteur est l'abondance de la matière première lithique représentée par le silex de la craie campanienne. Il peut être récolté directement sur les versants crayeux ou en position secondaire en bas de versant, sur les terrasses ou sur des dômes graveleux de la plaine alluviale. Enfin, la présence des blocs de grès paléocènes permet de s'approvisionner en pierre tendre et abrasive, notamment pour être utilisée en percuteur.
Par toutes ses caractéristiques, un tel milieu contraste avec la monotonie des plateaux picards. En effet, il offre des ressources abondantes et diversifiées qui ont du être particulièrement attractives pour les chasseurs-cueilleurs mésolithiques.

\section{LE PALÉOENVIRONNEMENT}

\section{La position précise des sites mésolithiques du gisement de Warluis}

À l'échelle des quarante hectares de la carrière, trois ensembles morpho-sédimentaires principaux peuvent être distingués en fonction de la dilatation de la sédimentation au-dessus de la nappe de fond (COUTARD et al. 2010 ; fig. 3) : 


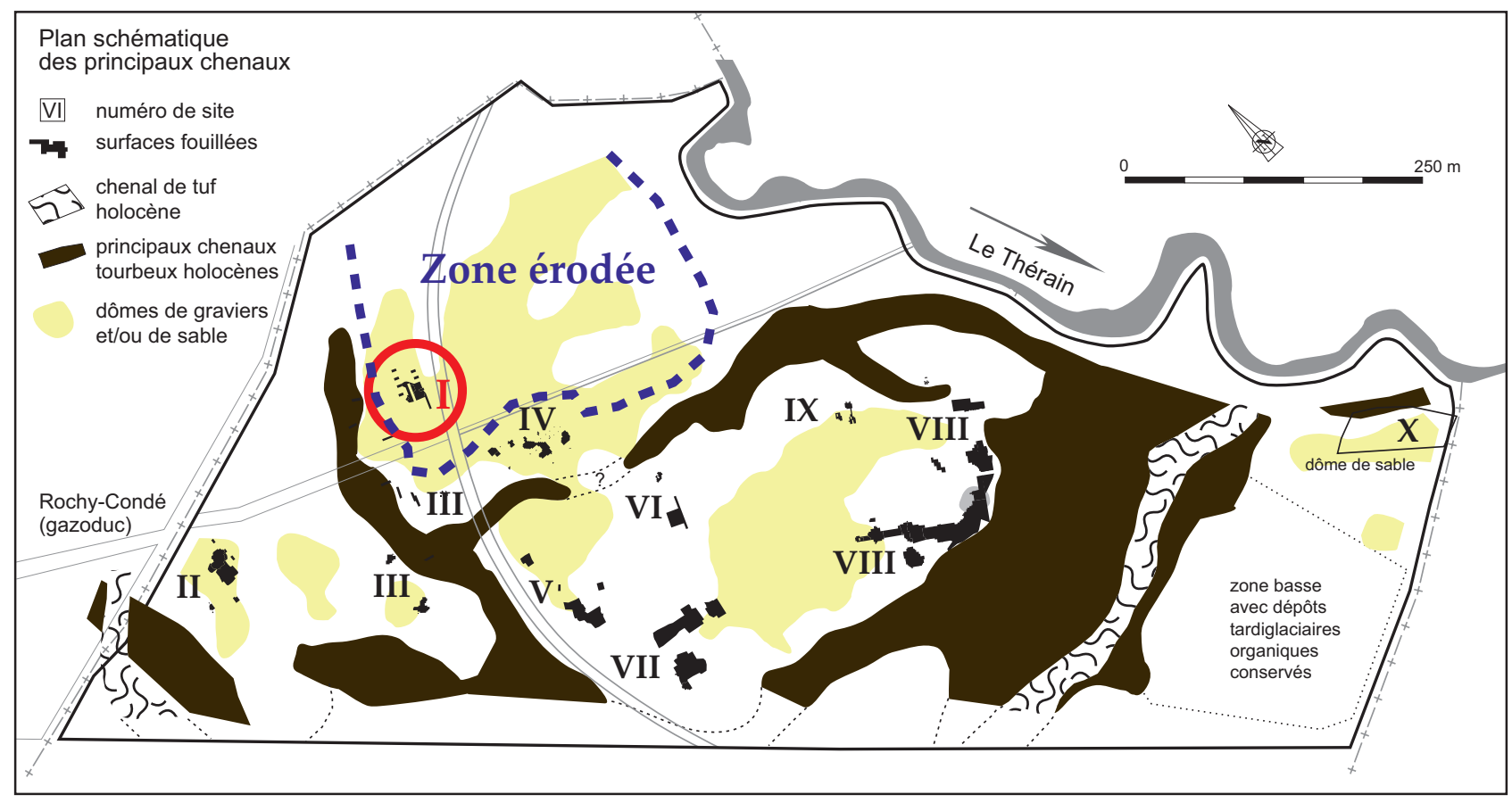

Fig. 3 - Répartition des sites, des chenaux et des dômes.

- les chenaux, colmatés par des sédiments généralement organiques ( $\mathrm{d}$ 'âge tardiglaciaire et/ ou holocène) ;

- une zone basse livrant des vestiges mésolithiques et paléolithiques inclus dans d'épais limons organiques recouverts par des tourbes (sites III, V, VI, VII, VIII, IX) ;

- des zones hautes (ou dômes) où ces limons sont quasiment absents. Les vestiges archéologiques y sont inclus dans des limons sableux ou des sables graveleux reposant généralement directement sur la grave (sites I, II et IV).

S'y ajoutent des zones dites "très hautes ", où l'épaisseur de sédiment recouvrant les graviers peut être réduite à moins de $50 \mathrm{~cm}$ (terre végétale comprise), sans dépôt organique. Aucun site archéologique n'a été reconnu dans ces secteurs, qui ont probablement subi une érosion importante.

Les zones hautes sont liées à la présence de dômes de graviers. En effet, la base de la séquence sédimentaire de fond de vallée est une nappe de fond composée de galets de silex plus ou moins roulés. Cette nappe de fond forme des dômes, probablement hérités des écoulements en tresse en contexte périglaciaire. Certains dômes sont recouverts par place de sables ou de limons sableux blanchâtres. Les zones hautes sont situées environ $50 \mathrm{~cm}$ plus haut que les zones dites basses. Ce faible écart altimétrique est suffisant pour entrainer une évolution différente de la sédimentation. Ainsi, les limons organiques des zones basses sont absents sur les points hauts. De même, les tourbes franches sont cantonnées dans un premier temps aux chenaux avant d'envahir la majeure partie du fond de vallée sans recouvrir les espaces les plus hauts. Sur le site I, leur équivalent latéral est une tourbe limono-graveleuse mince.

ÀWarluis,commepourtouslessitesmésolithiques des vallées tourbeuses picardes ((DuCROCQ 2001), les vestiges se trouvent dans un limon, parfois sableux, qui est scellé par des tourbes. C'est aussi le cas sur ce gisement I (fig. 4). Les implantations humaines se font sur des sols secs limoneux proches du cours d'eau. Cette configuration migre progressivement vers les hauteurs. La position du site I, sur une zone haute et en partie érodée, montre qu'il s'agit d'une des occupations mésolithiques les plus récentes de l'ensemble du gisement. Les phases postérieures, soit environ les 2/3 du Mésolithique, ne peuvent pas être préservées sur Warluis en raison d'une forte érosion.

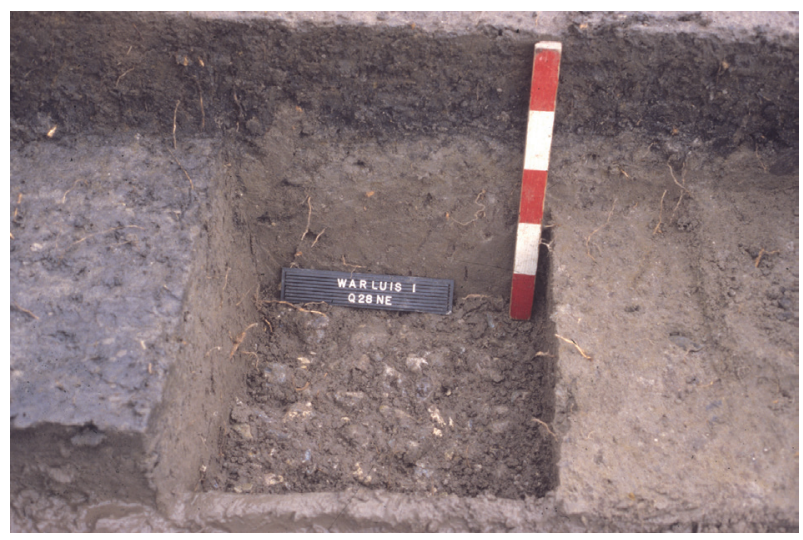

Fig. 4 - Profil stratigraphique au cœur du site avec les graviers à la base, le limon brun à vestiges mésolithiques dans la partie supérieure, recouvert par des tourbes et des limons organiques très dégradés. 


\section{Stratigraphie au niveau du site I}

\section{Unités morpho-sédimentaires}

Le site I est à quelques dizaines de mètres d'un chenal tourbeux holocène identifié dans le sondage 101. La dynamique fluviatile y est bien attestée par des bois flottés à la base des tourbes franches. La berge occidentale du paléochenal (à l'opposé du site I) n'a pas été nettement identifiée. La berge orientale a été reconnue dans les sondages 103, 100, 110,125 et 128 , où elle apparaît très raide. Ce chenal se poursuit vers le sud et le site III, où il a fait l'objet de prélèvements palynologiques et de datations $14 \mathrm{C}$ (fig. 5 et 6 ).

Le chenal est séparé du cœur du site I par une large zone érodée où la tourbe repose directement sur les graviers du dôme. Il n'y a donc pas de liaison stratigraphique stricte entre le cœur du site I et le paléochenal. Cependant, après avoir colmaté le chenal, la tourbe envahit l'ensemble de la zone et remonte sur les points hauts avec un faciès plus limoneux voire graveleux lorsqu'elle est mélangée à la grave sous-jacente.
Au niveau du cœur du site I, une dépression relative se dessine dans laquelle une couche de limons sablo-graveleux s'intercale entre le gravier de la nappe de fond (dôme) et la tourbe peu épaisse. $C^{\prime}$ est dans ces limons que se trouve l'essentiel des vestiges mésolithiques.

Vers l'est, ce limon sablo-graveleux tend à disparaître. La tranchée $1 / 2000$ révèle un épais limon blanchâtre, souvent orangé au sommet et reposant sur les graviers. Ces dépôts correspondent probablement au Pléniglaciaire ou au début du Tardiglaciaire (formation Lsbj, COUTARD et al.,2010). Quelques rares vestiges mésolithiques sont parfois présents au contact entre ce limon et la tourbe susjacente mais la majeure partie du niveau est absente.

\section{Les limons postérieurs aux tourbes}

La sédimentation postérieure aux tourbes est bien caractérisée à l'emplacement du paléochenal, sur ses berges et sur la zone basse, par un limon argileux brun-vert à brun sombre de 10 à $25 \mathrm{~cm}$ d'épaisseur (Lpl). Le caractère dense et très plastique $\mathrm{du}$ limon reflète sans doute une forte compaction post-dépositionnelle.

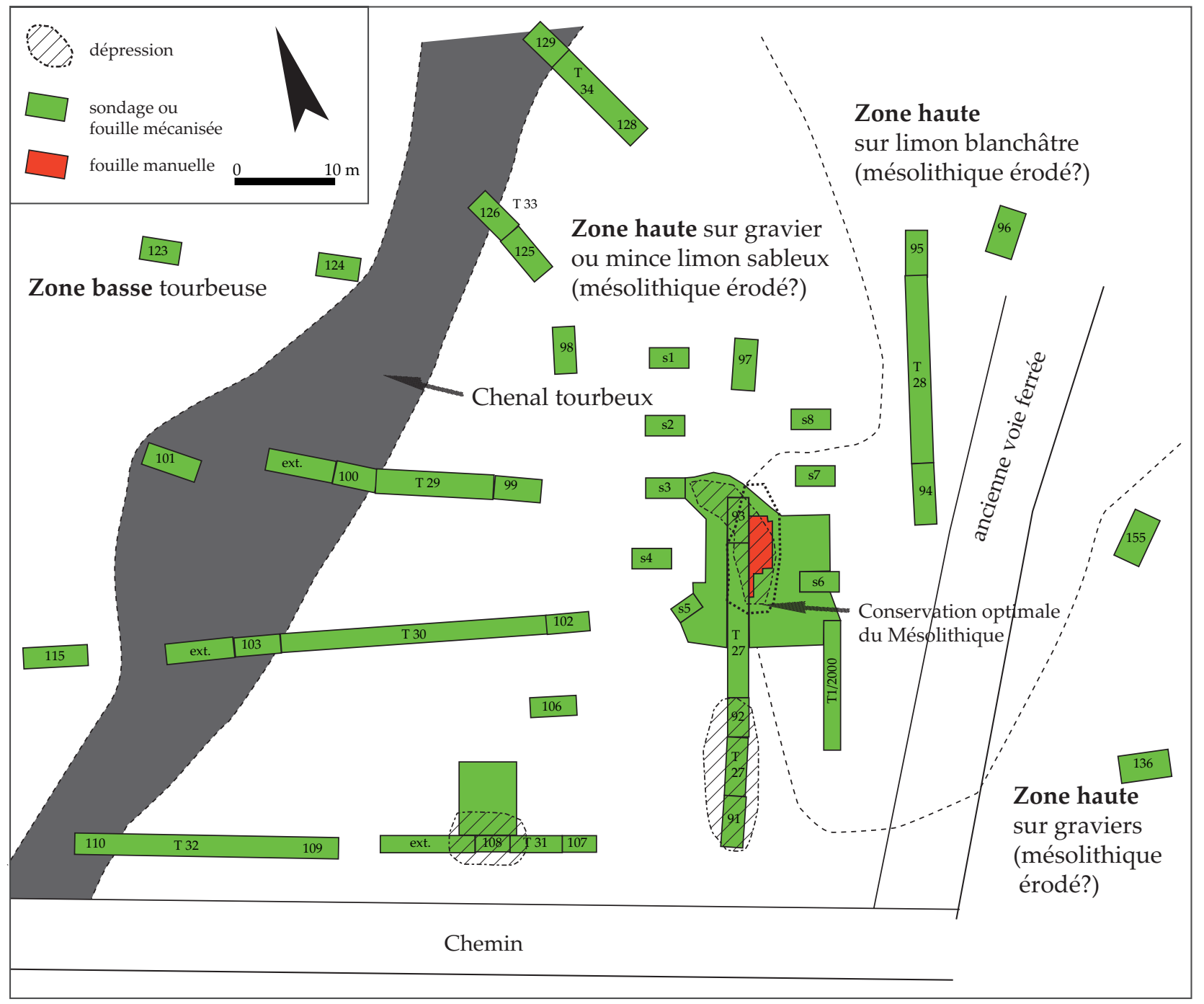

Fig. 5 - Plan de l'ensemble du site I. 

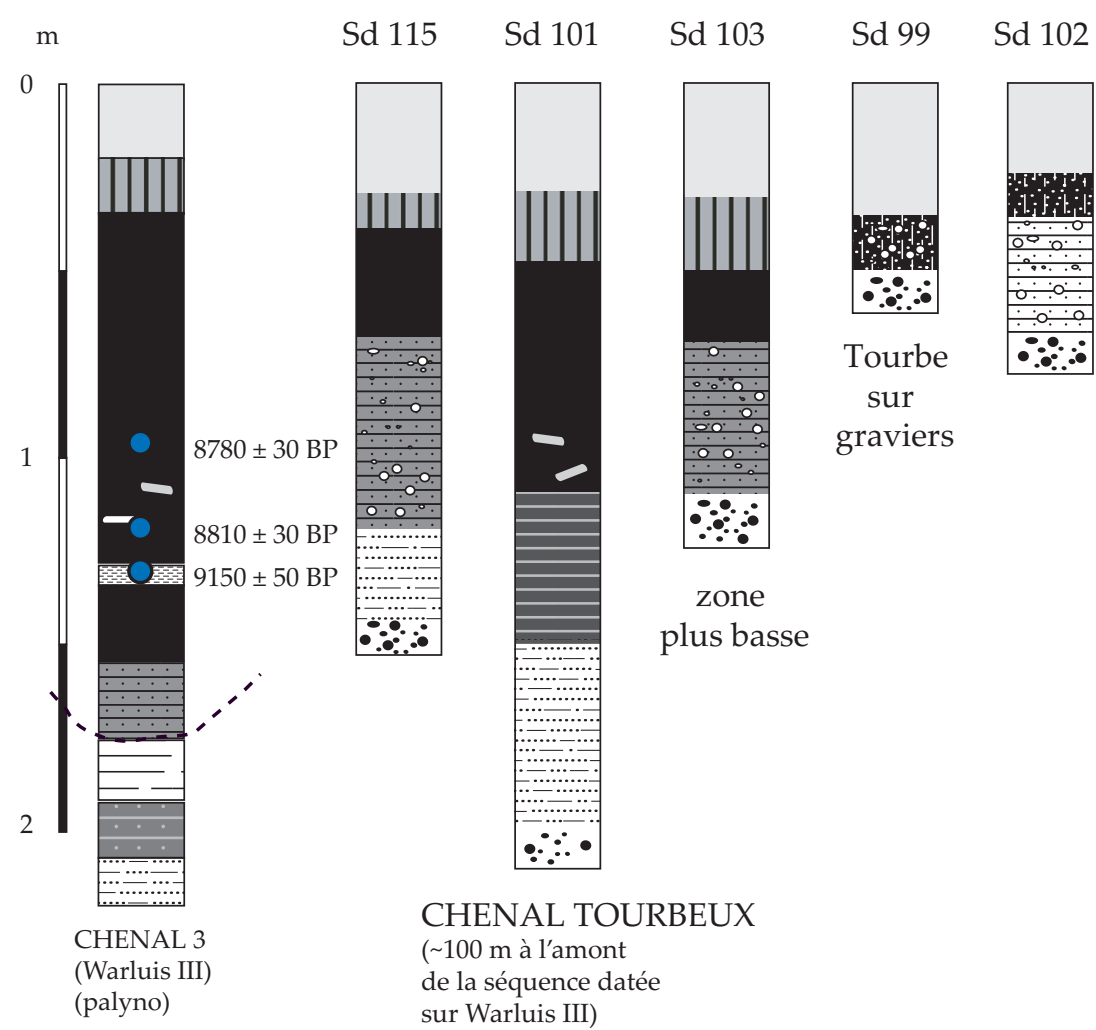

Tourbe

sur graviers
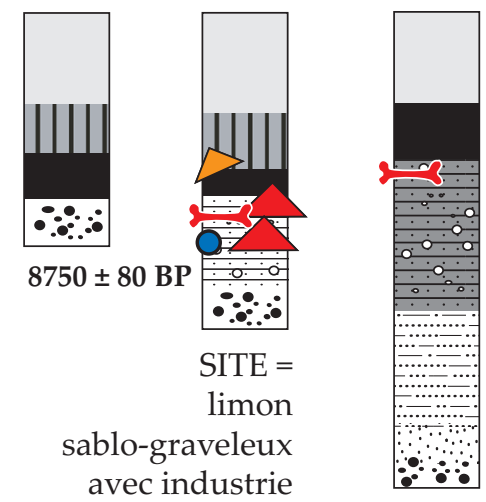

zone

plus basse
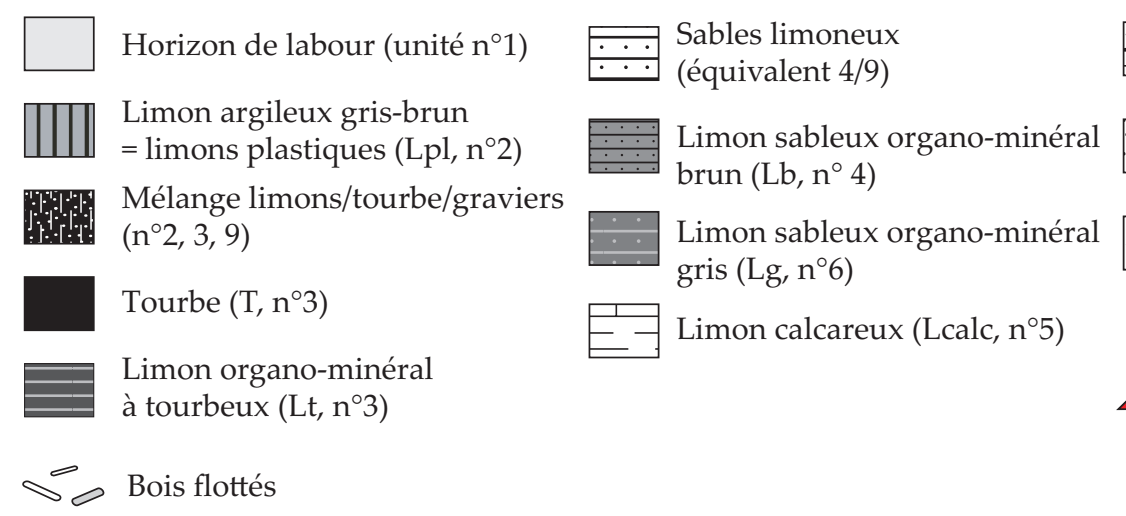

$\cdots$ Limons sablo-argileux à sables limoneux blancs à jaunâtres (Lsbj, $\left.\mathrm{n}^{\circ} 8\right)$

CHENAL TOURBEUX

( 100 m à l'amont

de la séquence datée

sur Warluis III)

Fig. 6 - Profils stratigraphiques schématiques sur l'ensemble du secteur du site I et lien avec le chenal tourbeux (détail des formations et de leur numérotation dans COUTARD et al. 2010).

$\mathrm{Au}$ cœur du site I et sur ses marges, la sédimentation postérieure aux tourbes et les tourbes elles-mêmes sont parfois difficilement identifiables du fait du caractère très comprimé de la séquence sédimentaire. Sur la zone fouillée, la base de la terre végétale est constituée d'un limon organique brun-sombre à mollusques qui repose sur un limon plastique noir faisant la transition avec une mince tourbe. Ce limon plastique noir a été vu ailleurs dans la carrière où il contient des lits de sables tufacés issus du débordement d'un chenal de tuf d'âge vraisemblablement atlantique. Sur le site III, une date sur des restes de cerf situés à la limite tourbe franche/limons plastiques a donné $6930 \pm 50$ BP (GrA-23551).
Une tourbière et un cours d'eau contemporains de l'occupation?

La compilation des données issues des sondages et des fouilles sur l'ensemble de la carrière a permis de cartographier plusieurs paléochenaux et de montrer l'extension des tourbes à tout le fond de vallée à l'exception des points les plus hauts (COUTARD et al. 2010).

Des arguments stratigraphiques, archéologiques, malacologiques, palynologiques et des datations radiocarbones permettent de montrer que la tourbification débute bien dans les chenaux au cours du Préboréal avant d'envahir progressivement 


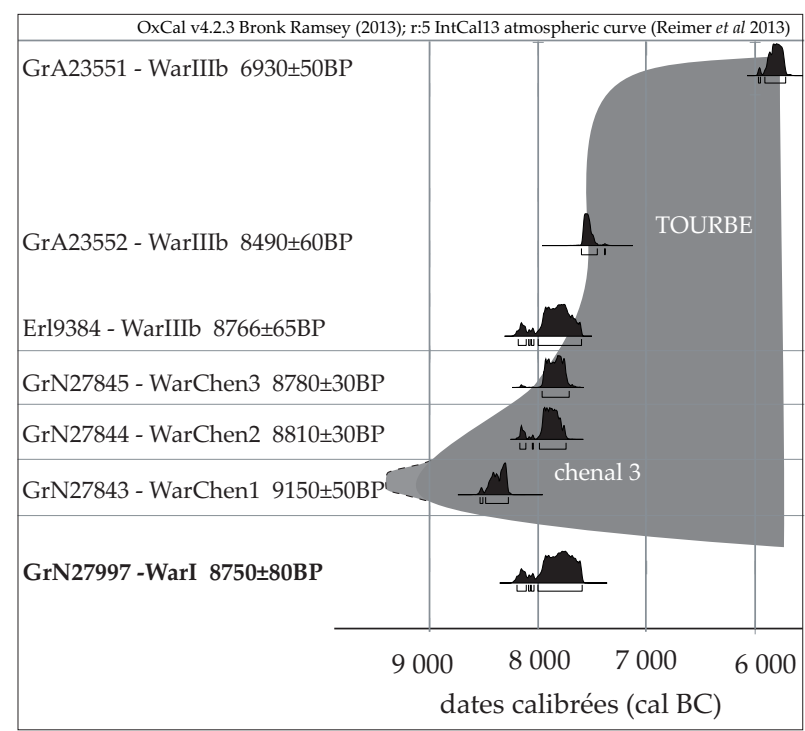

Fig. 7 - Datations $14 \mathrm{C}$ de Warluis I et du colmatage tourbeux (détail dans le tableau 1).

les zones basses au cours du Boréal. Les datations réalisées sur de la faune située en limite limons organiques à vestiges/tourbes en dehors des chenaux ont donné $8766 \pm 65 \mathrm{BP}$ (site IIIlb, Erl-9384) et $8490 \pm 60$ (site IIIb, GrA-23552) (fig. 6 et 7 ; tab. I).

Le site I est quant à lui daté de $8750 \pm 80$ BP (GrA-27997) à partir d'un échantillon de noisettes carbonisées bien associées à l'industrie. Placée sur une zone haute, l'occupation est donc contemporaine de l'extension de la tourbière

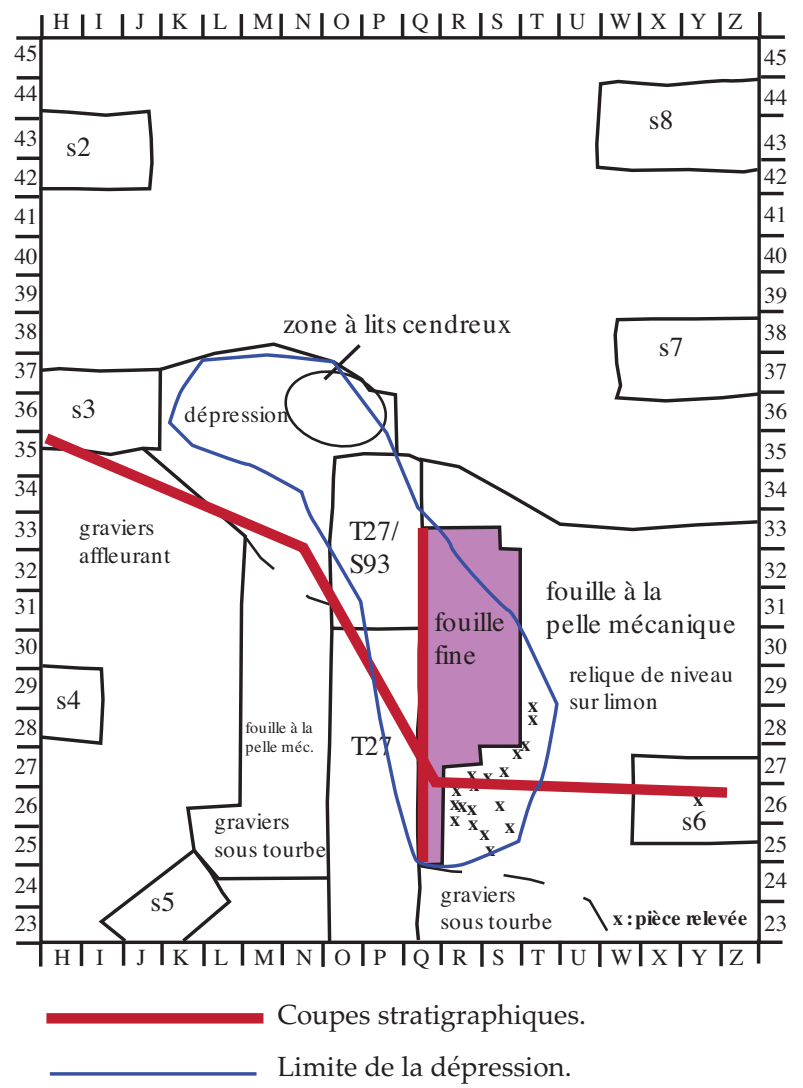

Fig. 8 - Plan du cœur du site 1 avec le carroyage, l'emplacement des coupes stratigraphiques de la figure 9 et la localisation de la dépression. aux zones basses. Elle est caractéristique des implantations humaines sur des sols secs limoneux proches de la zone humide. Cette configuration a migré au cours du Mésolithique depuis les zones basses envahies par les tourbes vers les zones plus hautes. D'après l'étude palynologique menée sur le chenal du site III (LEROYER in COUTARD et al. 2010), le paysage (palynozone War c) est alors dominé par une corylaie où se développent quelques chênes, ormes et arbustes. La végétation hygrophile prend une importance variable. Ainsi, dans la palynozone War c3 (qui comprend une date à $8780 \pm 30$ ), le fond de vallée, ou simplement les abords des chenaux, est occupé par un bas marais qui masque la perception des boisements.

Le paléochenal tourbeux est colmaté par des tourbes franches, synonymes de marécages, mais aussi par des tourbes à bois flottées. Or ces dernières ont une position chronologique identique à celle de l'occupation. Il y a donc un cours d'eau actif à une trentaine de mètres de l'implantation préhistorique. La portion de terrain comprise entre le site et le paléochenal est une zone plus haute que le site avec très peu de tourbe. L'accès au cours d'eau par une surface sèche est donc assuré à l'époque.

\section{TAPHONOMIE ET PALIMPSESTE}

\section{La principale dépression : érosion, accumulation post-depositionnelle et représentativité du corpus}

Trois dépressions sontidentifiées sur le gisement I (fig. 5) dont une placée au cœur du site (fig. 8 et 9). Ses contours sont irréguliers et sa profondeur est d'une trentaine de centimètres. Elle est en grande partie colmatée par du sable limoneux mais son remplissage n'est achevé qu'avec la formation de la tourbe ou du sol noir (fig. 9). Les plus gros vestiges lithiques et osseux sont bien en place dans cette cuvette dans la partie moyenne des sables limoneux. En revanche, les plus petits éléments sont extrêmement abondants dans les cinq centimètres supérieurs. De plus, le sommet du limon sableux de la partie septentrionale de la dépression est localement marqué par des lits cendreux (fig. 8) qui mettent en évidence le remaniement d'une aire de combustion. Par-ailleurs, en dehors de la cuvette, mais toujours au cœur du site I, des artefacts sont bien à plat entre les graviers et le sol noir (entre S4 et T27, fig. 8 et 9 ) ainsi que d'autres entre des limons et le sol noir vers S6 (fig. 8 et 9). De ces différentes observations, on peut conclure que la dépression existait avant la halte mésolithique. Elle était déjà en partie colmatée (fig. 9). Cependant, une phase de comblement postérieure à l'occupation s'est traduite par des lits cendreux et le remaniement de petits éléments accumulés dans la partie supérieure du limon sableux. Ainsi, la concentration de vestiges semble compter de nombreux éléments en place mais aussi des petits artefacts déplacés et accumulés 


\begin{tabular}{|c|c|c|c|c|c|c|}
\hline $\begin{array}{l}\text { Référence } \\
\text { laboratoire }\end{array}$ & $\begin{array}{c}\mathrm{N}^{\circ} \\
\text { échantillon }\end{array}$ & Site & yr BP & cal BC 95\% & échantillon & $\begin{array}{l}\text { Provenance de } \\
\text { l'échantillon }\end{array}$ \\
\hline \multicolumn{7}{|c|}{ Warluis (travaux T. DUCROCQ, AFAN puis INRAP ; A.BRIDAULT, CNRS) } \\
\hline GrN-27997 & 3 WI -3 & I & $8750 \pm 80$ & $8197-7596$ & Noisettes brûlées & $\begin{array}{c}\text { limons } \\
\text { sablo-graveleux }\end{array}$ \\
\hline GrA-23551 & 10WIIIb1 & $\mathrm{IIIl}$ & $6930 \pm 50$ & $5972-5721$ & $\begin{array}{l}\text { Os de cerf - } \\
\text { apport naturel }\end{array}$ & $\begin{array}{l}\text { surface de la tourbe } \\
\left(\mathrm{T}, \text { unité } \mathrm{n}^{\circ} 3\right)\end{array}$ \\
\hline Erl-9384 & $\begin{array}{l}\text { BB 16NW } \\
623\end{array}$ & $\mathrm{IIIl}$ & $8766 \pm 65$ & $8185-7602$ & $\begin{array}{l}\text { Os de chevreuil - } \\
\text { apport naturel }\end{array}$ & $\begin{array}{l}\text { base de la tourbe } \\
\left(\mathrm{T}, \mathrm{n}^{\circ} 3\right)\end{array}$ \\
\hline GrA-23552 & 11WIIIb2 & $\mathrm{IIIb}$ & $8490 \pm 60$ & $7603-7385$ & $\begin{array}{l}\text { Os de cerf - } \\
\text { apport naturel }\end{array}$ & $\begin{array}{l}\text { base de la tourbe } \\
\left(T, n^{\circ} 3\right)\end{array}$ \\
\hline GrN-27843 & 16Wch1 & III & $9150 \pm 50$ & $8537-8276$ & Bois flotté & $\begin{array}{l}\text { chenal } 3 \text { (passée } \\
\text { limoneuse grise dans } \\
\text { le tiers inférieur du } \\
\text { colmatage tourbeux } \mathrm{T}\end{array}$ \\
\hline GrN-27844 & 17 Wch2 & III & $8810 \pm 30$ & $8171-7745$ & Bois flotté & chenal 3, tourbe $(\mathrm{T})$ \\
\hline GrN-27845 & $18 W \operatorname{ch} 3$ & III & $8780 \pm 30$ & $7965-7716$ & Bois flotté & $\begin{array}{c}\text { chenal } 3,(\mathrm{~T}: \text { limite des } \\
\text { tourbes à bois et des } \\
\text { tourbes franches })\end{array}$ \\
\hline
\end{tabular}

Tab. I - Liste des datations 14C de la figure 7. Les calibrations sont effectuées avec le logiciel OxCal (courbe IntCal13, REIMER et al. 2013).
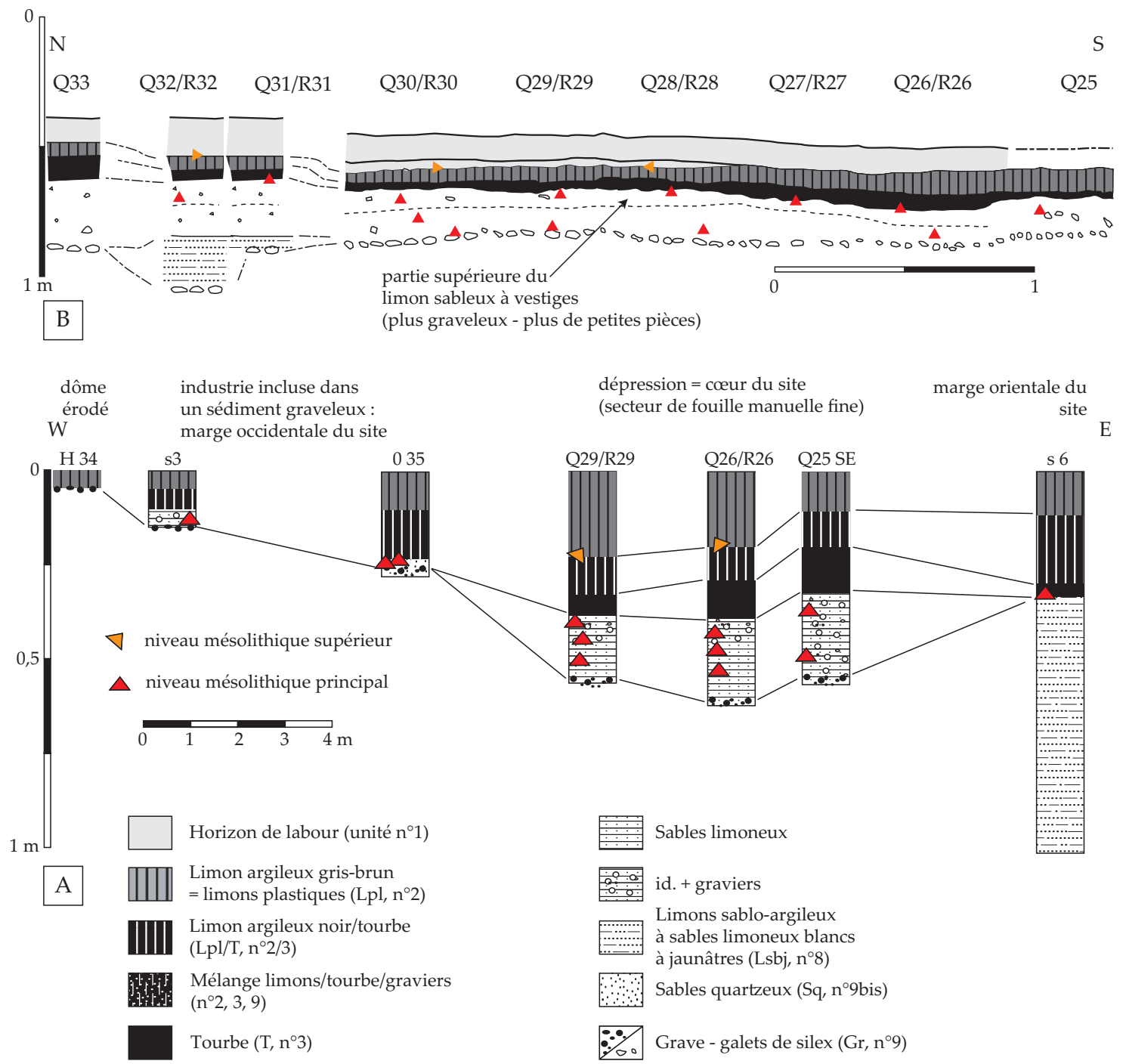

Fig. 9 - A : profils stratigraphiques schématiques sur le principal secteur du site I, mettant en évidence la dépression du cœur du site. B : coupe nord-sud, à travers la zone de fouille manuelle, qui montre la position stratigraphique des deux niveaux mésolithiques. 
au cœur du site. Il n'est donc pas judicieux d'étudier précisément l'organisation spatiale des vestiges sur Warluis I. En revanche, la majeure partie des vestiges lithiques et fauniques de la concentration a du être recueillie lors de la fouille et constitue un ensemble qualitativement et quantitativement représentatif. Antérieure à l'occupation, cette dépression n'est donc pas l'œuvre des Mésolithiques même si la correspondance entre la concentration et la cuvette n'est probablement pas fortuite (voir ci-dessous). La juxtaposition de plusieurs fosses créées par la chute d'arbres est vraisemblablement à l'origine de cette cuvette.

\section{Quelques fréquentations diachroniques}

\section{Une question indispensable}

L'attraction des plaines alluviales a suscité de multiples fréquentations diachroniques. Sur le marais de Warluis, des vestiges du Paléolithique final et de plusieurs phases du Mésolithique ont été identifiées (Ducroce et al. 2008). Une analyse critique des données a été conduite pour définir un phasage des occupations, notamment sur Warluis I. Elle s'appuie sur la stratigraphie, la répartition spatiale et sur des différences d'aspect physique du matériel qui coïncident avec des nuances technotypologiques significatives.

\section{Le niveau supérieur}

Un niveau, qualifié de supérieur, regroupe des vestiges découverts sous la terre végétale juste au dessus du limon plastique qui recouvre la tourbe. Cette position stratigraphique est incompatible avec un niveau en place du Mésolithique qui aurait un âge très récent postérieur à l'Atlantique récent. De plus, la répartition spatiale met en évidence une dispersion lâche sans réelle concentration (fig. 10). Ces deux éléments plaident pour un ensemble de vestiges lithiques en position remaniée. Les objets proviendraient de concentrations situées un peu plus haut vers le versant qui est très érodé. Quelques restes fauniques (cerf, chevreuil et boviné) proviennent du même niveau et semblent, eux, en place (bien à plat). Ils ne montrent pas de trace d'activité anthropique et pourraient avoir un âge totalement différent de l'industrie lithique. Cette dernière compte une centaine de pièces dont quelques microlithes (fig. 11). Ils sont totalement différents des objets du niveau principal : des microburins distaux sur lamelle corticale, une pointe à base retouchée latéralisée à droite, une vraie pointe de Sauveterre, un triangle atypique et un triangle scalène à trois côtés retouchés. De

Fig. 11 - Microlithes du niveau supérieur comportant une pointe à base retouchée (1), une pointe de Sauveterre (2), un triangle atypique (3), un triangle scalène (4) et deux microburins distaux (5 et 6).

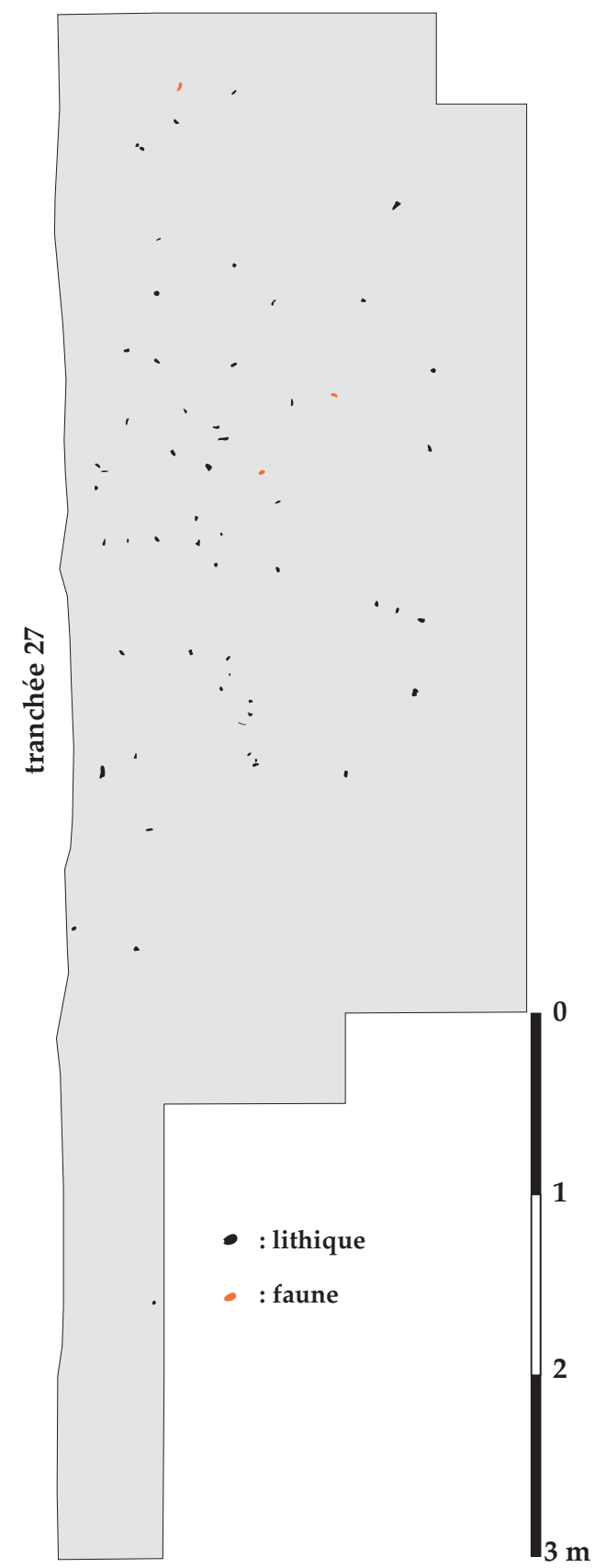

Fig. 10 - Répartition spatiale des vestiges du niveau supérieur sur la principale fenêtre de fouille manuelle.
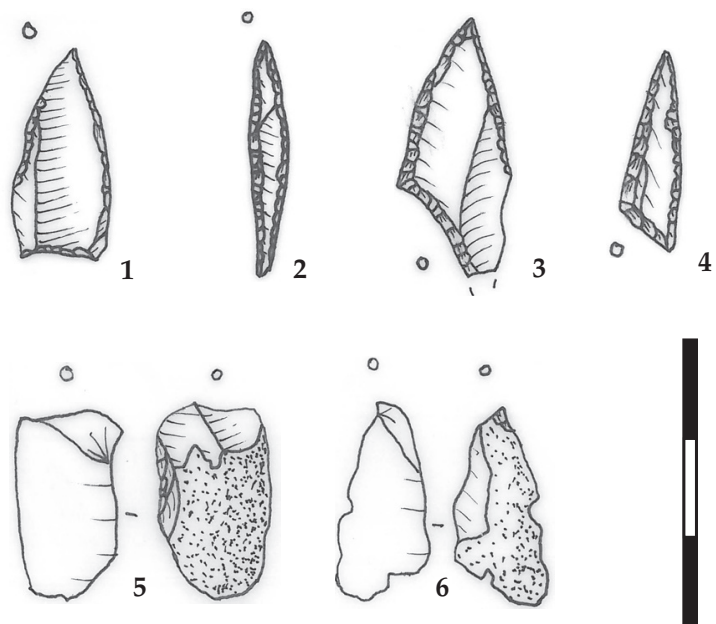
plus, rien ne garantit l’homogénéité de cette série. L'attribution reste délicate, mais la multiplication des types microlithiques, la présence d'un petit triangle et d'une pointe de Sauveterre orienteraient vers la fin de la chronozone du Boréal (Ducroce 2001) en complète contradiction avec les données de la chronostratigraphie.

\section{La dépression éloignée}

À une trentaine de mètres du cœur du site I, près du sondage 108 (fig. 5), une fouille relativement étendue a mis en évidence une cuvette tapissée par un limon organique à rares graviers. Des vestiges préhistoriques y étaient conservés sur quelques $\mathrm{m}^{2}$. Une dizaine d'artefacts lithiques (éclats, produits laminaires et 2 nucléus) se divisent en deux ensembles suivant leur aspect physique : des pièces non patinées et des objets à patine bleutée. L'une semble comparable à celle du centre du site I, l'autre pourrait être identique à celle du site III proche de ce secteur (fig. 3). Plusieurs dizaines d'ossements sont essentiellement attribuables au cerf (hémimandibule gauche avec des traces de découpe, vertèbres thoraciques et vertèbres lombaires et quelques fragments de côte et de vertèbre d'un grand ruminant de la taille du cerf). Ces restes fauniques peuvent être théoriquement associés à l'une ou l'autre des deux industries. Cependant, si cette espèce est abondante sur le site III (Ducroce et al. 2008), elle est absente du secteur principal du site I. Il semble donc cohérent de ne pas associer cet ensemble à l'occupation principale de Warluis I.

\section{Quelques intrusions dans la série principale}

L'examen du corpus microlithique met en évidence des différences d'aspect physique qui coïncident avec de sensibles nuances typologiques. Il s'agit de deux pièces avec un voile de patine bleutée qui n'ont pas leur équivalent dans la série principale : une bitroncature et un triangle isocèle (fig. 12). Ces microlithes ne choqueraient pas dans certaines séries plus anciennes de la zone basse.

\section{Quelques objets particuliers dans la série principale}

Les remarques précédentes ont permis d'écarter du corpus des éléments apparemment diachroniques. Il subsiste une série " homogène » pouvant résulter d'une seule fréquentation $\mathrm{du}$ lieu. Le corpus comporte de l'industrie lithique et des restes fauniques, mais aussi quelques objets insolites : un volumineux rognon de silex non débité, une coquille fossile et quelques petits éclats en grès.

Le bloc de silex a probablement été ramené par les Mésolithiques comme réserve de matière première ou comme calage, siège ou divers support.

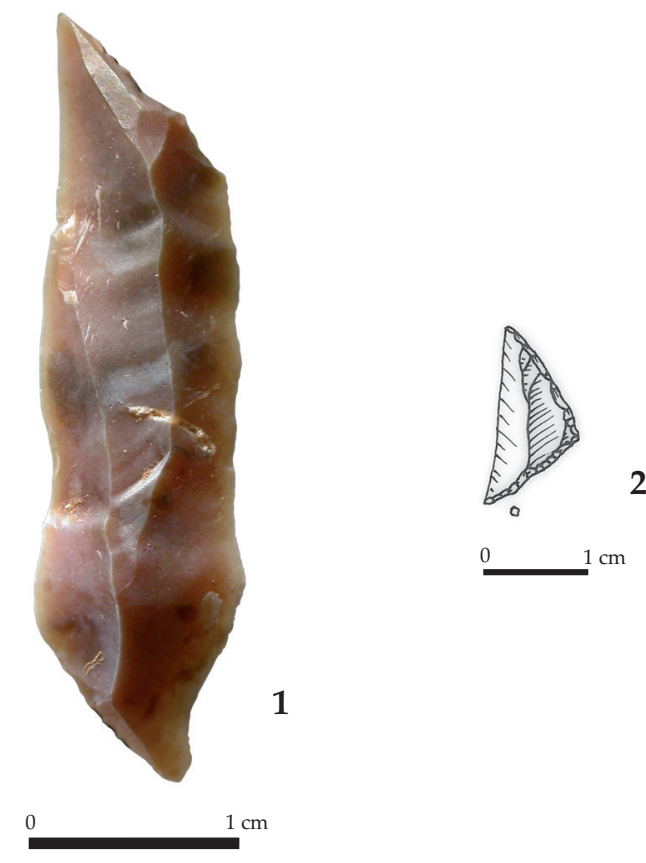

Fig. 12 - Microlithes à voile de patine probablement intrusifs ; bitroncature (1 ; clichés de S. Lancelot), triangle isocèle (2).

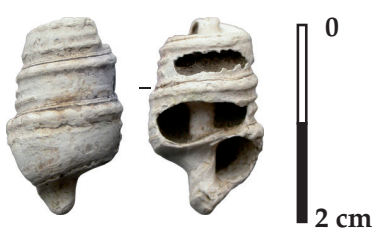

Fig. 13 - Coquille fossile de Tympanotonos (clichés de S. LANCELOT).

Le gastropode fossile (fig. 13) est un Tympanotonos du Sparnacien (détermination de P. Lozouet) qui a visiblement subi une érosion fluviatile. Sa présence peut être naturelle car il ne montre pas de modification anthropique et qu'il provient du Sparnacien (= Yprésien inférieur) présent sur cette portion de vallée (fig. 2). Toutefois, aucune coquille similaire n'a été observée lors des différentes opérations archéologiques sur la carrière. Ainsi, l'apport sur le terrain par les hommes du Mésolithique est aussi envisageable.

Les petits éclats en grès (fig. 14) ont été recueillis sur toute la surface de la fouille manuelle. Certains raccordent entre eux. Les talons sont souvent facettés. Ces grès ne ressemble pas au grès local et semble exogène. Des blocs de grès auraient pu être utilisés sur le site pour aménager une aire de combustion. Cependant, il n'y a ni grosses pièces, ni de trace d'altération thermique. L'extraction laminaire par percussion directe au grès aurait aussi pu laisser des esquilles. Pourtant, les artefacts 

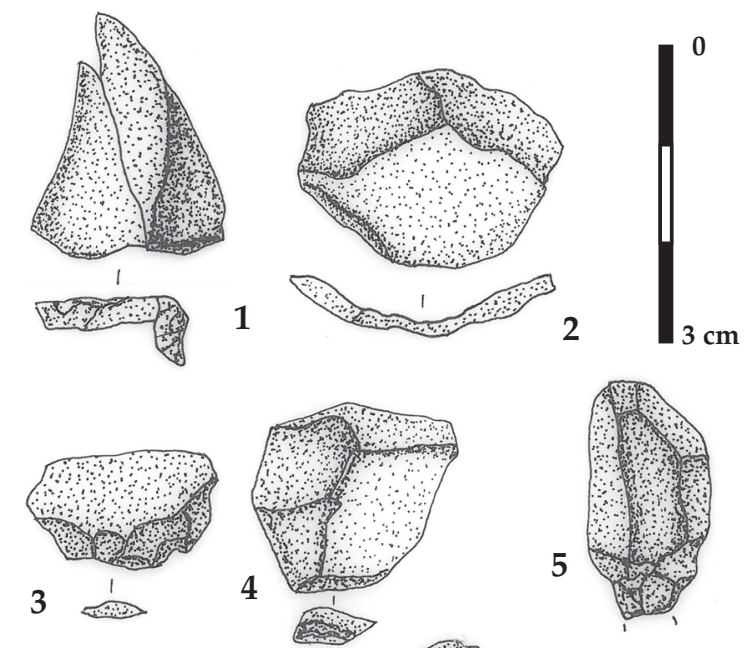

6

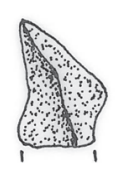

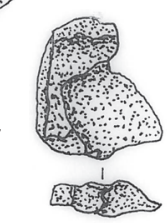

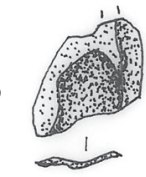

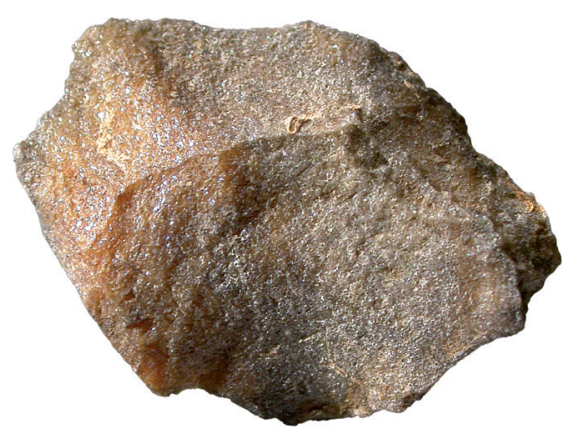

9

Fig. 14 - Petits éclats en grès ; (cliché de S. LANCELOT - n 9).

ne proviennent pas d'un percuteur. On peut aussi envisager le débitage d'un bloc de grès suivant la même chaîne opératoire que celle qui a été mise en évidence pour le silex. Cependant, il n'y a ni nucléus, ni produits lamellaires, ni microlithes. Une autre hypothèse paraît plus probable. Les artefacts seraient le fruit de réaménagements et d'affûtages d'un gros objet en grès qui n'a pas été abandonné sur le site. On pense évidemment à un prismatique de type Montmorencien qui est un outil bien attesté sur certains sites mésolithiques (GRISELIN et al. 2013, LANG \& Sicard 2008, Ducroce 2001 ; TARrête 1977 et 1989). D'ailleurs, un raccord (fig. 14, $\mathrm{n}^{\circ} 1$ ) met bien en évidence un angle droit compatible avec la morphologie d'un outil prismatique.

\section{CARACTÉRISTIQUES TECHNO- TYPOLOGIQUES DE L'INDUSTRIE PRINCIPALE}

\section{Le corpus étudié : définition, matière première et décompte global}

L'industrie lithique provient de la surface fouillée manuellement, de ses marges explorées à la pelle mécanique, des sondages $3,6,7,93$, et de la tranchée 27 . En effet, ces secteurs sont très proches et ils ne sont pas séparés par des surfaces stériles. De plus, de nombreux raccords existent entre des pièces lithiques issues des différentes zones. L'ensemble semble dessiner une seule concentration (fig. 15).

Les artefacts sont exempts de patine tout en présentant parfois un léger lustré prenant une teinte verdâtre ou orangée. La matière première est un silex secondaire au cortex roulé, usé. La couleur actuelle de la pâte est variable (le plus souvent orangée, parfois noire). Les blocs ne sont pas tous homogènes et contiennent souvent des impuretés (fossiles, vacuoles). Certains sont partiellement gélifs (fig. 16). Ils ont été ramassés par les Mésolithiques après un séjour prolongé près de la surface. Les dimensions initiales des nucléus exploités sont difficiles à déterminer faute de remontage complet, mais on peut estimer leur longueur moyenne à une dizaine de centimètres. Le lieu d'acquisition est directement sur le site, à la surface de la nappe de graviers du fond de vallée (fig. 15). D'ailleurs, les graviers de ce secteur ont des dimensions comparables aux blocs débités. Certains montrent aussi des tentatives de débitage (fig. 17). Cet affleurement est probablement un des facteurs qui a motivé l'implantation des Mésolithiques.

Le niveau principal de Warluis I a livré 4664 silex taillés pesant une dizaine de kilos :

- 2773 esquilles, petits éclats et petits débris,

- 1609 pièces de débitage y compris les nucléus,

- 31 pièces dites "utilisées",

- 3 outils du fonds commun,

- 8 lamelles à troncature oblique,

- 107 armatures, y compris les débris et les « ébauches",

- 133 microburins et pièces apparentées.

L'objectif principal est clairement la production de petites lames destinées à être transformées en microlithes. Le reste de l'outillage est façonné à partir de « déchets » issus des différentes phases de cette chaîne opératoire.

\section{Le débitage}

Le débitage compte :

30 débris de blocs,

15 débris de nucléus,

65 nucléus,

48 tablettes,

10 pièces à crête,

641 éclats, 


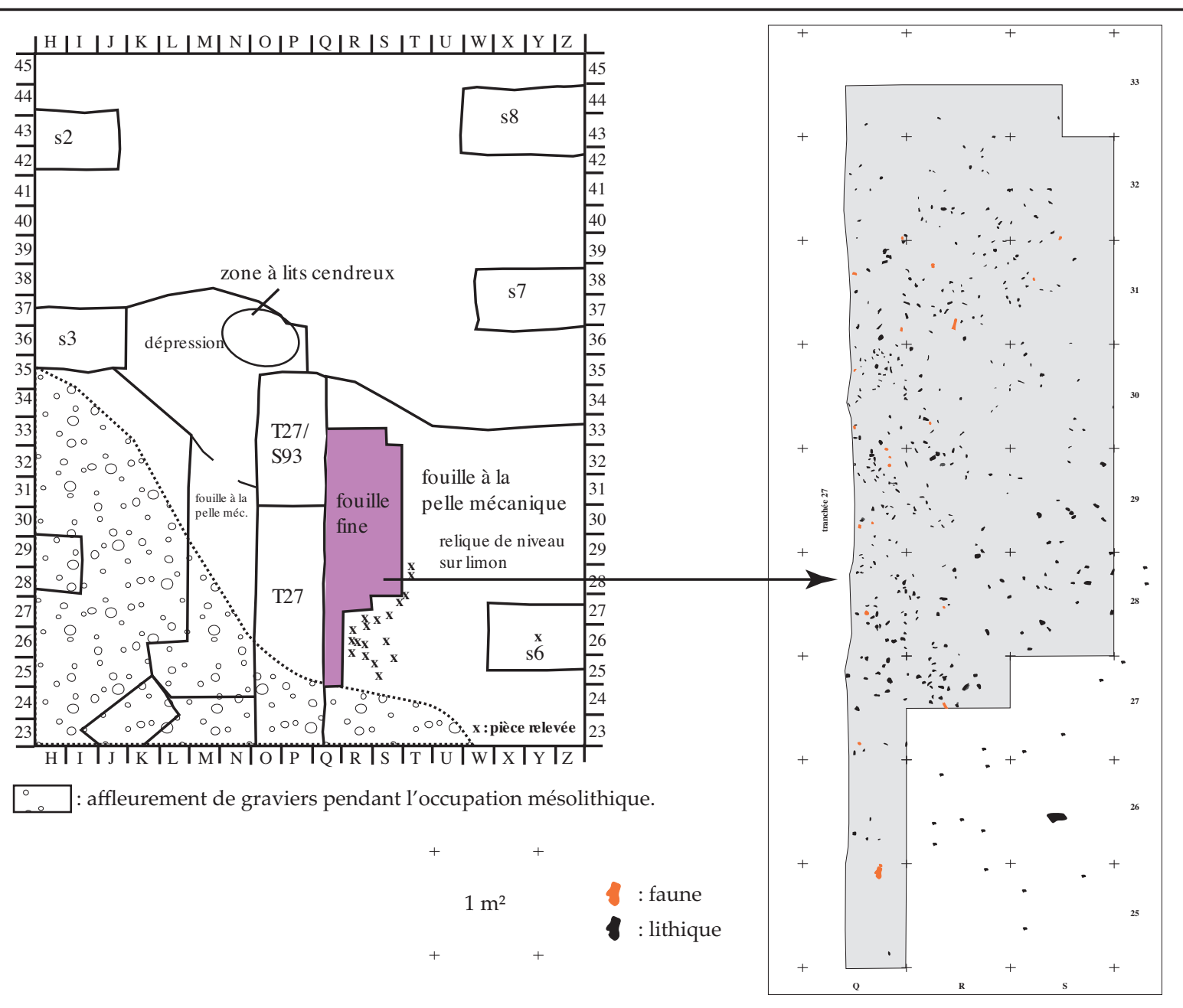

Fig. 15 - Plan du cœur du site avec la localisation des blocs de gravier accessibles et un détail de la zone de fouille fine.

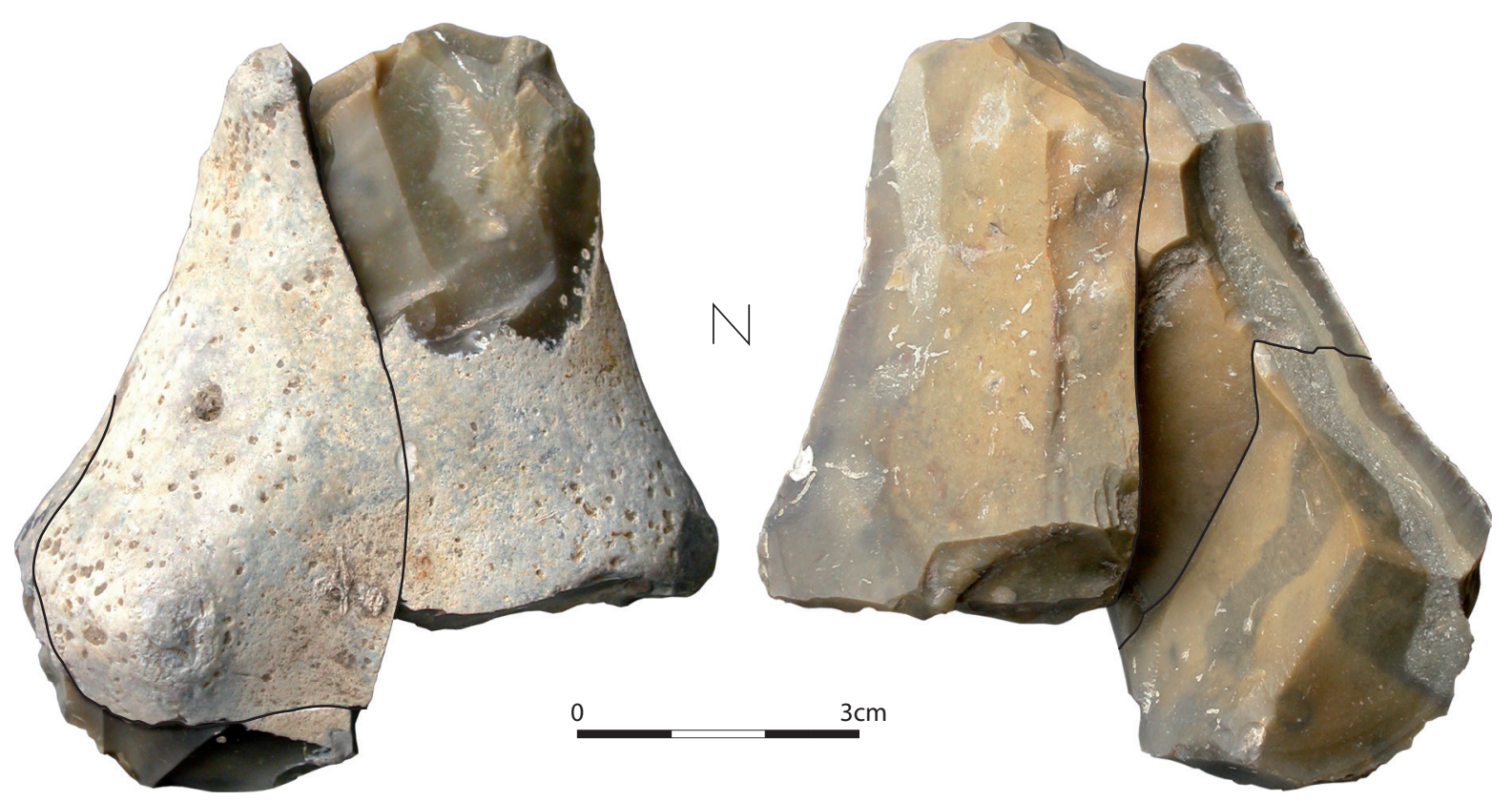

Fig. 16 - Tentative de débitage sur des fragments d'un bloc gélif (clichés de S. LANCELOT). 

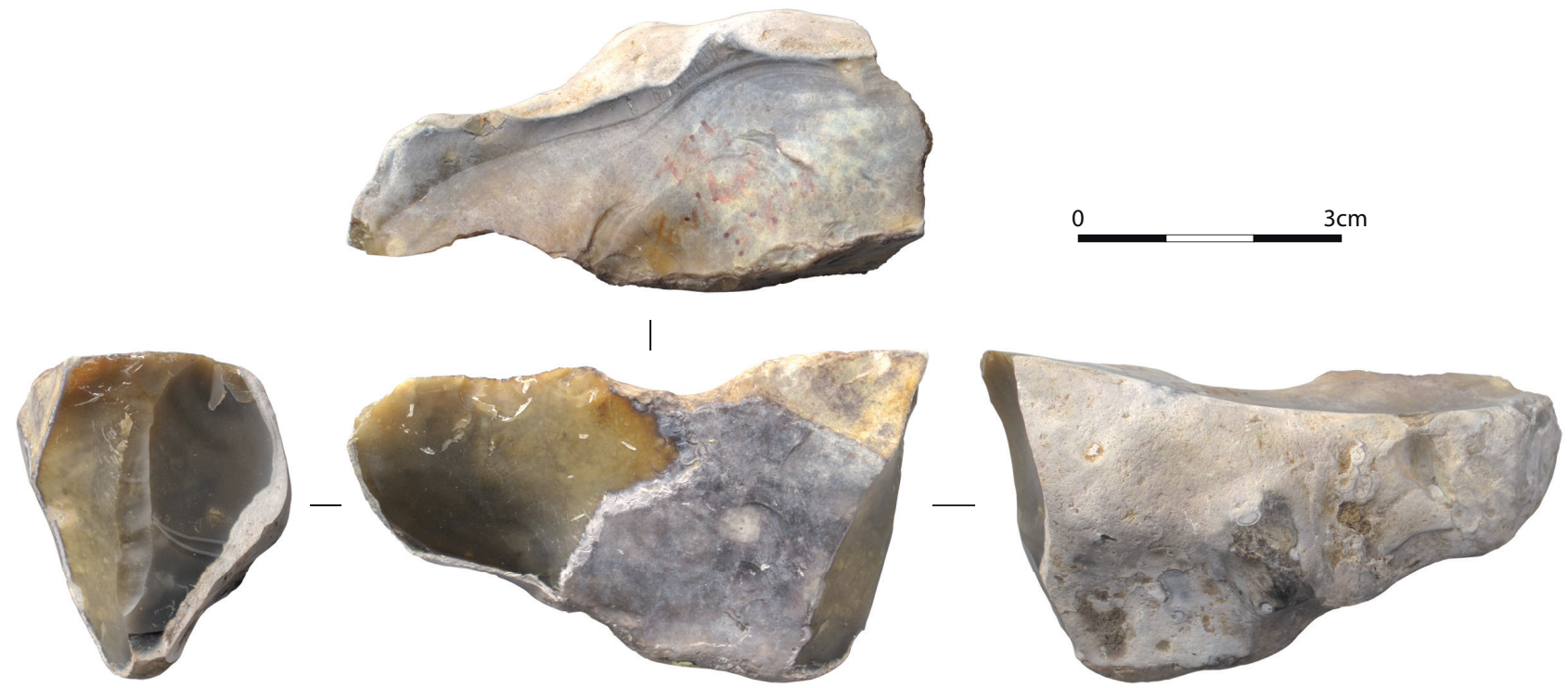

Fig. 17 - Tentative de débitage sur un gravier (clichés de S. LANCELOT).

327 fragments d'éclat,

154 produits laminaires entiers,

140 fragments proximaux de lamelle,

39 fragments mésiaux de lamelle,

140 fragments distaux de lamelle.

Toutes les phases de débitage sont représentées sur le site (mise en forme de blocs, production de supports d'outils et façonnage de ces derniers).

Les débris de blocs ont été produits lors du débitage sans montrer de trace évidente d'enlèvement. Il s'agit de fissures présentes sur de la matière première gélive. La qualité de cette dernière a sans doute perturbé le travail des tailleurs. Néanmoins, les Mésolithiques se sont adaptés au matériau. Plusieurs fragments de bloc gelé ont été repris comme nucléus (fig. 16 et $18, \mathrm{n}^{\circ} 1$ ). Quatre éclats épais de mise en forme ont aussi été débités (fig. 18, $\mathrm{n}^{\circ} 2$ ). Les nucléus sur fragment de bloc ou sur éclat peuvent être plus nombreux, mais ils sont difficiles à repérer quand les nucléus sont épuisés. Les Préhistoriques n’ont négligé aucune opportunité pour trouver du volume à débiter.

Exceptés quelques blocs à peine débités (fig. 17) et un nucléus à éclats probablement utilisé comme percuteur (fig. 18, $\mathrm{n}^{\circ} 3$ ), les nucléus témoignent essentiellement d'un débitage " laminaire " (au sens large) organisé et méthodique, nécessitant un minimum de préparation des blocs.

Une petite vingtaine d'éclats d'entame sont présents et les éclats corticaux (surface corticale égalant au moins la moitié du dos) de mise en forme sont nombreux avec une centaine d'unités soit près de $20 \%$ des éclats entiers. Peu de gros ou grands éclats ont été retrouvés avec un peu moins d'une quarantaine de pièces avec une longueur ou une largeur supérieure à $5 \mathrm{~cm}$. Ceci conforterait l'impression de relative petitesse des blocs de matière première collectés par les Mésolithiques.
Les méthodes préparatoires employées semblent plutôt sommaires. La mise en forme du plan de frappe est l'étape primordiale de la préparation des blocs de matière première, sauf dans le cas des nucléus sur fragment de bloc gélif où le plan de frappe est situé directement sur une surface de fracture. Aucun nucléus ne montre d'aménagement du dos. Seuls cing fragments de lame à crête à un seul versant préparé par des retouches unilatérales directes ont été identifiés. Ils témoignent d'une préparation ponctuelle de la table à l'extraction laminaire. Plus généralement, les surfaces à débiter sont mises en forme par l'enlèvement d'éclats corticaux allongés.

La phase de préparation des nucléus semble surtout réalisée par une technique de percussion à la pierre dure (PELEGRIN 2000). Les talons des éclats de mise en forme sont épais et lisses, les points d'impact ont une surface limitée et des rides fines et serrées sont fréquemment présentes dans les tous premiers millimètres des bulbes. L'emploi de percuteurs en pierre tendre (grès sans doute) parait cependant aussi attesté. Certains talons sont en effet réduits, minces, avec un point d'impact visible. Surtout, leur ligne antérieure est arrondie par une abrasion. Enfin, de nombreuses faces inférieures des éclats de préparation sont couvertes d'ondulations fines et serrées et on peut remarquer des esquillements bulbaires débutant dans l'épaisseur de certains talons. Ces deux accidents sont assez évocateurs de la percussion à la pierre tendre.

La production laminaire s'effectue essentiellement à partir de 2 plans de frappe opposés (37 nucléus sur 65 soit $57 \%$ ) le long d'une même table (fig. 19, $\mathrm{n}^{\circ}$ 2) qui peut être un peu décalée vers le deuxième plan de frappe (fig. 19, $\mathrm{n}^{\circ} 1$ ). Ils sont créés dès la phase de préparation ou durant le plein débitage et fonctionnent de façon autonome. Leur exploitation est presque toujours 

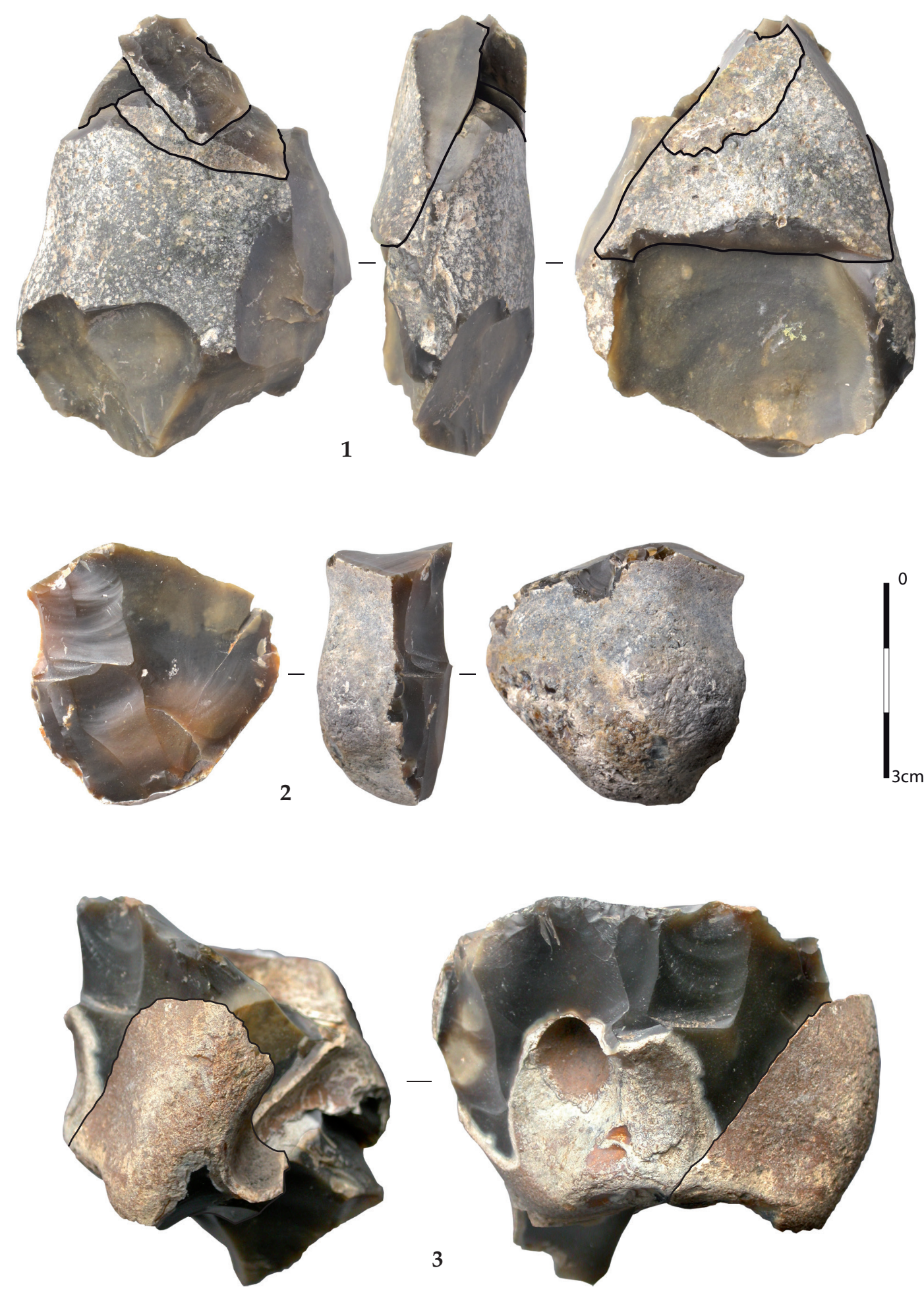

Fig. 18 - Débitage d'un bloc gélif (1), d'un éclat épais (2) et percuteur sur nucléus à éclats (3) (clichés de S. LANCELOT).

successive (90\% des cas), afin sans doute d'accroître le rendement du nucléus et la rectitude des produits. Plus rarement, elle est de type plan de frappe principal / secondaire (un des plans de percussion ne servant que ponctuellement à exercer des tâches de réfection de la table) (fig. 19, n 3 et fig. 20, n 3 ). Certains nucléus sont unipolaires car l'utilisation du plan de frappe opposé n'a pas été nécessaire pour corriger des accidents de rebroussement intervenus tardivement lors de l'extraction laminaire (fig. 20, $\mathrm{n}^{\circ} 1$ et 2 ). Ces derniers ont conduit à $\mathrm{l}^{\prime}$ abandon du nucléus. D'autres unipolaires correspondent à l'exploitation d'un éclat ou d'un fragment de bloc. L'ensemble des nucléus unipolaires représente $20 \%$ du total avec 13 unités.

Deux nucléus à deux plans de frappe opposés utilisés successivement montrent ensuitel'ouverture d'une nouvelle table laminaire par l'exploitation du dos initial. C'est le cas sur la pièce de la fig. 21 avec 

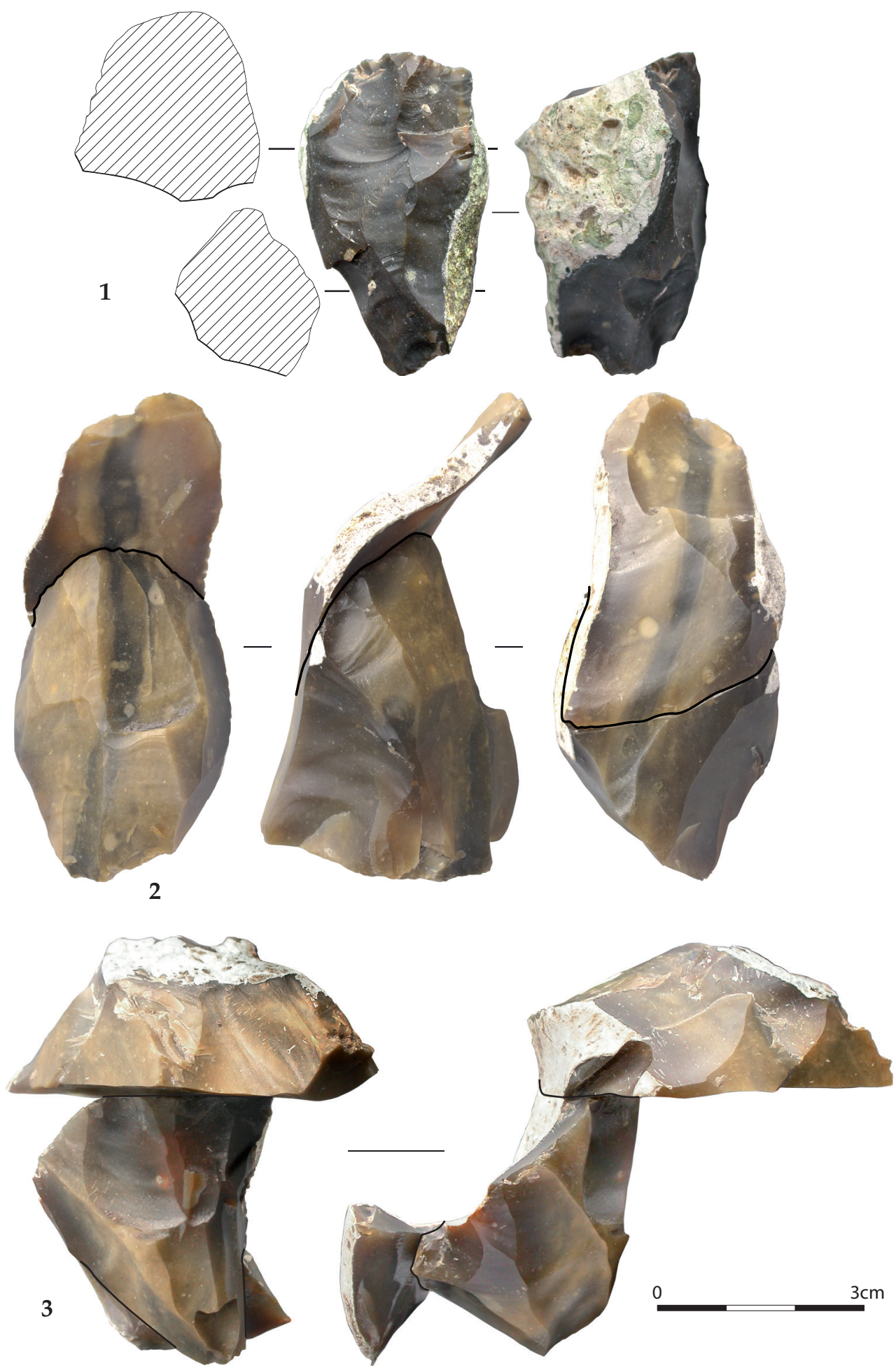

Fig. 19 - Nucléus (1) et remontages (2 et 3) (clichés de S. LANCELOT).

d'ailleurs le raccord de deux pièces " utilisées » : une lame débitée à partir du premier plan de frappe et une pièce outrepassée issue du plan de frappe opposé. Cette dernière dégage un nouveau plan de frappe pour exploiter le dos du nucléus.

Douze nucléus ont de nombreux plans de frappe et une forme grossièrement ronde qui permettent de les qualifier de nucléus globuleux au sens du Dr Rozoy (1969). Ces changements de sens de débitage pourraient dans certains cas ne pas être détectés
L'exploitation de la table est réalisée par un débitage semi-tournant qui envahit les flancs du nucléus et parfois le dos.

Les réfections de la table durant le plein débitage se font surtout par des enlèvements d'éclats latéraux détachés à la jonction table / flanc ou sur les flancs du nucléus. Par contre, il n'y a pas de trace de réaménagements en crête. Des ravivages des plans de frappe ont aussi été pratiqués comme l'attestent une cinquantaine de tablettes et fragments (d'une longueur moyenne d'environ $3 \mathrm{~cm}$ (la plus grande mesure $5,6 \mathrm{~cm}$ de long et la plus petite $0,4 \mathrm{~cm}$ ). 

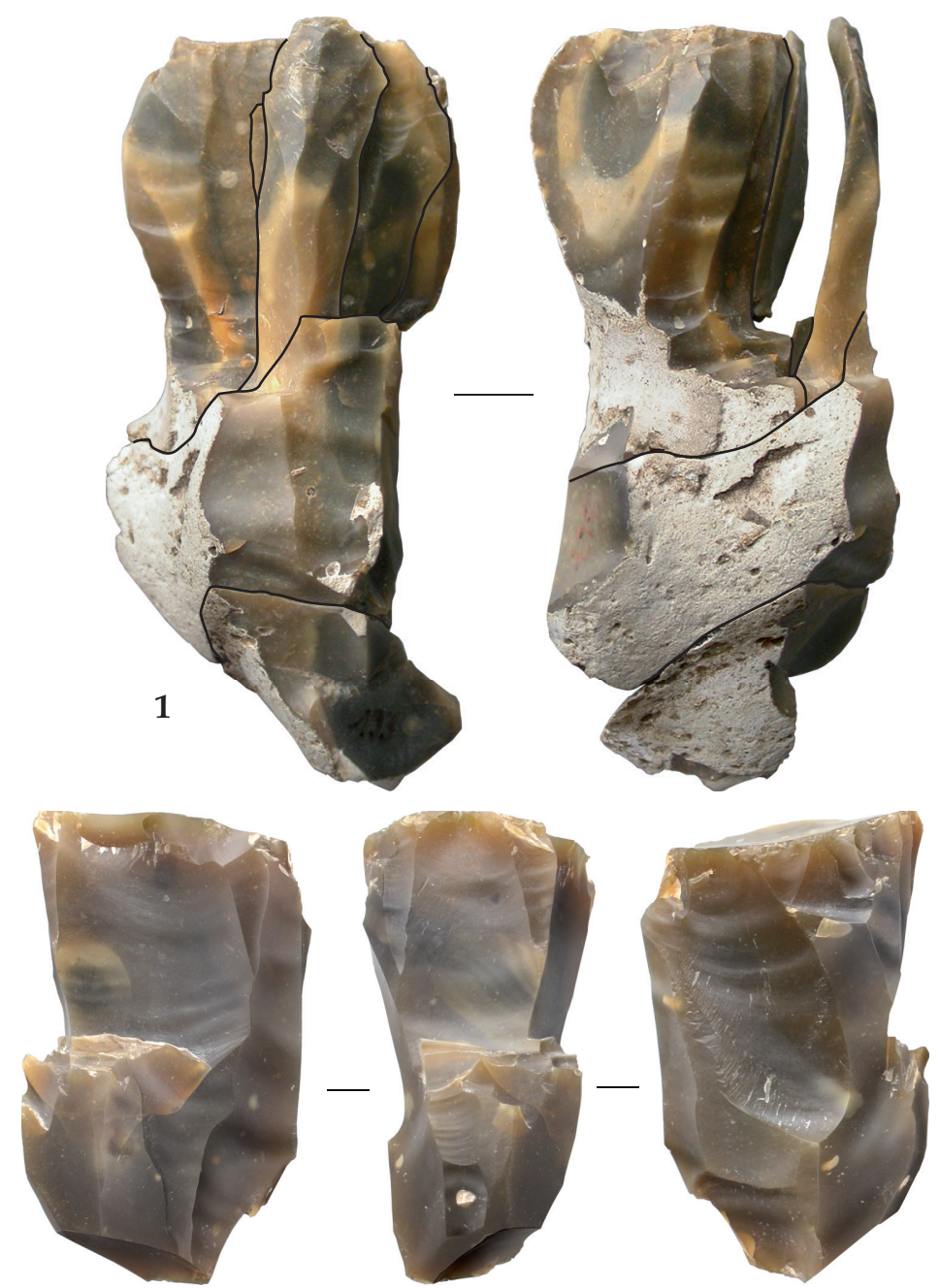

2

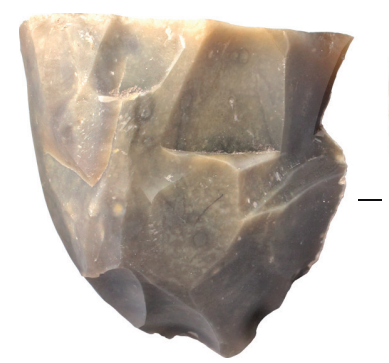

3

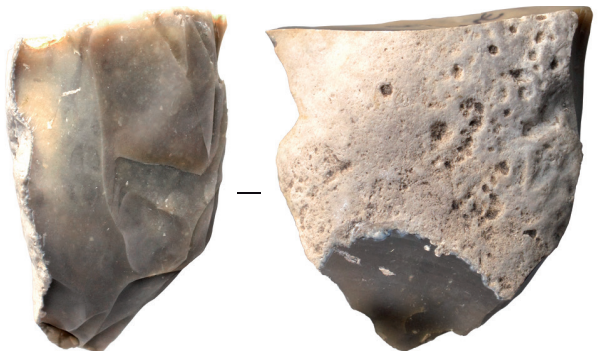

$3 \mathrm{~cm}$

Fig. 20 - Remontage (1) et nucléus (2 et 3) (clichés de S. LANCELOT).

Les produits sont essentiellement de petite taille: il s'agit de lamelles (fig. 22). La majorité (65\%) des 154 produits laminaires entiers a une longueur inférieure à $3 \mathrm{~cm}$ et $90 \%$ a une longueur inférieure à $4 \mathrm{~cm}$ (fig. 23). Seules trois lames dépassent $5 \mathrm{~cm}$ de long sans atteindre $6 \mathrm{~cm}$. Les produits sont relativement étroits et très minces : $80 \%$ ont une épaisseur inférieure à $3 \mathrm{~mm}$ (fig. 23). Les fragments laminaires sont également nombreux avec 319 pièces.

Le style des produits correspond très bien au " Style de Coincy » défini par le Dr Rozoy (1969). Les nervures dorsales obliques ou sinueuses divisent les dos des produits le plus souvent en deux pans (fig. 22). Leurs bords ne sont pas toujours très parallèles. La majorité des extrémités distales est pointue $(70 \%)$. Les talons sont à $90 \%$ linéaires ou punctiformes. Ils montrent quasiment tous une préparation au détachement (abrasion), caractère que l'on retrouve d'ailleurs sur la majorité des bords des plans de frappe des nucléus (52 / 65).

La minceur des talons et la technique de l'abrasion, associées à la lisibilité des points d'impact, l'esquillement de certains talons, la présence d'ondulations fines et serrées sur la face d'éclatement de nombreuses lamelles et l'existence de nombreux 

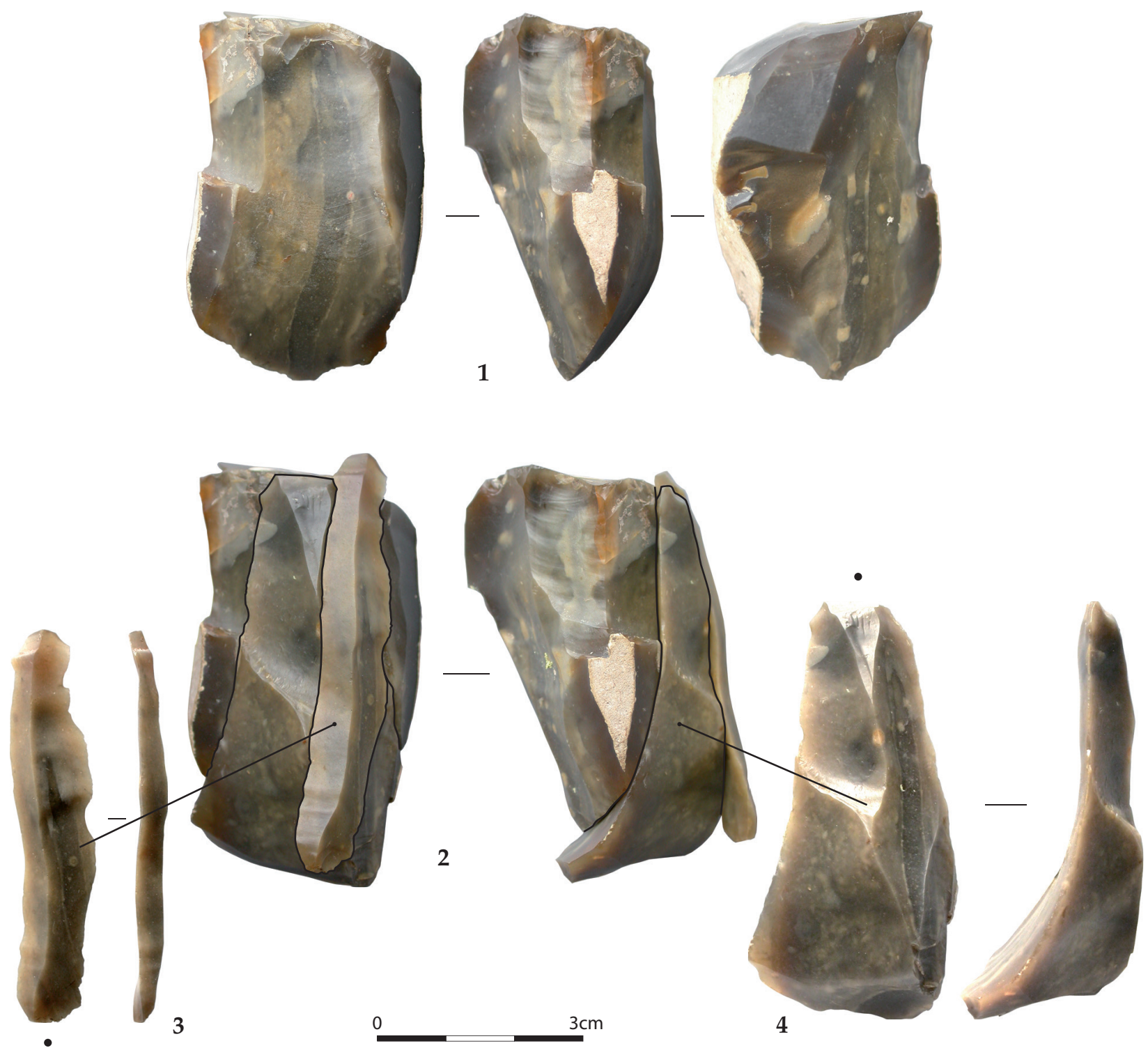

Fig. 21 - Nucléus seul (1) et associé (2) aux pièces « utilisées » raccordées (3 et 4) (clichés de S. LANCELOT).

accidents de réfléchissements plaideraient pour un plein débitage effectué essentiellement au percuteur de pierre tendre (grès probablement). Quelques nucléus témoignent pourtant d'un certain acharnement en fin d'exploitation sur des plans de frappe peu inclinés et peut-être d'un changement de technique de percussion avec la réutilisation de la pierre dure.

La plupart des nucléus semblent exploités de manière intensive (fig. 19, $\mathrm{n}^{\circ} 3$ ). L'histogramme des longueurs de la table laminaire lors de leur abandon dessine une courbe unimodale avec une valeur généralement comprise entre 3 et $6 \mathrm{~cm}$ (fig. 24). Un seul nucléus a une table inférieure à 3 $\mathrm{cm}(2,3 \mathrm{~cm})$. Une longueur proche de $3 \mathrm{~cm}$ pourrait indiquer un seuil économique d'interruption du débitage, les produits n'étant plus acceptables en deçà. La comparaison avec les lamelles (fig. 24) montre un décalage entre les longueurs des produits et des tables. Il s'agit d'un phénomène connu au Mésolithique (Ducroce 2001) qui traduit le prélèvement intensif des potentiels supports d'armature (entre 4 et $6 \mathrm{~cm}$; voir ci-dessous) et la non utilisation des plus petites lamelles. De plus, les produits sont généralement moins longs que la table, surtout dans le cas des débitages bipolaires.

\section{Les pièces retouchées (hors microlithes)}

\section{Description}

Sur 42 outils, 31 sont très peu caractéristiques (fig. 25, $\mathrm{n}^{\circ} 1$ à 17) avec simplement quelques retouches plus ou moins irrégulières qui suivent parfois une distribution alternante sur les bords les plus tranchants des objets (fig. $25, n^{\circ} 1$ à 3 ). La plupart des retouches semblent consécutives à une utilisation même si certaines, un peu plus régulières, pourraient résulter d'un façonnage du support. 


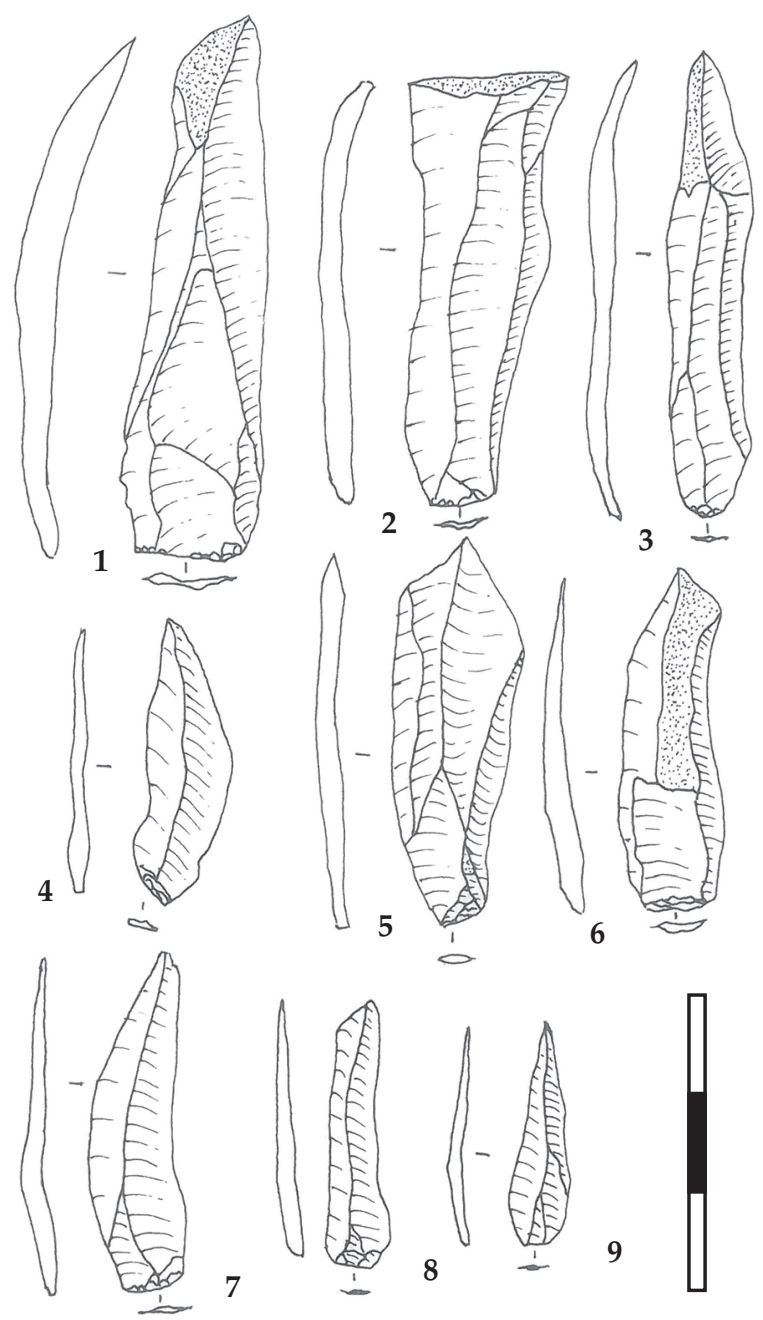

Fig. 22 - Produits laminaires.

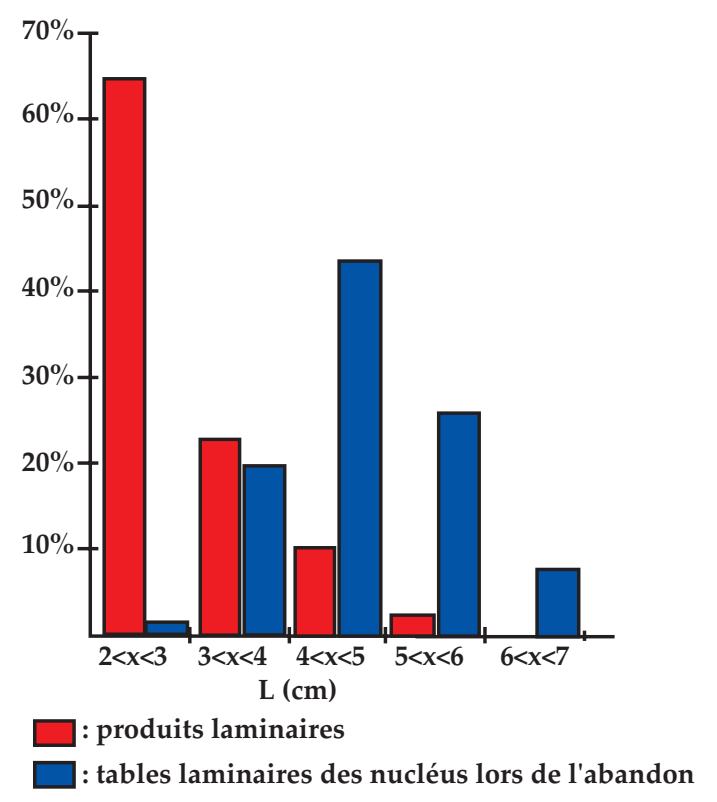

Fig. 24 - Comparaison des longueurs des tables laminaires et des produits laminaires.
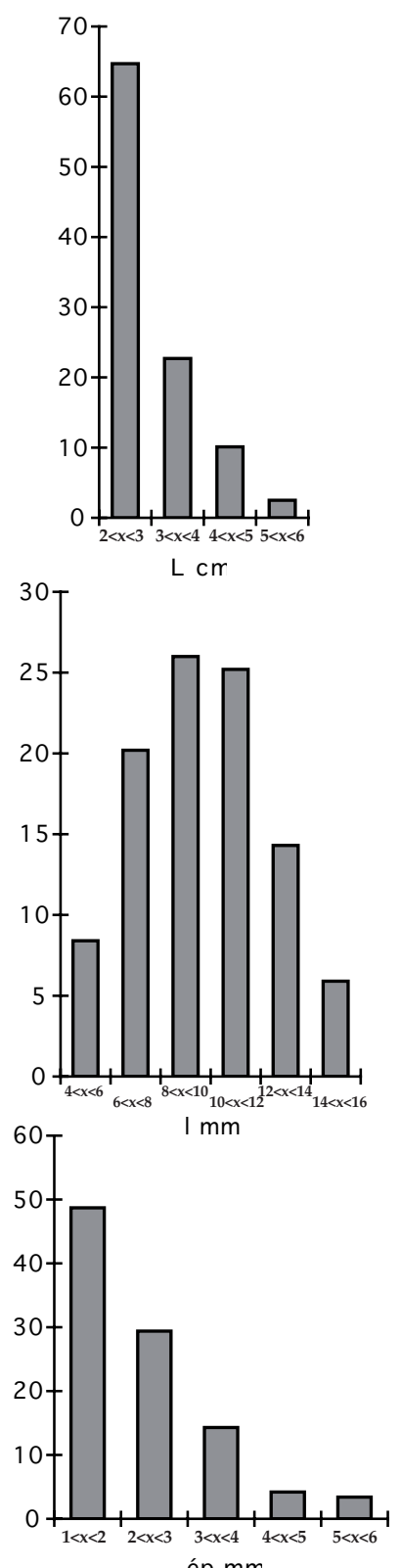

ép $\mathrm{mm}$

Fig. 23 - Dimensions des produits laminaires.

Les outils du fonds commun "plus classiques » sont très rares avec un grattoir (fig. $25, \mathrm{n}^{\circ} 18$ ), un couteau à dos retouché $\left(n^{\circ} 19\right)$ et un burin $\left(n^{\circ} 20\right)$.

Les lamelles à troncature oblique (fig. 26) montrent une certaine hétérogénéité interprétée initialement comme un ensemble hétéroclite qui rassemblerait des ébauches de microlithes et d'éventuels outils du fonds commun.

\section{Les supports}

Les supports des pièces simplement retouchées sont des éclats plutôt allongés et des produits laminaires (fig. 25). Le remontage 23 (fig. 21) rassemble deux pièces avec des retouches $a$ posteriori : un beau produit laminaire et un éclat outrepassé lié à l'entretien du plein débitage. Les 

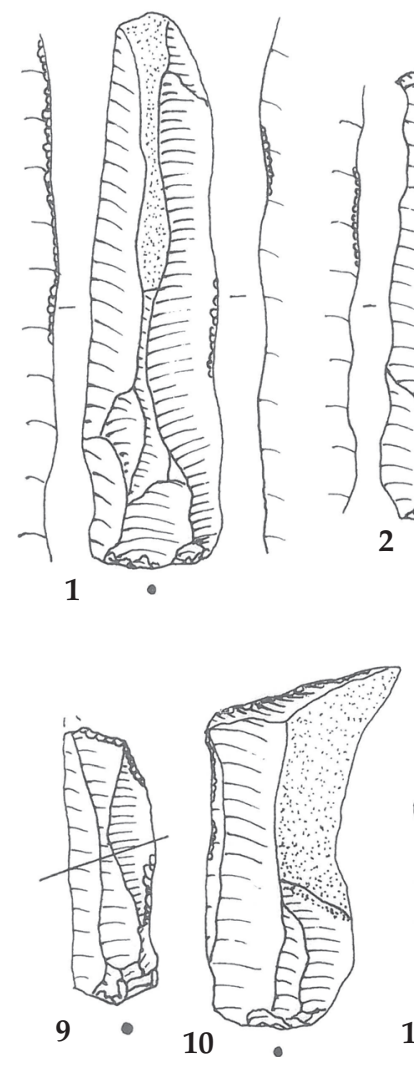
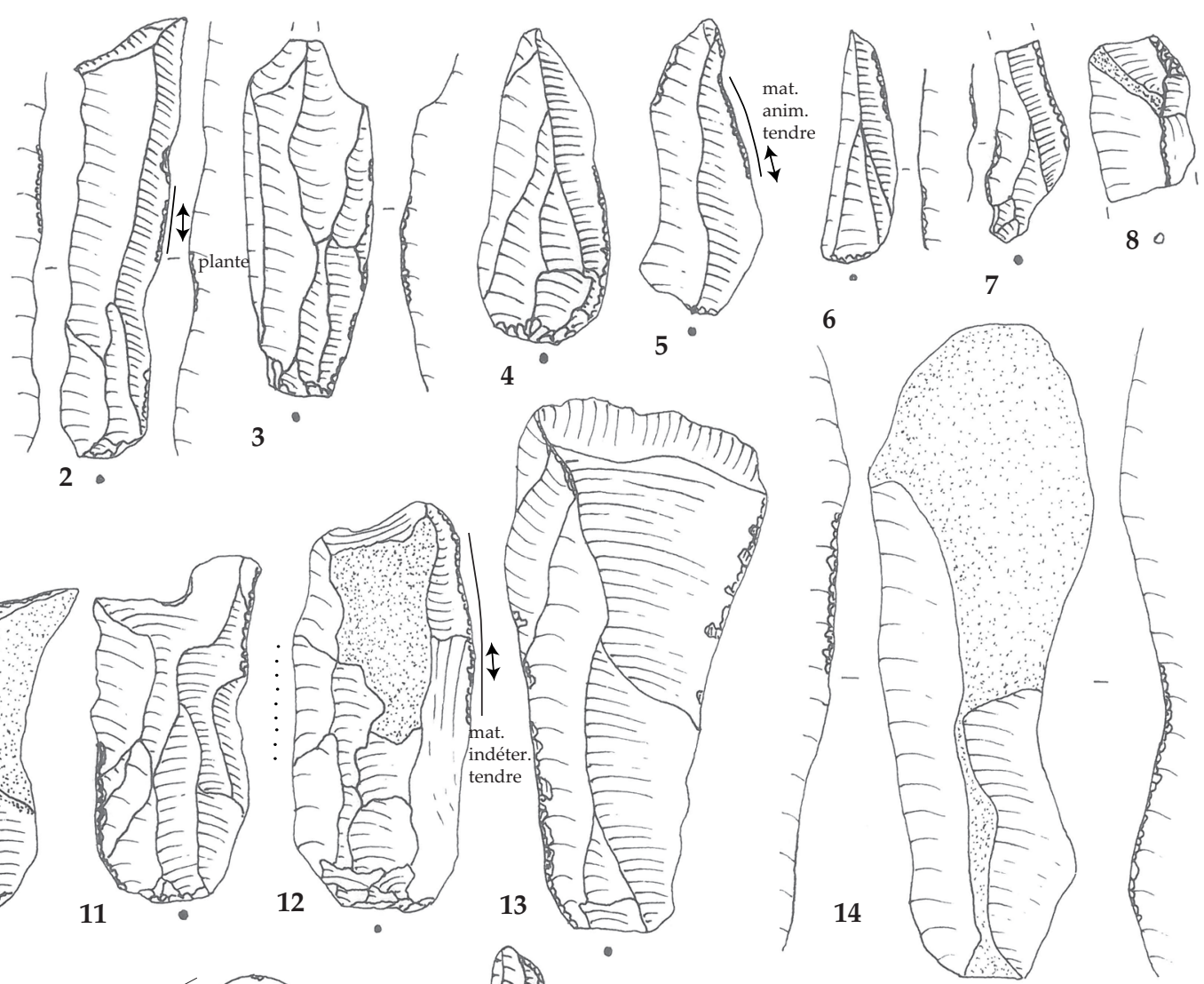
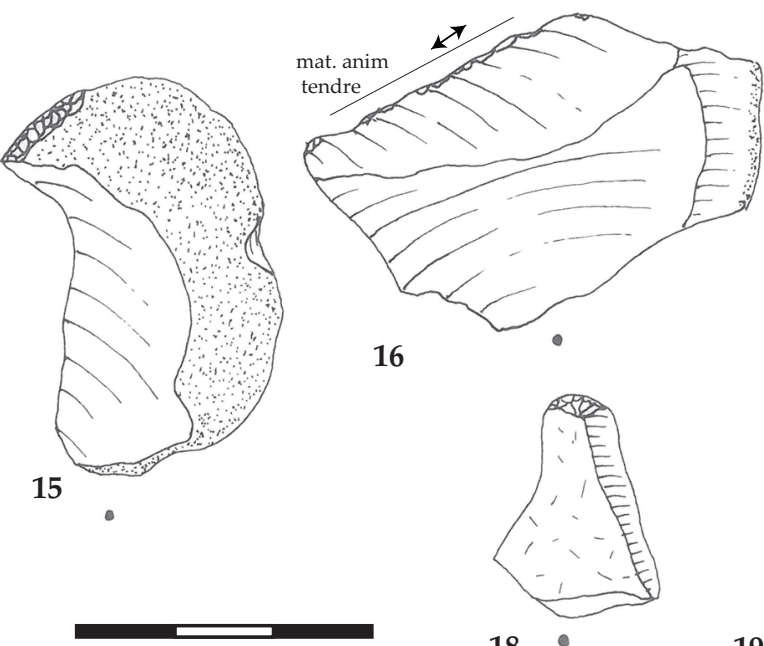

16

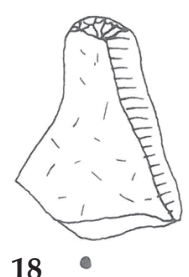

19

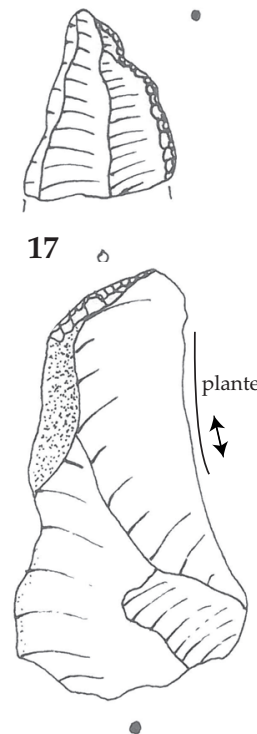

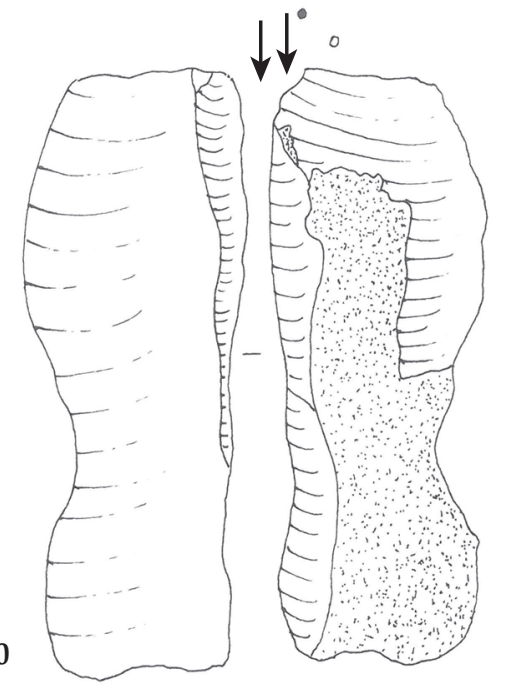

Fig. 25 - Pièces simplement retouchées (1 à 17), grattoir (18), couteau à dos retouché (19) et burin (20).

autres supports laminaires retenus sont très variés avec des lamelles qui auraient pu être transformées en armature et d'autres qui sont nettement plus épaisses que les microlithes (5 à $7 \mathrm{~mm}$ ). Les éclats employés apparaissent assez disparates (fig. 25) et peuvent aussi bien provenir de la phase de mise en forme des blocs que de la phase d'entretien du plein débitage. Les lamelles à troncature oblique (fig. 26) montrent aussi une faible standardisation des supports.

En fait, la chaîne opératoire orientée vers la production d'armatures crée assez de rebuts pour le reste de l'outillage.

\section{Les microlithes}

\section{Décompte typologique}

La série des microlithes (pièces techniques + armatures ; Rozoy 1978) compte 133 microburins et pièces assimilées, 60 armatures identifiables, 3 possibles ébauches et 44 fragments indéterminables. On observe la large prédominance des segments et des pointes à base retouchée d'assez belle facture (fig. $27, \mathrm{n}^{\circ} 1$ à 5 ). Il est tentant $\mathrm{d}^{\prime}$ avancer $\mathrm{l}^{\prime}$ idée que ces Mésolithiques utilisent un seul type de trait armé de silex avec une pointe à base retouchée à l'extrémité et plusieurs segments pour former 

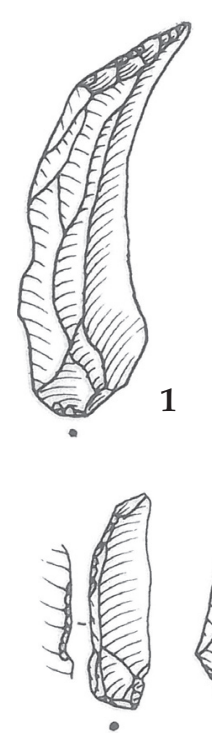

5

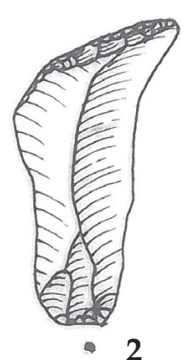

2

6

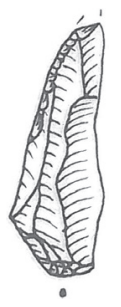

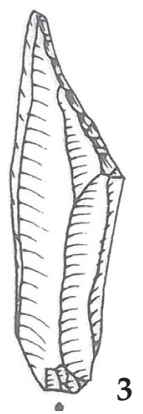
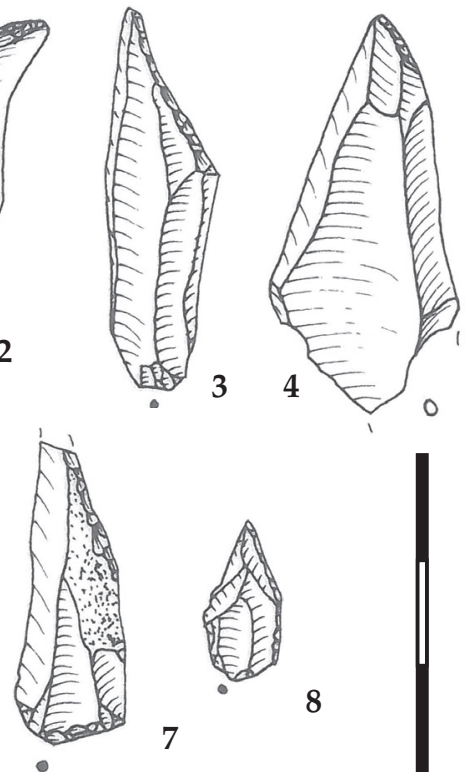

Fig. 26 - Lamelles à troncature oblique.

le tranchant latéral ou des barbelures, même si des travaux récents (CHESNAUX 2013) avancent l'hypothèse d'un emploi de certains segments en pointe-barbelure.

Les armatures comptent :

12 pointes à base retouchée (fig. $27, \mathrm{n}^{\circ} 6$ à 17 ) ;

40 segments (fig. $27, \mathrm{n}^{\circ} 18$ à 57 ) ;

6 pointes à base non retouchée (fig. $27, \mathrm{n}^{\circ} 58$ à 63);

2 divers microlithiques (fig. 27, $\mathrm{n}^{\circ} 64$ à 65) ;

44 fragments de microlithes (fig. 27, nº 66 à 71).

\section{Les supports des microlithes}

Les microlithes ont été réalisés à partir de supports essentiellement lamellaires, plutôt plats, dont le style irrégulier évoque tout à fait celui des produits lamellaires non transformés en outil. Les talons des nombreux microburins proximaux sont à $95 \%$ linéaires et ils sont tous abrasés. Ce sont sans doute les lamelles les plus « soignées » qui ont été prélevées pour servir de support d'armature. Quelques plages corticales réduites sont préservées sur quelques rares microlithes ( 2 segments, 1 pointe à troncature oblique, 1 ébauche), preuve qu'il n'y a pas toujours de rigidité dans la gamme des supports choisis.

La partie pointue des segments qui est située vers le talon de la lamelle est toujours obtenue par le procédé du microburin. Ce n'est pas toujours le cas pour l'autre extrémité qui peut simplement être un aménagement par retouche d'une extrémité distale pointue (fig. 27, $\mathrm{n}^{\circ} 37,40,43,44,47,50$ et 51 ). Cette forme de produit est donc particulièrement prisée, même si le recours à un nouveau procédé de microburin n'est pas un problème.
Les segments présentent à $70 \%$ une épaisseur strictement inférieure à $2 \mathrm{~mm}$ (fig. 28). Les 12 pointes à base retouchée montrent une épaisseur plus variable allant jusqu'à $4 \mathrm{~mm}$. Par contre, 5 des 6 pointes à base non retouchée ont une épaisseur inférieure à $2 \mathrm{~mm}$. L'épaisseur des microburins est strictement identique. La distribution des épaisseurs des produits laminaires est assez proche tout en montrant un léger déficit pour la classe comprise entre 1 et $2 \mathrm{~mm}$. Ce dernier peut révéler un prélèvement de ces produits les plus recherchés. Ce sont donc surtout des contraintes d'épaisseur qui ont guidé le choix des supports d'armature. Cette sélection est assez souple mais la bonne réussite du procédé de façonnage des piquants trièdres dépend de la minceur des lamelles supports.

\section{Détail des microburins et des pièces techniques}

L'abondance des microburins et le raccord entre un microlithe et un microburin (fig. 29, 28) témoigne du façonnage sur place des armatures. Ces microburins sont au nombre de 119 auquel il convient d'ajouter 4 écailles, 2 lamelles à coche (fig. 29, $\mathrm{n}^{\circ} 21$ à 22) et 8 lamelles cassées dans la coche (fig. 29, 20, 23 à 27). Ces pièces à coches sont maintenant considérées comme des accidents intervenus lors du procédé du microburin. Deux objets sont clairement des segments inachevés (fig. 29, n 30 à 31).

La prédominance des microburins proximaux (tab. II) témoigne de la nécessité d'obtenir la principale extrémité pointue dans la partie la plus épaisse de la lamelle. Cette opération n'est réalisable qu'avec le procédé du microburin qui permet d'éliminer le talon et le bulbe tout en dégageant une pointe oblique. La latéralisation majoritaire de l'encoche des microburins à droite correspond à la latéralisation à gauche des pointes. La présence de microburins sénestres s'explique par l'abondance des segments qui ne sont pas latéralisables. D'ailleurs, le recours au façonnage de deux piquants trièdres à chaque extrémité conduit à l'abandon de deux microburins à la latéralisation opposée.

Les 7 microburins Krukowski (fig techni, n 13 à 19 ; Rozor 1978) mettent en évidence le détachement simultané de deux microburins et/

\begin{tabular}{|c|c|c|c|}
\hline Microburins & $\begin{array}{c}\text { encoche } \\
\text { dextre }\end{array}$ & $\begin{array}{c}\text { encoche } \\
\text { senestre }\end{array}$ & Totaux \\
\hline Proximaux & 49 & 22 & $\mathbf{7 1}$ \\
\hline Mésiaux & 11 & 6 & $\mathbf{1 7}$ \\
\hline Distaux & 14 & 10 & $\mathbf{2 4}$ \\
\hline Krukowski & 7 & 0 & $\mathbf{7}$ \\
\hline Totaux & $\mathbf{8 1}$ & $\mathbf{3 8}$ & $\mathbf{1 1 9}$ \\
\hline
\end{tabular}

Tab. II - Latéralisation et décompte des microburins. 


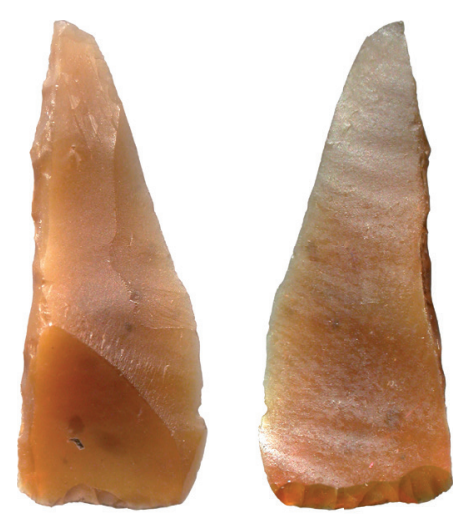

1

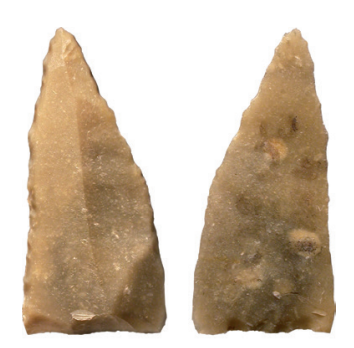

2

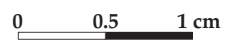

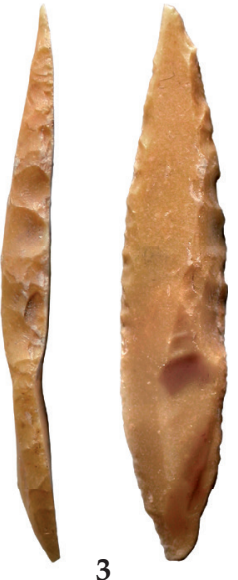
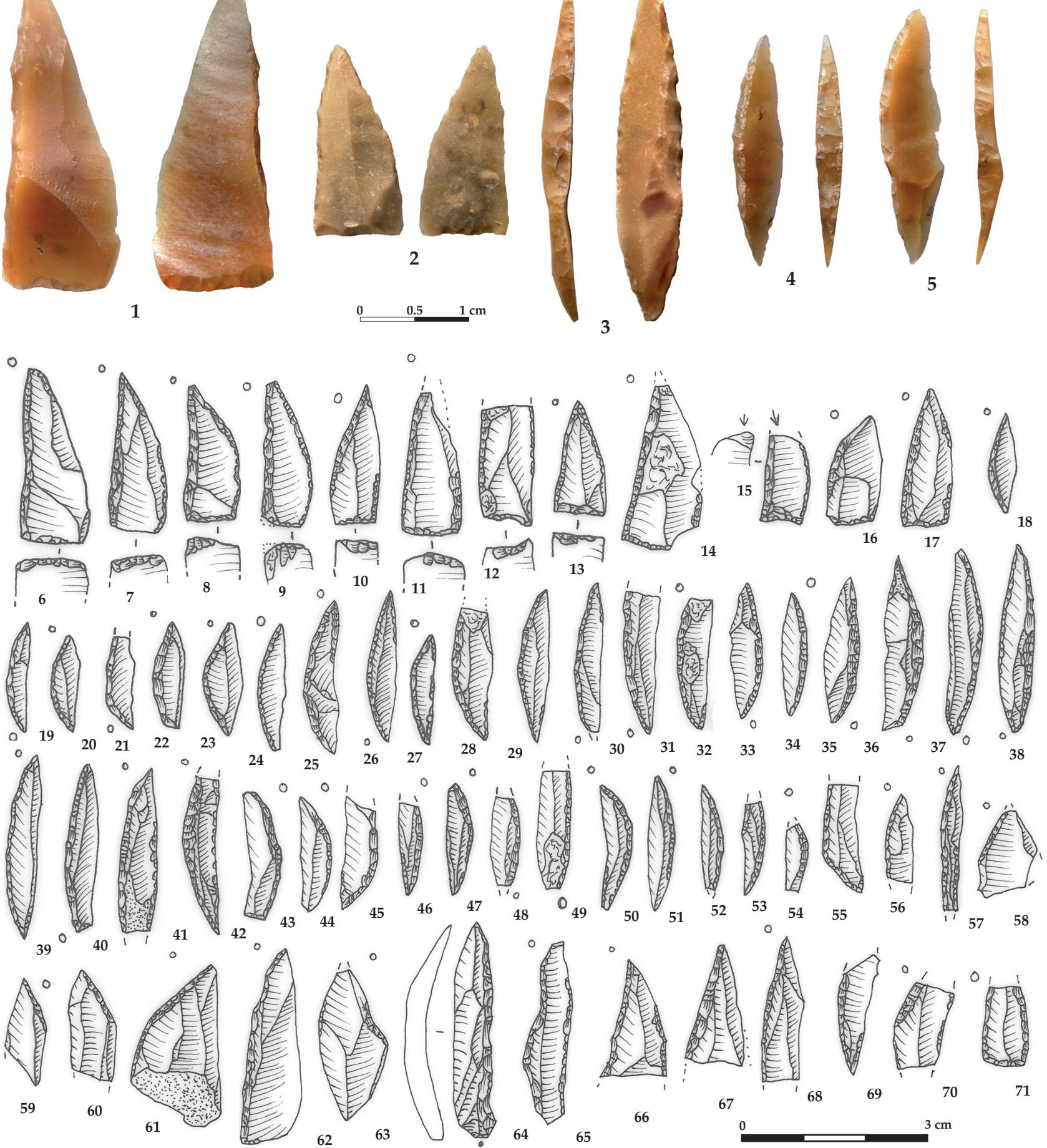

Fig. 27 - Pointes à base retouchée (1 et 2) et segments (3 à 5)(clichés de S. Lancelot) ; pointes à base retouchée (6 à 17), segments (18 à 57), pointes à troncature oblique (58 à 63), divers microlithiques $(64,65)$ et fragments d'armature $(66$ à 71$)$. 


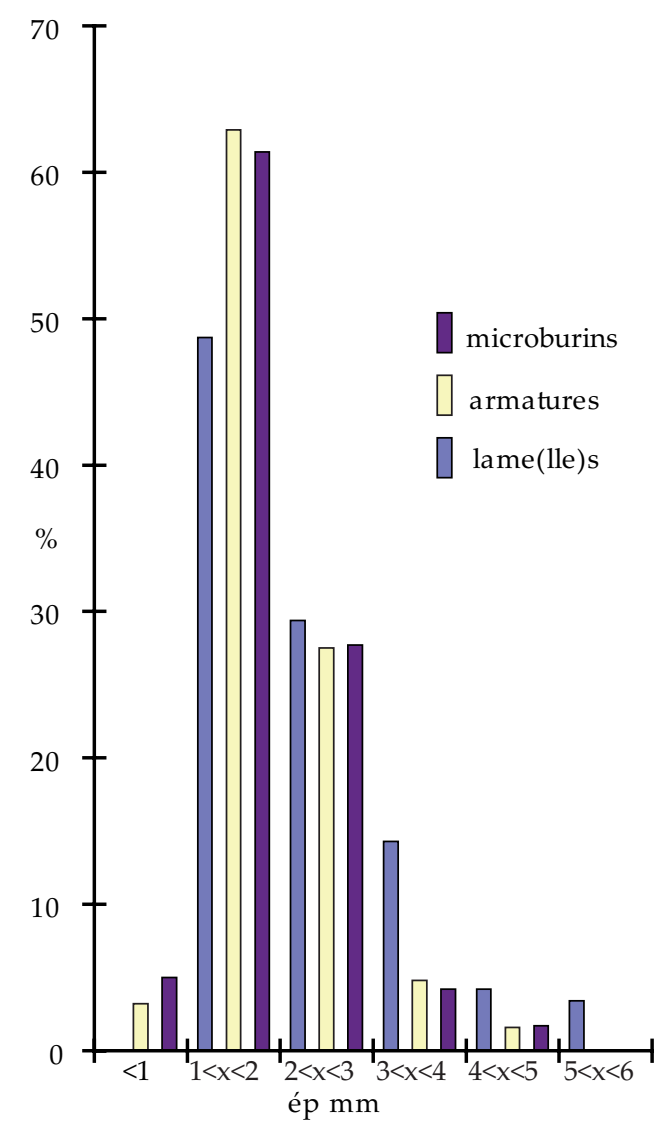

Fig. 28 - Histogramme des épaisseurs des lamelles entières, des microburins et des armatures.

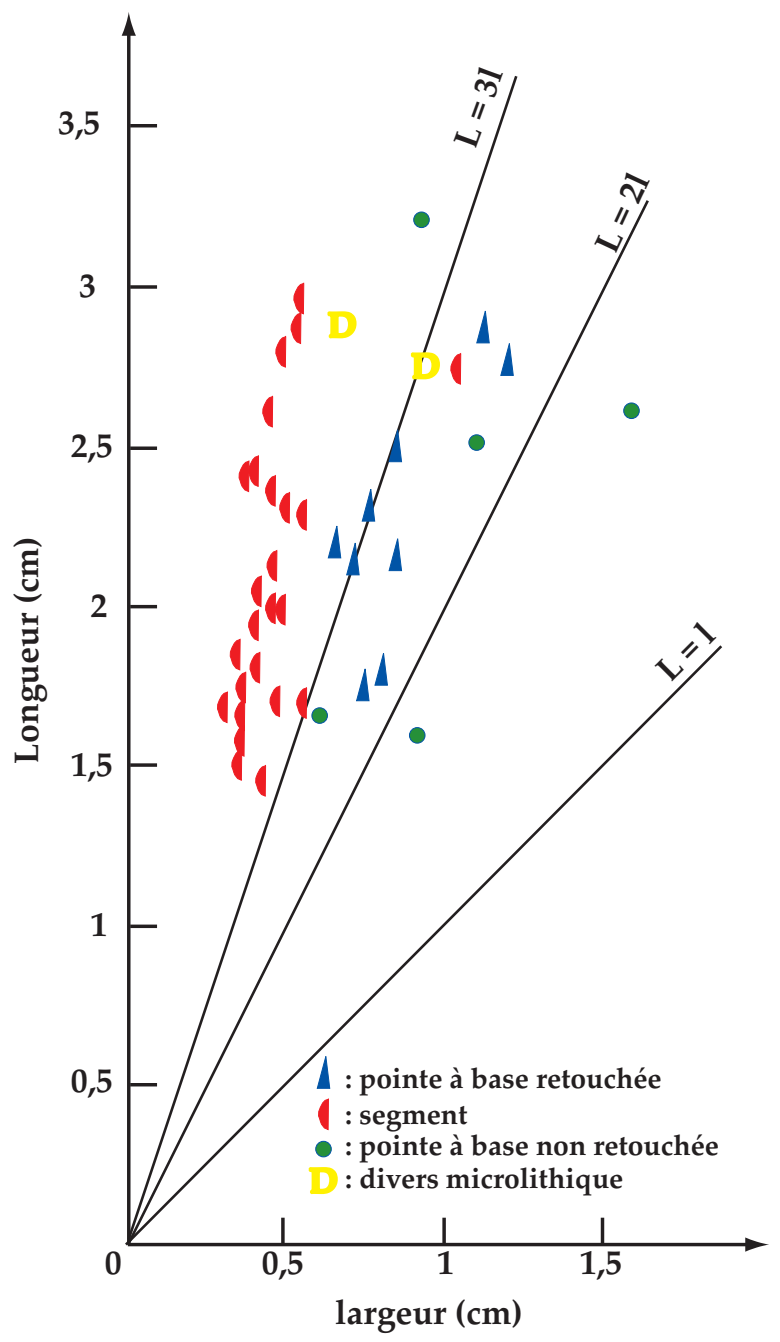

Fig. 30 - Diagramme largeur / Longueur des armatures de Warluis I.

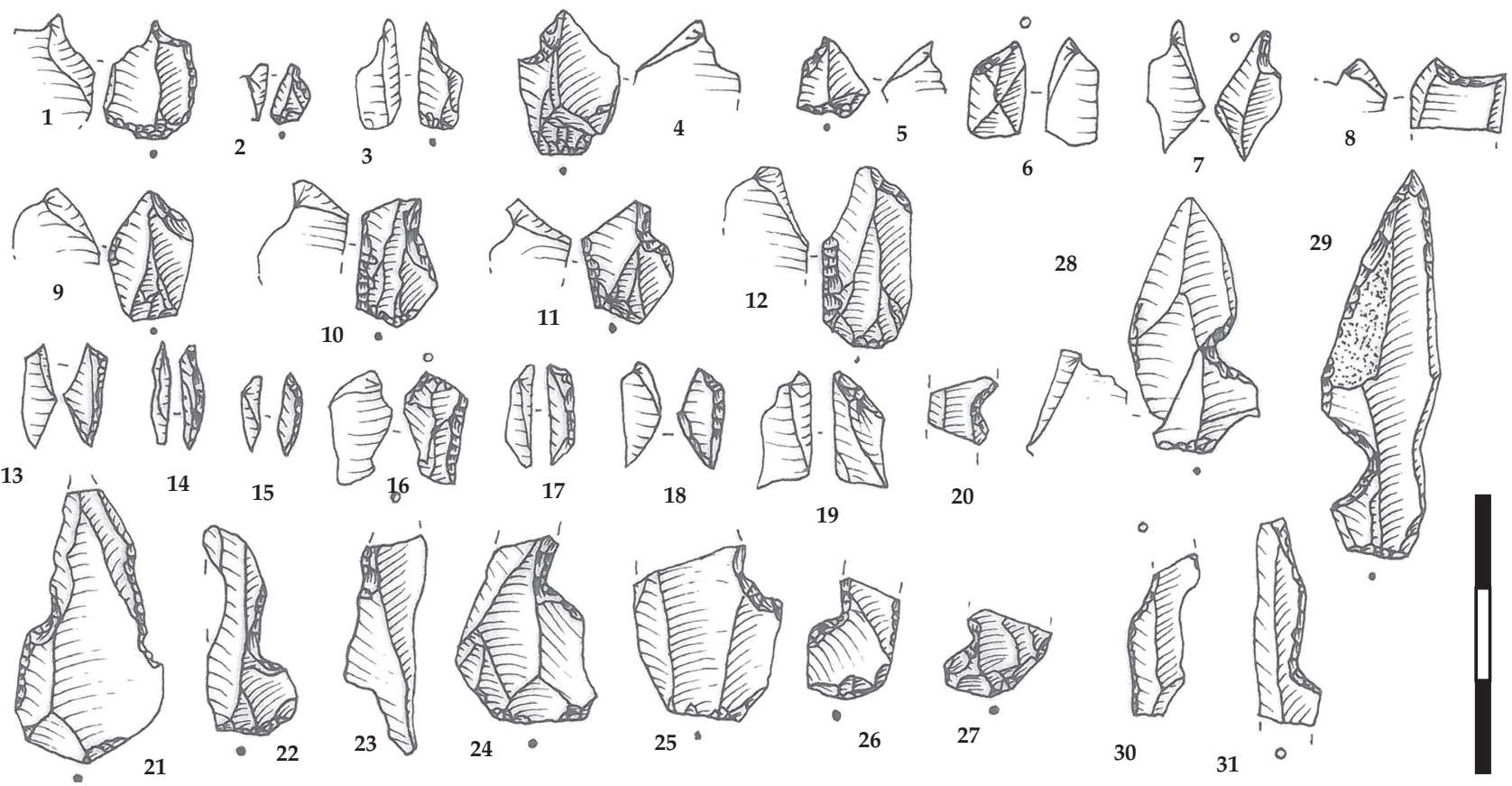

Fig. 29 - Microburins (1 à 8), microburins avec une retouche secondaire marginale d'un bord (9 à 12), microburins Krukowski (13 à 19), lamelles à coche (20 à 27), raccord d'un microburin sur une pointe à base non retouchée (28), probable ébauche de pointe à base retouchée (29), probables ébauches de segment (30 à 31). 
ou un procédé de raccourcissement d'armature. Une pointe est d'abord obtenue par le détachement d'un microburin ou par un simple aménagement de l'extrémité du support. Ensuite, cette opération est renouvelée. Le second microburin porte parfois la trace du premier piquant trièdre.

Sept microburins montrent une retouche marginale développée sur le bord opposé à l'encoche (fig. 29, nº 9 à 12). Il s'agit d'une régularisation du bord du support réalisée avant le détachement du microburin (DuCROCQ 1987).

\section{Détail des armatures}

Excepté les deux armatures dominantes, les autres types sont surtout représentés par une série de pointes à base non retouchée (fig. 27, $\mathrm{n}^{\circ} 58$ à 63) qui semble assez hétéroclite au niveau de la latéralisation et surtout du module (fig. 30). Cette hétérogénéité contraste avec la standardisation de ce type microlithique dans les industries plus anciennes de Warluis (DuCROCQ et al. 2008 ; COUTARD et al. 2010, fig. 7). Cet ensemble doit regrouper essentiellement des armatures inachevées ou ratées et éventuellement des versions simplifiées des pointes à base retouchée (fig. 27, n 62).

Les deux divers microlithiques (fig. 27, n 64 à 65) sont des sortes de pointes à dos qui pourraient être des segments atypiques ou inachevés.

Le tailleur mésolithique a respecté certaines constantes pour obtenir des pointes à base retouchée (fig. 27). Elles sont toutes latéralisées à gauche avec leur partie pointue orientée vers le talon du support. La longueur est toujours comprise entre le double et le triple de la largeur (fig. 30). Le bord opposé à la troncature dessine une ligne convexe obtenue par le tranchant brut de débitage du support et par une retouche secondaire de régularisation $(11 / 12)$. Cette courbe s'oppose à une troncature quasiment rectiligne. Cette distinction produit des pièces souvent asymétriques. Le tailleur a eu un seul objectif pour la base. Il fallait l'amincir et la rendre tranchante. Cette opération a été réalisée par des retouches directes $(4 / 12)$, inverses $(1 / 12)$ ou plus souvent par des retouches directes abruptes suivies de retouches inverses plates à obliques (7/12). Il n'y a pas eu de soucis de standardisation pour la forme de la base. Elle peut être rectiligne (9/12), concave $(2 / 12)$ et parfois convexe $(1 / 12)$. On observe des bases transversales $(8 / 12)$ ou obliques $(4 / 12)$. Ce fait est intéressant car certains sites contemporains de la Somme sont par bien des points rigoureusement identiques à Warluis I mais divergent par la base des pointes à base retouchée qui est systématiquement oblique. Il s'agit de certaines concentrations de Saleux et d'Amiens-Etouvie (FAGNART et al. 2008). La plupart des autres séries picardes à segments et pointes montrent la même souplesse sur ce point de signaler une apparente ébauche de pointe (fig. 29, n²9) qui est une lamelle à troncature oblique affectée d'une encoche. Cette dernière était probablement destinée à initier le procédé du microburin pour dégager une base oblique et éliminer le talon de la lamelle. L'armature obtenue aurait été une pointe à base retouchée oblique qui serait bien latéralisée à gauche. Cependant, la pointe serait exceptionnellement orientée vers l'extrémité distale du support qui est, dans ce cas, la partie la plus épaisse de la lamelle.

Les segments montrent une large variabilité des longueurs, grossièrement entre $1,4 \mathrm{~cm}$ et $3 \mathrm{~cm}$, et une nette standardisation des largeurs centrée autour de $0,45 \mathrm{~cm}$ (fig. 30). Cette caractéristique est classique dans le nord de la France. Elle est interprétée comme une contrainte liée à l'utilisation des segments pour réaliser le tranchant latéral des traits. Les plus longs des segments peuvent ainsi présenter un dos quasi rectiligne (fig. $27, \mathrm{n}^{\circ} 3,38$ et 52) et pourraient être qualifiés de Pointe de Sauveterre. Cependant, ils font clairement partie de la série des segments. De plus, des retouches marginales sont parfois présentes sur la corde pour la régulariser ou mieux dessiner les extrémités pointues (18/40). La plupart des pièces sont des segments typiques. Cependant, quelques-unes sont asymétriques (fig. 27, $n^{\circ} 50$ et 55) avec parfois une petite troncature transverse d'une des pointes (fig. $27 n^{\circ} 40$ et 43).

\section{Du support à l'armature (résumé)}

Segments :

1) sélection de supports lamellaires plutôt plats peu réguliers mais minces $(<2 \mathrm{~mm})$ et parfois pointus ;

2) régularisation facultative d'un bord du support par des retouches marginales (pression, égrisage ?) ;

3) retouche du bord curviligne ;

4) procédé du microburin (proximal) pour dessiner une pointe en éliminant le talon de la pièce ;

5a) poursuite du bord abattu curviligne jusqu'à dessiner la seconde pointe sur les supports pointus ;

5b) recours au procédé de microburin (distal) pour dessiner la seconde pointe de la majorité des pièces ;

6) retouches secondaires facultatives sur la corde, notamment vers les pointes.

Pointes à base retouchée :

1) sélection de supports lamellaires identiques à ceux des segments tout en étant parfois plus épais (entre 1 et $4 \mathrm{~mm}$ ) ;

2) régularisation optionnelle des bords du support par des retouches marginales (pression) ;

3) retouche du bord droit de la lamelle jusqu'à dessiner une encoche ;

4) procédé du microburin (proximal avec encoche à droite) pour dessiner une pointe sénestre en éliminant le talon de la pièce ; 
5) troncature transversale ou légèrement oblique sur la partie distale du support ;

6) retouche inverse de la base ;

7) terminer le microlithe par une retouche marginale facultative des bords et / ou un microburin Krukowski pour raccourcir le microlithe.

De cette suite d'opérations, il reste à préciser la technique employée pour les diverses retouches (percussion, pression, égrisage).

Il est surtout évident que les Préhistoriques ont mis en place un protocole assez complexe pour transformer les supports en microlithes. Ce fait tranche avec la souplesse qui caractérise le traitement des blocs de matière première jusqu'à la production de lamelles.

\section{ATTRIBUTION CHRONO-CULTURELLE DE L'ENSEMBLE PRINCIPAL}

\section{Localisation géographique des séries comparables}

Les principaux assemblages microlithiques dominés par les segments et les pointes à base retouchée ont été recensés récemment (nombreuses références bibliographiques dans Ducroce 2013) avec une forte concentration en Picardie : Gravière II Nord à Hangest-sur-Somme (fig. 31, $\mathrm{n}^{\circ}$ 1), L'étang à Crouy-Saint-Pierre ( $\left.\mathrm{n}^{\circ} 2\right)$, Warluis I, II et IV ( $\left.{ }^{\circ} 3\right)$, Étouvie-Chemin de la Marine et Rue Saint Maurice II à Amiens ( $\left.\mathrm{n}^{\circ} 4\right)$, La Vierge Catherine et Les Baquets à Saleux $\left(n^{\circ} 5\right)$, Le Marais de Conty $\left(n^{\circ} 6\right)$, La Petite Tête à Blangy-Tronville $\left(n^{\circ} 7\right)$, Le Marais de Berny à Ailly-sur-Noye (n 8), L'Abbayeaux-Bois à Ognolles et La Haute Borne à Beaulieules-Fontaines $\left(n^{\circ} 9\right)$, Lihus II ( $\left.n^{\circ} 11\right)$, Le Bois de la Bocquillière - MESO II à Attilly $\left(n^{\circ} 12\right)$ Sermoise $\left(n^{\circ}\right.$ 13) et plusieurs sites de Choisy-au-Bac ( $\left.n^{\circ} 27\right)$. Des séries similaires sont également abondantes en Îlede-France avec Piscop M1 ( $\left.{ }^{\circ} 14\right)$, Hédouville ( $\mathrm{n}^{\circ}$ 15), Les Près-Saint-Laurent à Beaumont-sur-Oise $\left(n^{\circ} 16\right)$, Chaville I ( $\left.n^{\circ} 18\right)$, Le Dentu à Boinvillers et Haussepied à Orvilliers $\left(n^{\circ} 17\right)$. D'autres sont attestées plus au sud : Lorges I ( $\left.n^{\circ} 20\right)$ et Le Chêne des Fouteaux à Saint-Romain-sur-Cher 1,3 et $4\left(n^{\circ}\right.$ 21). Elles sont présentes en Normandie avec SaintWandrille-Rançon ( $\left.\mathrm{n}^{\circ} 19\right)$, dans le Nord Pas-deCalais avec Le Bois du Marais à Masny ( $\left.n^{\circ} 10\right)$, mais aussi au Luxembourg avec Galgebierg à Diekirch $\left(n^{\circ} 22\right)$, en Wallonie avec Seilles 2 et $3\left(n^{\circ} 23\right)$, L'Ourlaine $\left(\mathrm{n}^{\circ} 24\right)$ et en Flandre avec Verrebroeck

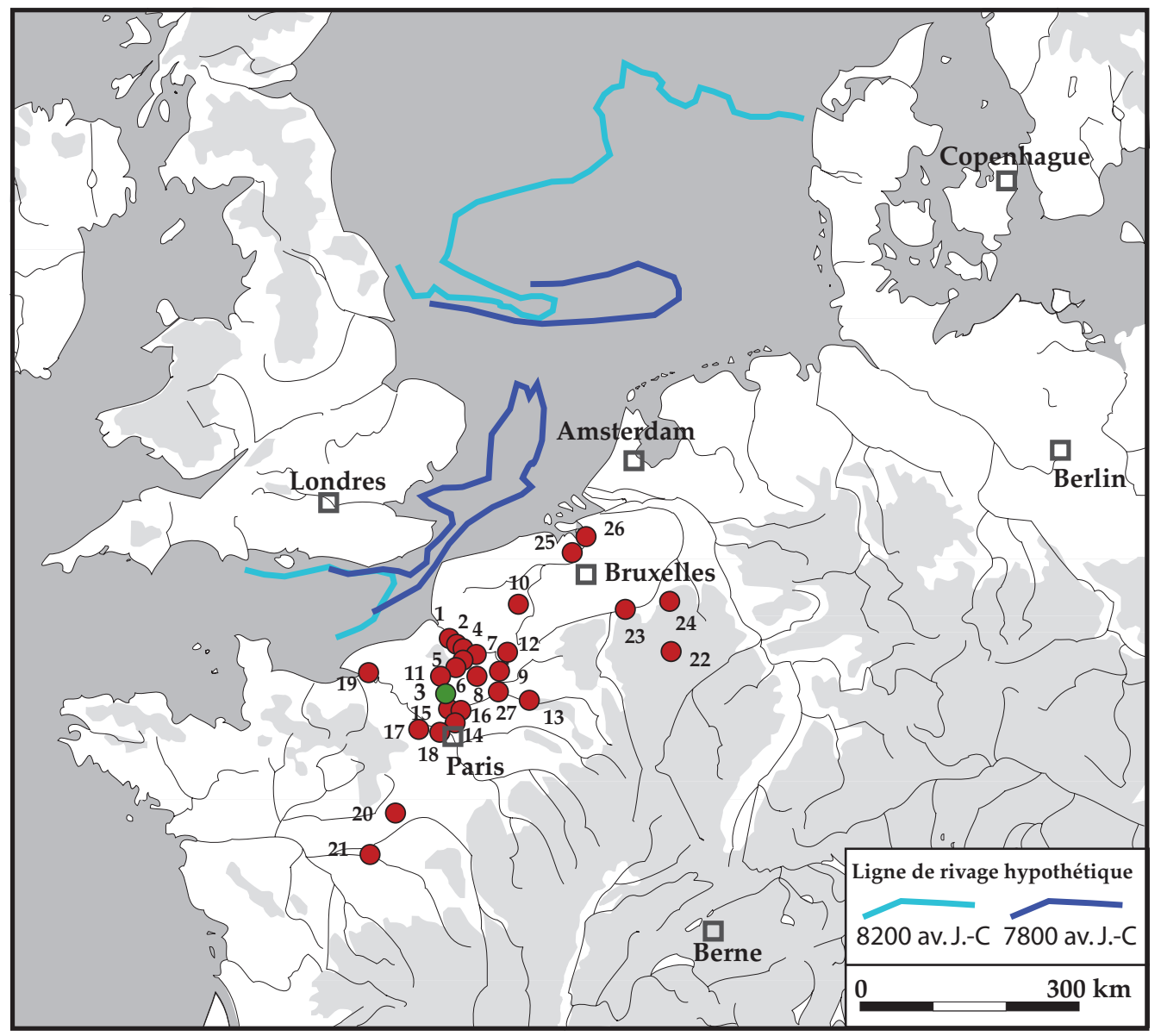

Fig. 31 - Localisation des principaux sites à assemblage microlithique dominé par les segments et les pointes à base retouchée. Les modifications du trait de côte sont déduites des travaux de JelgerSMA (1979), Coles (1998), SOMMÉ (1999) et SOMMé et al. (1994). 
4 et $23\left(n^{\circ} 25\right)$ et Doel Deurganckdok $3\left(n^{\circ} 26\right)$. Ce vaste territoire s'étend sur $600 \mathrm{~km}$ suivant un axe SW-NE et sur $300 \mathrm{~km}$ d'ouest en est et compte essentiellement des régions au relief monotone. Une analyse plus détaillée des séries disponibles à l'est et à l'ouest serait susceptible d'étendre cette répartition, notamment dans une direction orientale. Des affinités sont aussi parfois perceptibles avec des sites de Grande-Bretagne mais aucune série microlithique avec une telle domination des segments et de pointes à base retouchée $n^{\prime} y$ est clairement attestée. L'identification de ce large territoire pourrait se prêter à des interprétations palethnographiques plus précises qui semblent encore prématurées (Ducroce 2013). Pourtant, de sensibles nuances typologiques peuvent signer des faciès locaux et/ou des variations chronologiques.

\section{La position chronologique}

L'insertion chronologique de Warluis I est assurée par la datation de noisettes carbonisées $(8750 \pm 80 \mathrm{BP})$ bien associées à l'industrie et par l'analyse palynologique qui la place dans un environnement marqué par le développement de la corylaie, caractéristique du début de la chronozone du Boréal (voir ci-dessus).

Des séries comparables de Picardie apportent aussi des informations précises sur la chronologie. Ainsi les vestiges de Crouy-Saint-Pierre sont inscrits dans une séquence palynologique qui situe l'occupation au début de la palynozone 7 de Van Zeist (VAn ZeIst et al. 1980) soit au début de la chronozone du Boréal (MunAut et al. 1997). Des datations absolues sont aussi disponibles depuis la découverte du site de Hangest Gravière II Nord (fig. 32 ; Ducroce 1992), confortées par l'étude de certaines concentrations de Saleux (FAGNART et al., 2008) puis par des résultats issus d'autres gisements de Warluis (DuCROCQ 2009).

Comme d'autres dates de ce faciès, la datation de Warluis I se place dans le plateau de 8800 BP qui correspond à un âge compris grossièrement entre 7900 et 7500 avant notre ère.

\section{L'attribution culturelle}

L'un d'entre nous (TD) a d'abord qualifié les séries avec ce type d'assemblage microlithique de groupe de Hangest avant de le dénommer sous le terme de Beuronien à segments (Ducroce 1991 et 2013). Le Beuronien, au sens strict, a d'abord été défini au sud de l'Allemagne par Wolfgang TAUTE (1973) pour désigner des assemblages à pointes à base retouchée et triangles, puis Stefan Karol KozŁowsKi (1983) a déterminé un Beuronien au sens large (culture de Beuron-Coincy) sur un plus large territoire en regroupant des ensembles à fortes affinités typologiques (Gов 1985). Ce dernier à pointes à base retouchée. La cartographie de cette entité sur l'Europe occidentale permet de dessiner grossièrement trois grandes zones pendant la première moitié du Boréal avec le MaglemosienDuvensee, au nord, le Beuronien, au centre, et le Sauveterrien au sud. Le Beuronien à segments n'est qu'un élément de ce « grand » Beuronien qui se caractérise par le remplacement des triangles par les segments. Cette nomenclature permet de hiérarchiser les différences entre cultures matérielles et d'éviter une balkanisation des dénominations avec des terminologies différentes suivant chaque département.

\section{IDENTIFICATION DES ACTIVITÉS PRATIQUÉES ET STATUT/FONCTION DU SITE}

\section{L'approche fonctionnelle de l'industrie lithique}

\section{Méthode d'analyse et réflexion sur l'état de conser- vation des traces d'utilisation}

L'analyse fonctionnelle de l'industrie lithique est réalisée à partir de trois échelles d'observation : à l'œil nu, à faible grossissement (de x 6 à x 40 ; binoculaire stéréoscopique Wild) et à fort grossissement (microscope métallographique Olympus BX51M). Elle reprend le protocole expérimental défini par KEELEY (1980) ainsi que les procédures d'observation et d'interprétation adoptées par de nombreux chercheurs (CASPAR 1988, Plisson 1985, VAUGHAN 1985).

Les 66 pièces analysées ont été sélectionnées suivant des critères typologiques afin de tester en premier lieu le potentiel informatif d'un matériel caractérisé par un état de surface médiocre. Ce lot comportait aussi des objets simplement affectés de minuscules retouches irrégulières (pièces dites " utilisées », voir ci-dessus). Le taux de pièces avec des traces d'utilisation n'est que de $22 \%$. Ce pourcentage résulte probablement du degré d'altération de la surface des outils. En effet, le lustré de sol a probablement pu masquer les usures les plus superficielles, correspondant à des utilisations brèves ou de faible ampleur. On peut par exemple s'attendre à une sous-représentation des activités sur matière carnée tendre, qui d'après nos résultats expérimentaux, occasionnent souvent un endommagement modéré du bord actif, surtout dès que l'outil n'effectue que peu de contacts avec une matière de plus forte dureté telle que l'os.

\section{Les armatures}

Sur les douze pointes à base retouchée analysées, une seule porte des stigmates d'un impact violent probable (fig. 27, $\mathrm{n}^{\circ} 15$ ). Il s'agit d'une fracture burinante apicale à terminaison en marche, dont la longueur dépasse $1 \mathrm{~mm}$. La patine de la pièce a empêché l'observation d'autres stigmates d'usures à l'échelle microscopique. Une autre pointe (fig. 27, 
calibrated dates

cal BC

OxCal v4.2.3 Bronk Ramsey (2013); r:5 IntCal13 atmospheric curve (Reimer et al 2013)

$95,4 \%$ probability

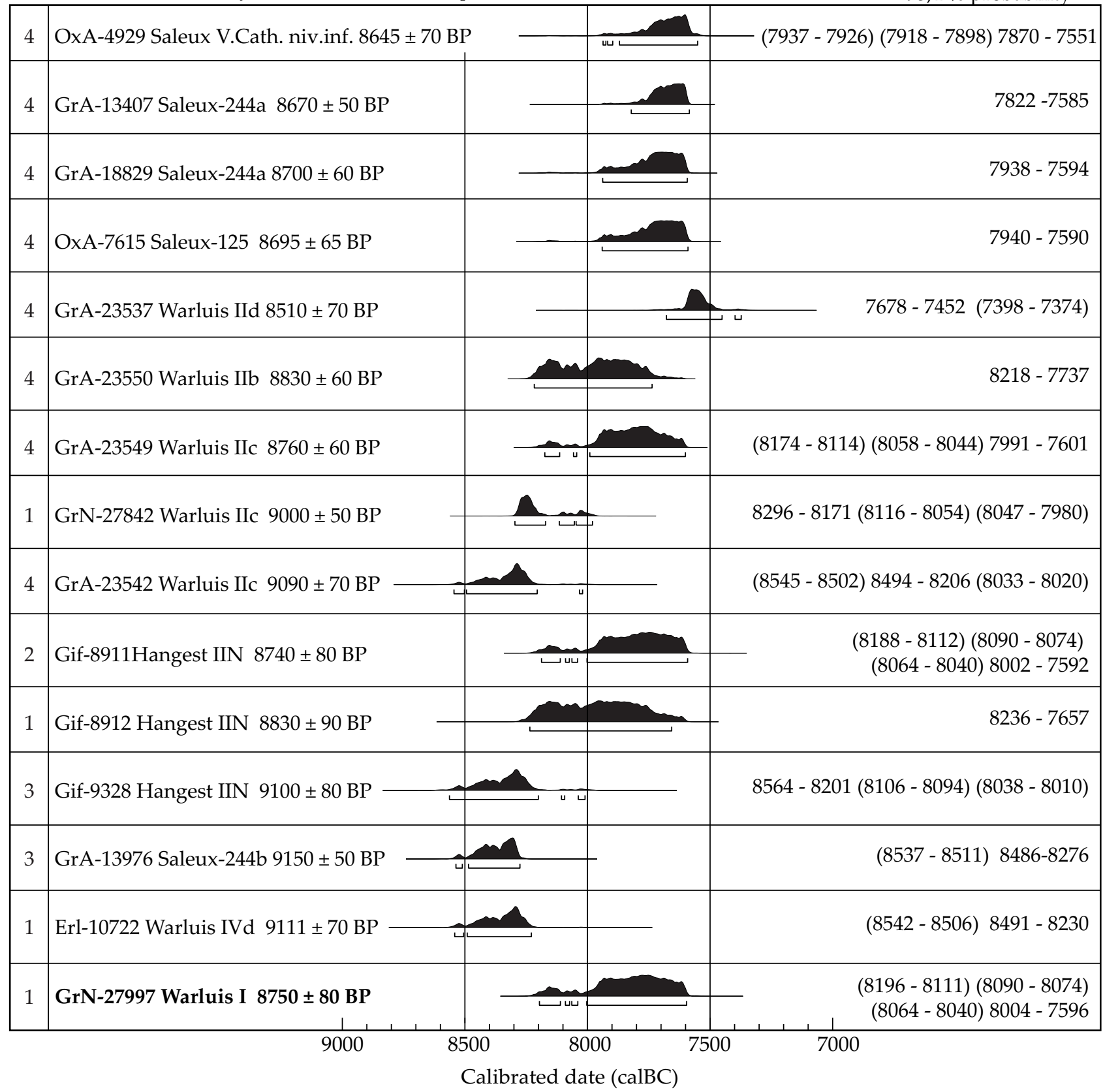

Fig. 32 - Datations absolues concernant le Beuronien à segments (calibration d'après REIMER et al., 2013 ; noisettes carbonisées (1), charbons (2), os (3), os de sanglier (4)).

$\left.\mathrm{n}^{\circ} 7\right)$ présente une abrasion d'une petite portion de son bord latéral convexe sur moins d'un centimètre. Bien qu'elle soit marquée, cette usure est trop restreinte pour pouvoir être interprétée avec certitude comme le résultat d'une action intentionnelle.

Quatre des onze segments analysés portent des traces caractéristiques d'un impact. Le segment $\mathrm{n}^{\circ} 21$ de la figure 27 présente une fracture transversale de son extrémité distale associée à un enlèvement burinant d'une longueur supérieure à $1 \mathrm{~mm}$. Le $\mathrm{n}^{\circ} 42$ révèle à la fois une fracture transversale par flexion avec une languette à extrémité en gradin avec terminaison en escalier sur une pointe et, sur l'autre bout, une zone d'abrasion et de stries superficielles organisées légèrement de biais par rapport à l'axe longitudinal de l'armature.

\section{Les outils $d u$ fonds commun}

Le front du grattoir (fig. 25, $\mathrm{n}^{\circ} 18$ ) présente quelques stigmates trop limités pour être interprétés.

L'observation macroscopique du bord brut de retouche d'aménagement du couteau à dos (fig. 25, $\left.\mathrm{n}^{\circ} 19\right)$ révèle une usure qui témoigne d'une action longitudinale (coupe) avec une matière végétale non ligneuse vraisemblablement assez souple (fig. 33). 
La longueur du bord usé est de $22 \mathrm{~mm}$ et son angle de taillant est d'environ $30^{\circ}$. Sa délinéation est légèrement concave. Le lustre brillant est associéà de multiples écaillures et ébréchures macroscopiques du bord actif. L'analyse microscopique montre qu'il est caractéristique d'une utilisation sur une matière végétale tendre. Cette usure apparaît cependant assez peu développée et témoigne d'un temps d'utilisation assez bref.

Le burin (fig. 25, n²0) ne présente pas de trace.

Deux des six lamelles à troncature obliqueanalysées (fig. 26, $\mathrm{n}^{\circ} 4$ et 7) livrent des traces d'utilisation localisées sur le bord opposé à la troncature. Les usures sont discrètes, faiblement développées et peu caractéristiques. Une utilisation sur une matière animale tendre peut être envisagée avec prudence. Les lamelles à troncature oblique ne regroupent donc pas uniquement des ébauches d'armatures mais aussi des outils à fonction domestique.

\section{Les pièces «utilisées 》}

L'analyse des 31 pièces retouchées peu caractéristiques révèle 6 objets avec des traces d'utilisation interprétables.

Un éclat a sur son bord droit une zone usée sur une longueur de $20 \mathrm{~mm}$ avec un angle de taillant de $60^{\circ}$. Il est affecté par un écaillage millimétrique discontinu et bifacial qui touche plus fortement la
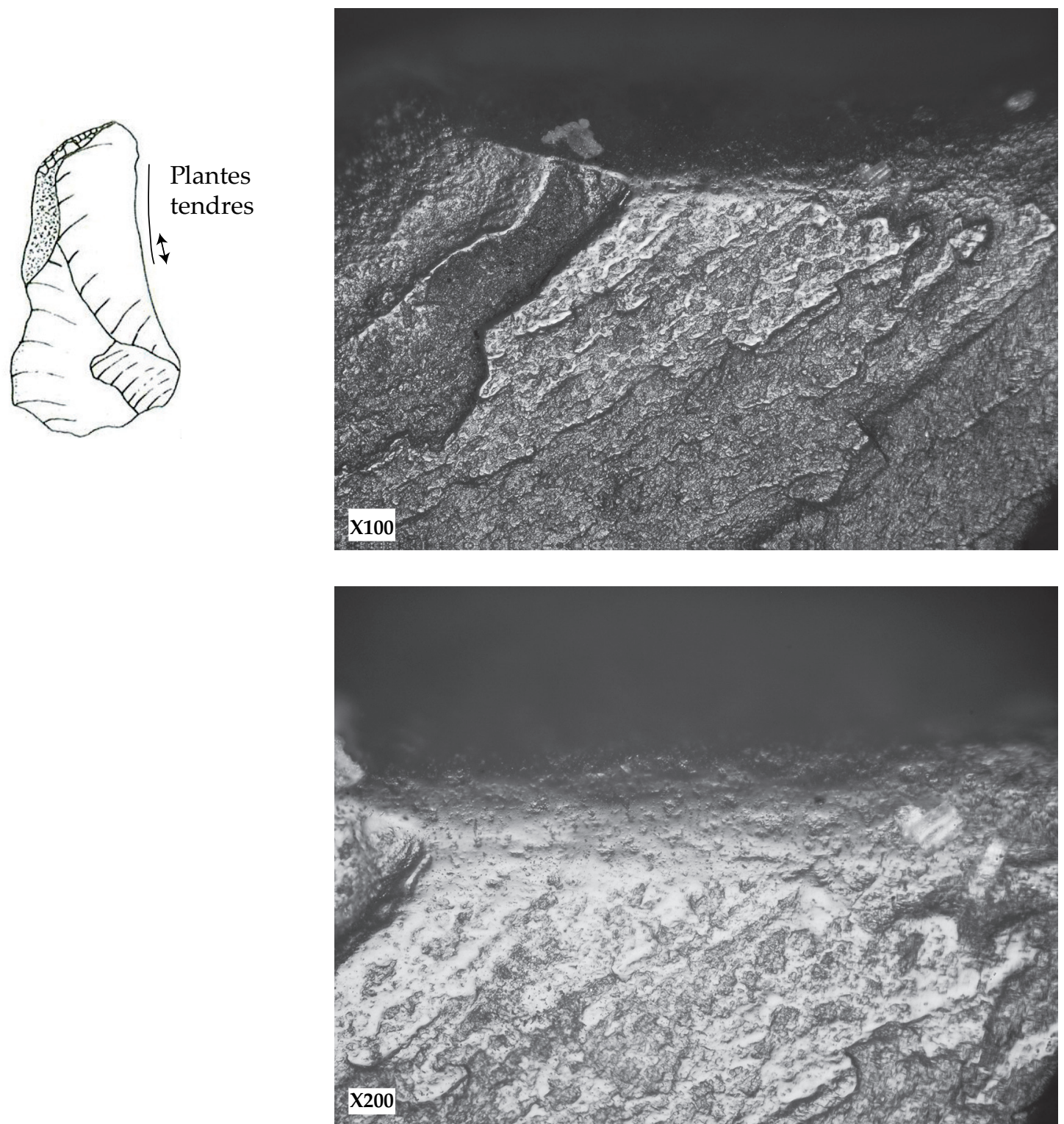

Fig. 33 - Vue du bord brut de retouche d'aménagement du couteau à dos. Une usure témoigne d'une action longitudinale (coupe) avec une matière végétale tendre (vraisemblablement souple). Un lustre brillant est associé à de multiples écaillures et ébréchures du bord actif. Le poli est bifacial, envahissant, brillant à trame unie. Sa coalescence évolue de dure lisse légèrement bombée à douce en retrait du fil. Peu de stries sont visibles. En revanche le poli s'étire et s'agence plutôt longitudinalement ou légèrement de biais par rapport au fil actif. 
face averse. Un micropli assez faiblement développé accompagne cette usure et semble attester de contacts assez brefs et longitudinaux (coupe) sur une matière végétale sans qu'il soit possible d'en préciser la nature exacte.

Le bord droit d'une lamelle « utilisée » (fig. 25, $\mathrm{n}^{\circ} 2$ ) est usée sur une longueur de $22 \mathrm{~mm}$ et l'angle taillant du bord actif est de $40^{\circ}$. L'usure se matérialise par de nombreux enlèvements disposés de manière continue sur le fil et de morphologie variée (écaillure en demi lune et plus rarement scalariforme avec un développement plus envahissant sur la face d'éclatement). Un lustré nettement visible à l'œil nu affecte les deux faces du bord actif. À l'issue de l'examen microscopique, une utilisation de cette pièce en action longitudinale, c'est-à-dire en coupe, d'une matière végétale tendre non ligneuse peut être proposée.

Un autre éclat «utilisé» (fig. 25, n 12) présente un bord droit usé en coupe sur une matière tendre. Ces stigmates peu développés témoignent probablement d'une utilisation assez brève. Ils sont localisés sur une portion de $35 \mathrm{~mm}$ rectiligne avec un angle de taillant de $45^{\circ}$ environ. L'examen du bord gauche révèle un poli faiblement développé associé à un écaillage microscopique de distribution aléatoire. Il montre aussi des spots plus intenses de polis brillants, parfois à coalescence plus dure bombée, sur la microtopographie haute. Ces caractéristiques pourraient évoquer des contacts avec une matière végétale ligneuse de type bois. Très faiblement développés, ces stigmates n'ont pas permis d'être affirmatif sur leur origine, qu'elle soit due à une altération de la pièce ou liée à une opération anthropique. Cependant, un dispositif de type emmanchement est susceptible de laisser ce type de stigmates.
Un nouvel éclat " utilisé » a une portion de bord légèrement usée $\left(\mathrm{L}=60 \mathrm{~mm}\right.$; angle de $\left.40^{\circ}\right)$. L'endommagement du bord est nettement visible à l'œil nu. Les enlèvements sont discontinus et de morphologie diverse (écaillage, ébréchures...). Les stigmates microscopiques sont cependant très ténus (fig. 34). Avec une certaine réserve, il est possible d'envisager que cette pièce ait été actionnée en percussion posée longitudinale, lors d'une action de coupe, sur une matière tendre ou souple, probablement d'origine animale.

Un éclat utilisé (fig. 25, n 16) porte des stigmates assez proches de ceux de la pièce précédente qui pourraient être liés à des contacts en cinématique longitudinale avec des matières animales $(\mathrm{L}=30 \mathrm{~mm}$; angle de $45^{\circ}$ ). L'écaillage est cependant plus marqué avec de nombreuses écaillures scalariformes associées à des spots de polis lisses. Il pourrait provenir de contacts avec un matériau plus dur comme de l'os, survenus lors d'une opération de boucherie.

La lamelle 5 de la figure 25 a également des stigmates de contacts avec une matière animale tendre. Une action longitudinale sur une matière animale tendre peut être envisagée prudemment.

\section{L'exploitation des ressources végétales}

Le travail des plantes est attesté par trois plages usées sur les bords de deux pièces dites utilisées et d'un couteau à dos. La faiblesse de l'échantillon ne permet pas de caractériser plus précisément l'activité. Comme pour la plupart des sites qui ont fait l'objet d'analyses tracéologiques, la proportion des usures liées à l'exploitation des matières végétales est faible. Par exemple, la sphère végétale paraît limitée dans les industries lithiques sauveterriennes (Philibert 2002).
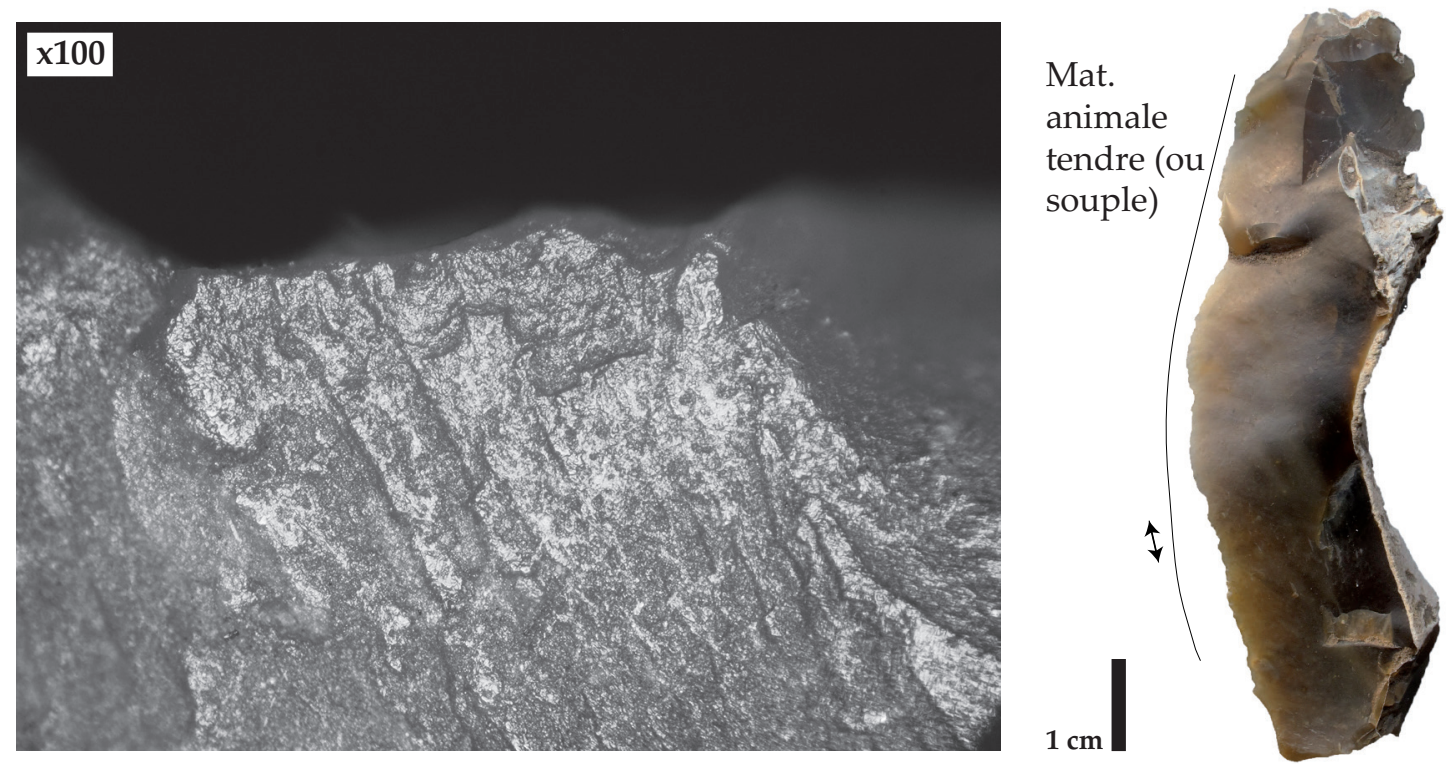

Fig. 34 - Vue du bord usé de l'éclat «utilisé» en coupe longitudinale sur une matière animale tendre (ou souple). Un léger émoussé discontinu par quelques micro écaillures affecte le fil actif de la pièce. Un poli bifacial peu brillant, d'extension modérée, avec une coalescence évoluant de douce grenue à fluide, microtroué, accompagne ces stigmates. Des stries majoritairement fines et courtes barrent longitudinalement ce poli. 


\section{L'exploitation des ressources animales}

Les activités ayant trait aux matières animales sont à peine mieux représentées. Seules 3 pièces utilisées et 1 lamelle tronquée attestent clairement de contacts avec des matières animales tendres en cinématique longitudinale. Ces actions de découpe de viande et de tissus carnés tendres peuvent être sous-estimées par l'analyse pour des raisons taphonomiques.

Un objet montre un endommagement plus important avec une usure. Il s'agirait d'un contact avec os et matière carnée qui pourrait illustrer des opérations de décarnisation ou encore de désarticulation.

Les autres usures sont trop faibles pour que l'on puisse déterminer plus précisément les tissus animaux travaillés. Elles semblent cependant correspondre à la découpe des tissus mous - peau, viande, tissu carné.

\section{L'apport de l'analyse fonctionnelle de l'industrie lithique à l'interprétation de la fonction du site}

Le site correspond à un gîte de matière première où le débitage est une des activités principales. Une seule chaîne opératoire est identifiée avec pour objectif la réalisation de microlithes.

La mise en évidence d'armatures avec des stigmates d'impact montrent aussi l'abandon sur le site d'éléments de projectile utilisés. Ces deux observations témoignent d'un entretien sur le site d'armes de chasse et de l'importance de cette activité.

Les autres pièces utilisées ont également été produites sur place comme le montre le remontage de la figure 21. Le Préhistorique n'avait qu'à récupérer opportunément divers déchets liés à la principale chaîne opératoire pour satisfaire ses besoins en outillage.

Ces supports bruts, par définition peu élaborés, attestent d'activités qui concernent essentiellement l'acquisition et le traitement des tissus carnés, ainsi que de manière plus secondaire, le travail de matières végétales. On note l'absence de témoins concernant d'éventuelles activités artisanales plus élaborées (artisanat des peaux, du bois ou encore des matières osseuses). De plus, les parties utilisées des artefacts sont très peu étendues et résultent probablement d'un usage peu intense ou relativement bref. Il n'y a aucune évidence d'avivage, de recyclage. Aucune utilisation multiple n'a été remarquée et toutes les pièces avec des traces d'utilisations n'ont qu'un seul bord actif. Elles sont donc employées pour une seule tâche. Ces éléments plaident pour un séjour assez court.
Les données fonctionnelles disponibles pour ces industries sont encore rares. L'étude du locus 295 de Saleux (GUERET 2008) offre le point de comparaison le plus proche, dans le temps et l'espace, bien qu'il concerne un Beuronien à triangles scalènes plus récent de quelques siècles (FAGNART et al. 2008).

Les résultats fonctionnels obtenus sont proches de ceux acquis pour Warluis I avec un nombre d'activités limitées dans le temps et dans l'espace. L'occupation de ce locus de Saleux semble correspondre à une halte sûrement assez brève où les activités principales sont centrées autour du réarmement et la fabrication des armes de chasse puis l'acquisition et le traitement des matières animales tendres. La transformation des matières végétales et des matières osseuses est également attestée. On note en revanche la présence plus importante de grattoirs et de produits retouchés, qui pourraient témoigner d'activités de transformation de peaux. L'auteur souligne, cependant, que ces quelques témoignages recueillis concernant le travail des peaux tiendrait plus de l'acquisition que du véritable traitement des tissus carnés en cuir.

\section{Exploitation des ressources animales et implications pour la caractérisation du site}

\section{Caractéristique de l'ensemble faunique}

L'ensemble faunique provenant de l'occupation principale comprend une majorité de fragments de très petite taille, entre 1 et $2 \mathrm{~cm}$ de longueur (fig. 35) et quelques fragments osseux proches d'une configuration anatomique initiale. Une part prépondérante du matériel a subi l'action du feu, d'intensité variable, car les restes sont tantôt carbonisés, tantôt grisâtres, voire calcinés (fig. 36). Parmi ces vestiges brûlés, de nombreux os de bas de pattes de suidé ont été identifiés, évoquant des rejets en connexion. L'hypothèse d'une partie $d u$ matériel issue de structures de combustion ou de vidange de foyer n'est pas à exclure. Parmi les restes non brûlés, on peut remarquer quelques fractures en spirales, notamment sur un fémur et un radiusulna de sanglier (Sus scrofa scrofa), résultant d'une action sur os frais d'origine anthropique (fig. 37). Les os ont également subi des modifications postdépositionnelles comme l'indiquent certaines surfaces et bords de fractures émoussés. Une seule trace de mâchouillage a été identifiée. Par ces quelques caractéristiques, cet ensemble nous rappelle globalement ce que nous avons pu constater sur d'autres séries mésolithiques de sites de plein air étudiées par ailleurs.

\section{Acquisition du gibier}

Avec un total de 114 restes, c'est une faible partie du matériel $(13,8 \%)$ qui a pu être déterminé spécifiquement et anatomiquement. Néanmoins, ce taux doit être relativisé en raison de la très 


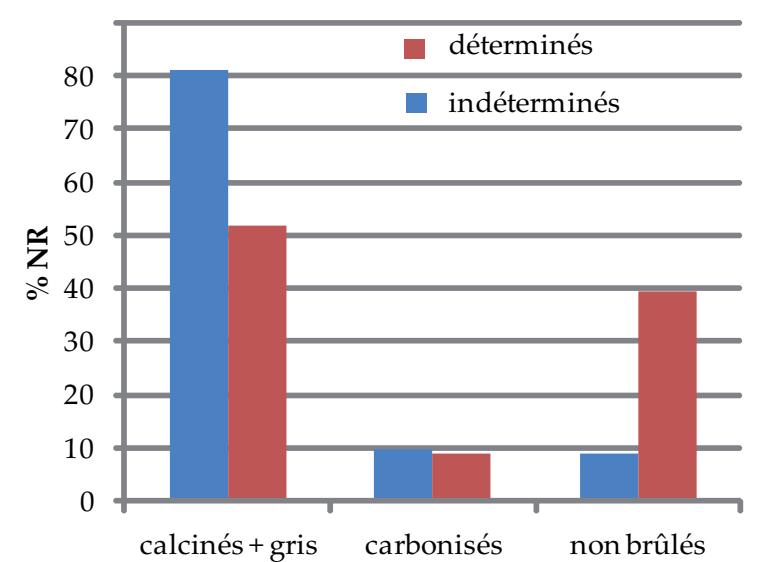

Fig. 35 - Fréquence relative des restes fauniques brûlés et non brûlés.

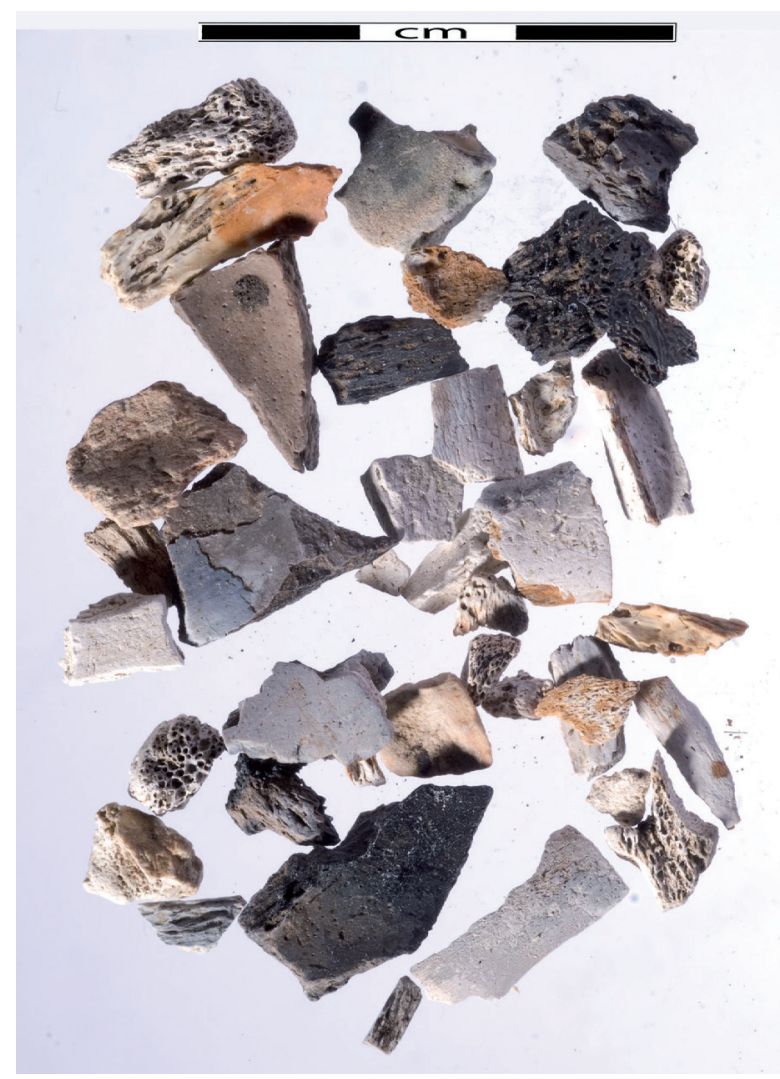

Fig. 36 - Esquilles osseuses brûlées.

forte proportion de petites esquilles brûlées indéterminées. Les ossements de sanglier (Sus scrofa scrofa) sont quasi exclusivement représentés dans cet ensemble (Tab. III). En effet, un fragment proximal de scapula brûlée d'un oiseau (Aves) de petite taille (fig. 38) et deux humérus, non brûlés, de taupe (Talpa europea) sont les seuls autres taxons identifiés. Ces deux derniers restes n'ont probablement aucun lien avec l'activité anthropique et ont été décomptés à part. En revanche l'extrémité de la scapula d'oiseau présente de fines traces obliques résultant probablement d'une désarticulation. En dépit d'un tamisage des sédiments, le cortège de petits mammifères est donc absent sur Warluis I. La proportion d'os brûlés étantimportante, on aurait pu s'attendre à y trouver des ossements de petite taille

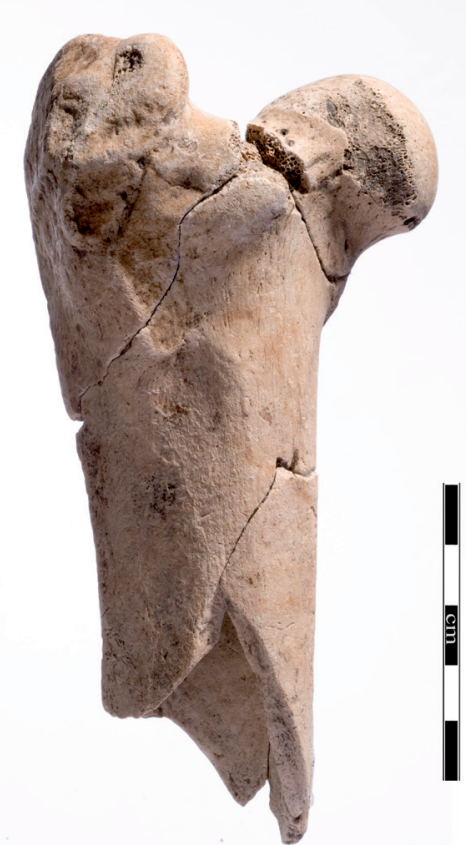

Fig. 37 - Fragment de fémur de sanglier présentant une fracture en spirale sur os frais.

ayant bénéficié de la carbonisation comme facteur de préservation, ainsi que cela a été observé dans certains cas (BRIDAULT et al. 2000), ce qui aurait pu compenser les effets d'une destruction différentielle qui joue en défaveur des petites espèces.

Si l'on tient compte des ossements les plus fréquents, on peut estimer le nombre minimal de sangliers à deux individus (NMIf). Cependant, si l'on tient compte de l'âge individuel en utilisant les stades de développement dentaire et squelettique (BRIDAULT et al. 2000), on obtient un décompte (NMIi, soit par individualisation) plus proche du nombre réel d'individus ayant participé à la constitution de cet ensemble (Tab. III). Quatre individus peuvent être recensés : un d'environ 5-9 ans; deux de 24-26 mois et un juvénile de près d'un an, représenté par un bourgeon dentaire de M2 inférieure et par

\begin{tabular}{|c|c|c|c|}
\hline Espèce & NR & $\%$ NR & NMIf \\
\hline Sanglier (Sus scrofa scrofa) & 96 & 99 & 2 \\
\hline Oiseau indét. (Aves) & 1 & 1 & \\
\hline Total déterminés spécifiquement & 97 & 100 & \\
\hline $\begin{array}{l}\text { Côtes } \\
\text { Taille sanglier } \\
\text { Taille indéterminée }\end{array}$ & $\begin{array}{c}1 \\
11 \\
\end{array}$ & & \\
\hline $\begin{array}{l}\text { Vertèbres } \\
\text { Taille sanglier } \\
\text { Taille indéterminée }\end{array}$ & $\begin{array}{l}2 \\
1\end{array}$ & & \\
\hline $\begin{array}{l}\text { Microfaune } \\
\text { Taupe (Talpa europaea) }\end{array}$ & 2 & & \\
\hline Total identifiés & 114 & 13,8 & \\
\hline Total indéterminés & 712 & & \\
\hline Total & 826 & & \\
\hline
\end{tabular}

Tab. III - Composition de l'ensemble faunique. NR = nombre de restes $;$ NMIf $=$ nombre minimal d'individus de fréquence 


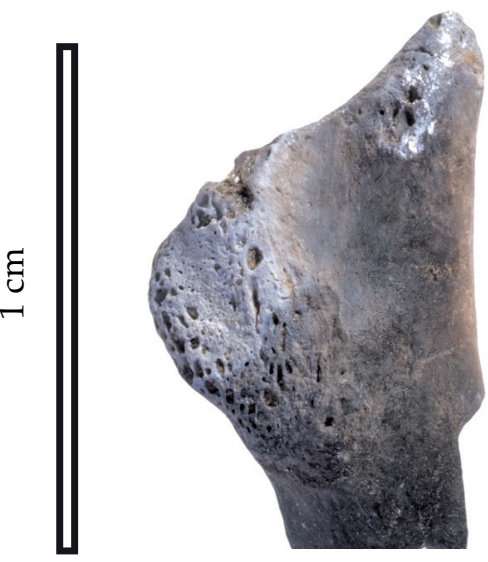

Fig. 38 - Fragment carbonisé de scapula d'oiseau.

une troisième phalange non épiphysée (avec un risque d'erreur sur l'âge plus important que pour les précédents). L'absence de parties diagnostiques (partie antérieure de la mâchoire ou canines) rend impossible l'identification du sexe de ces individus. La structure des âges des animaux abattus pourrait être compatible avec celle d'une compagnie (femelle (s) adulte (s) et jeunes jusqu'à deux ans), ce qui correspondrait à un type de chasse déjà documenté dans différentes régions au Mésolithique (BRIDAult 1994, 1997 ; Leduc 2010 ; MAGNeLL 2005).

Différentes études montrent que les naissances des sangliers s'étalent sur plusieurs mois, variables selon les régions, voire sur plusieurs saisons dans une année, le plus souvent concentrées autour de deux pics saisonniers. On observe fréquemment une première période de mise bas durant la fin de $l^{\prime}$ hiver jusque dans le printemps et éventuellement une deuxième, durant la fin de l'été. Dans une première hypothèse, naissance fin hiver - début printemps, l'occupation se placerait dans une séquence temporelle couvrant la fin de l'hiver et le printemps. Dans l'hypothèse de deux périodes de naissances dans l'année, avec un deuxième pic à la fin été (août-septembre), le site aurait été alors occupé durant l'été, voire jusque dans l'automne.

\section{Traitement des sangliers}

Des traces sub-horizontales ont été observées sur deux fragments d'une même mandibule et correspondent à une opération de désarticulation. Sur la face jugale (ou externe) elles se situent au niveau de la base de la branche, (fig. 39). Presqu'en symétrique, sur la face linguale, d'autres traces, d'une longueur de 21,6 mm, sont localisées au dessous du foramen sur le deuxième fragment conservé. Les mandibules ainsi dissociées du crâne, parce qu'elles n'ont pas été rejetées dans le même secteur, ont dû suivre un « trajet » différent. Enfin, un grand fragment de radius-ulna de sanglier ne présente pas de traces conservées mais une belle fracture longitudinale sur le bord latéro-dorsal du radius (fig. 40). Une des interprétations possible est que la fracturation (pour récupérer la moelle?) intervenait sur l'os encore solidaire d'un segment.

Lorsque l'on tente d'appréhender les 4 individus par les vestiges du squelette post-crânien, il apparaît clairement une représentation différentielle des individus en termes de quantité de vestiges. Certains ne sont attestés que par 1 élément comme l'individu juvénile et d'autres par quelques restes dentaires voire quelques os non soudés. Avec de gros fragments d'os, le squelette de l'individu le plus âgé est le mieux documenté. La représentation proportionnelle des os de sangliers (sur la base du

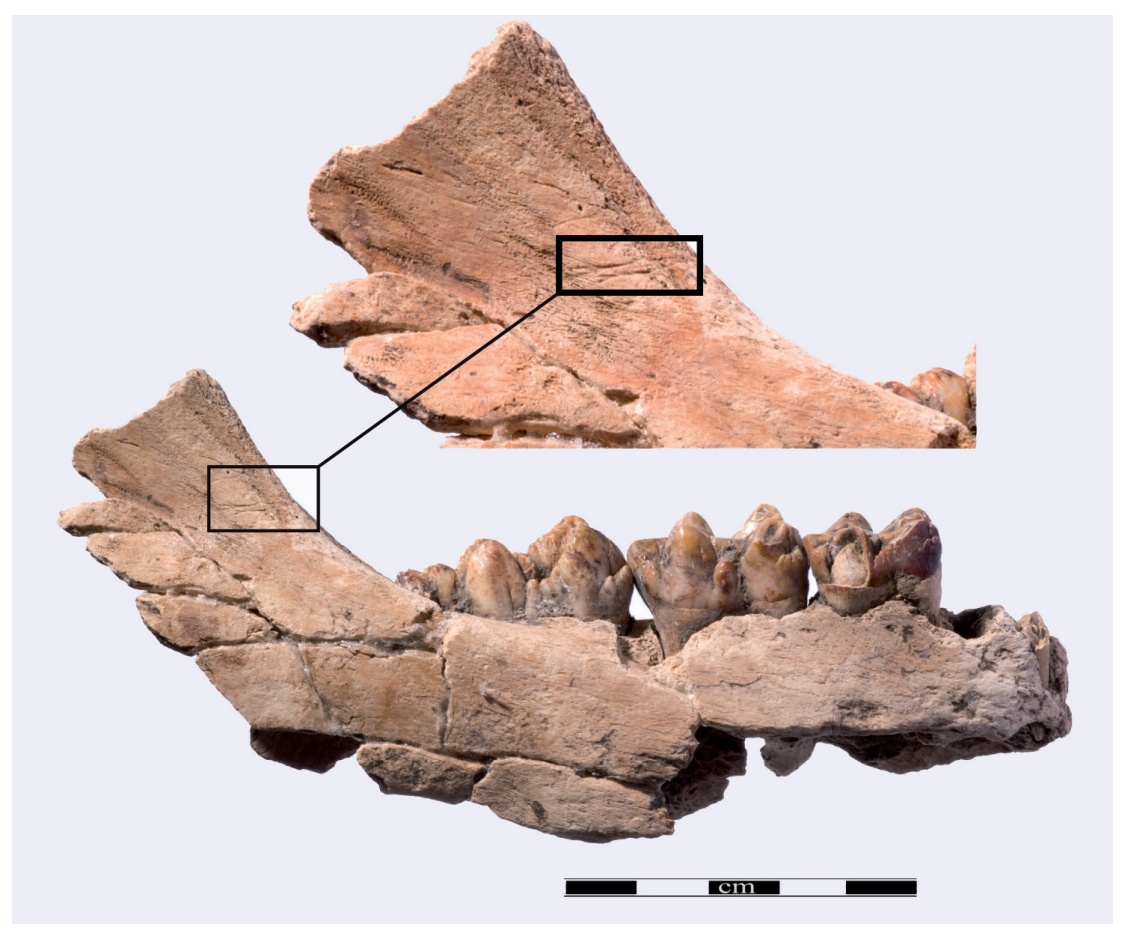

Fig. 39 - Mandibule de sanglier avec des traces de désarticulation. 


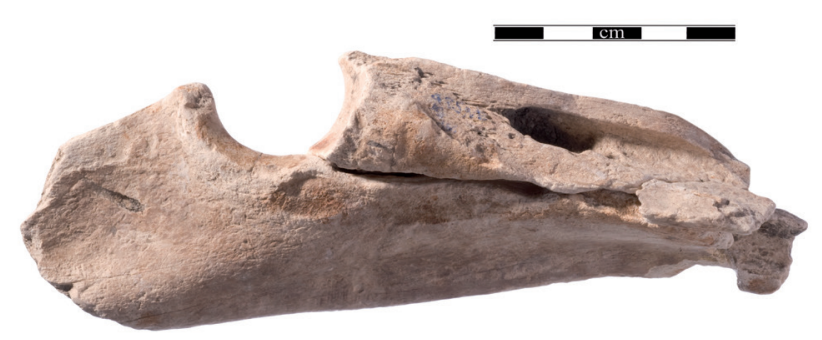

Fig. 40 - Fracture sur radius-ulna de sanglier.

NMIf) de cet ensemble, par rapport au nombre théorique attendu si les squelettes étaient complets, peut aider à caractériser davantage ce corpus (tab IV ; fig. 41).

On constate alors que la représentation proportionnelle des os longs qui composent les segments des membres n'est ni en rapport avec une cohérence de connexion anatomique, ni avec celle de la conservation différentielle. Par exemple, il y a une plus forte représentation des fémurs que des tibias. En revanche, la proportion relative des différents éléments des extrémités des pattes, pour la plupart brûlés, est assez cohérente, bien que l'on observe plus de doigts latéraux que de doigts axiaux. La bonne représentation des os sésamoïdes plaide en faveur d'un rejet sous forme de portions de pieds de deux individus. On note, parmi les éléments totalement absents, les os du crâne, les

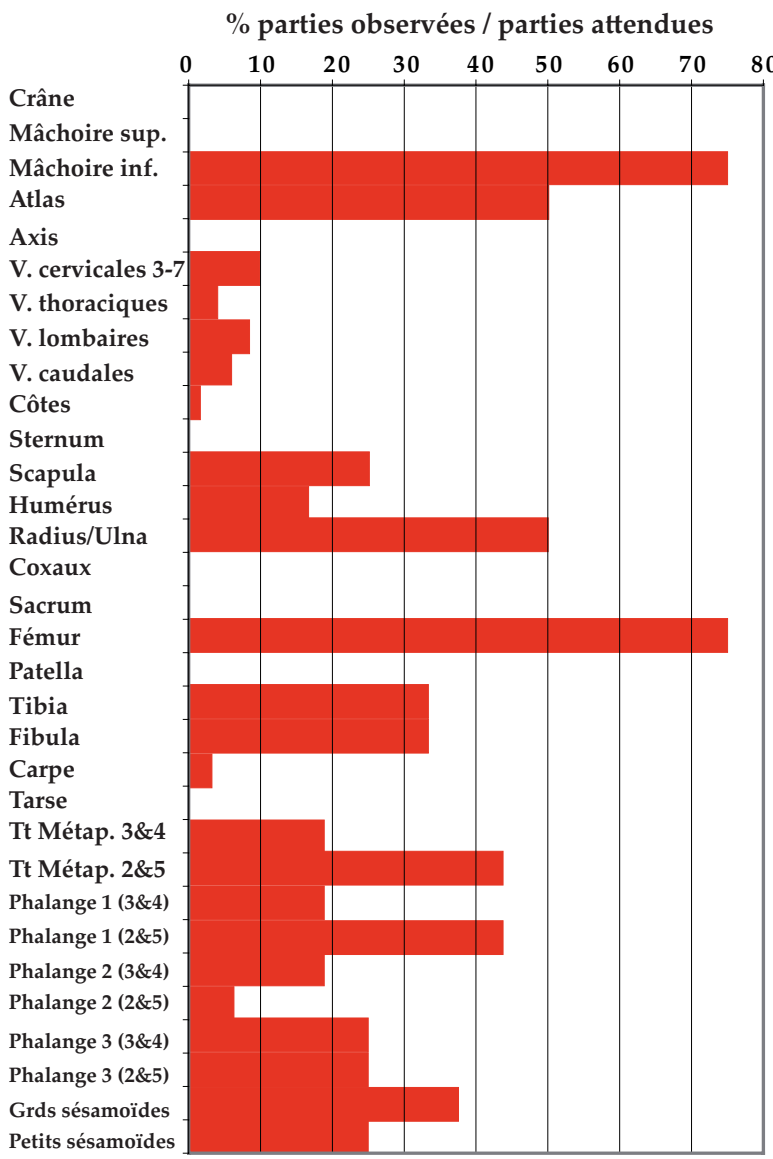

Fig. 41 - Distribution des parties squelettiques de sanglier (en $\%$ PO, $c f$. tab. IV). maxillaires (y compris les dents), les axis, sternums, bassins, sacrums, rotules et les os du tarse. La non préservation des os les plus fragiles ne peut pas expliquer totalement cette configuration car certains possèdent des parties denses et résistantes. Le jeu de la détermination différentielle peut également avoir une incidence, mais on a tenté d'en limiter les effets, en donnant un décompte supplémentaire par identification anatomique. Ici ce sont essentiellement les déficits en vertèbres et en côtes (Tab. III) qui peuvent ainsi être pondérés. Par conséquent, la totalité des manques ne peut pas être expliquée par un biais lié à la détermination ou à un problème taphonomique.

Il faut alors envisager d'autres facteurs pour interpréter cette absence dans une concentration de vestiges qui a été fouillée totalement :

- une sélection pré-dépositionnelle en relation avec la fonction du site et donc la nature des opérations qui ont conduit à ces rejets ;

- la présence des parties anatomiques manquantes dans des extensions non conservées de la concentration ou sur d'autres locus relativement éloignés mais strictement contemporains ;

- voire une combinaison très probable de ces deux facteurs.

La première hypothèse est illustrée par ce paradoxe apparent : l'absence totale de fragment crânien, de mâchoire et de dents supérieures alors qu'une première vertèbre (atlas) quasi entière de sanglier est présente dans l'échantillon. Cette dernière porte quatre petites traces $(0,5 \mathrm{~cm}$ maximum) parallèles deux à deux sur le bord crânio-dorsal. Il y aurait donc eu simplement désarticulation du crâne sur le site, alors que ce dernier et qu'une bonne partie des vertèbres auraient été emportés ailleurs.

Le développement des études menées sur des sites proches sur le plan chronologique et culturel, comme par exemple Warluis II (Ducroce 2013), démontrent que les sites sont généralement plus vastes que prévu. Des remontages systématiques entre des concentrations de vestiges relativement distantes dessinent des occupations préhistoriques sur plusieurs centaines ou milliers de $\mathrm{m}^{2}$ qui comportent plusieurs unités. Par conséquent, si l'on envisage les séquences de traitement / consommation des gibiers ainsi que le déplacement de portions de carcasses à une échelle spatiale plus vaste, la part des carcasses absente sur le site I pourrait se trouver sur d'autres concentrations éventuellement contemporaines. Or, des concentrations du Beuronien à segments ont été détectées à environ $75 \mathrm{~m}$ sur les sites III et IV. Sans compter que des zones maintenant érodées auraient pu correspondre à d'autres unités préhistoriques. 


\begin{tabular}{|c|c|c|c|c|c|c|c|c|c|c|c|}
\hline \multirow[t]{2}{*}{ Partie squelettique } & \multicolumn{3}{|c|}{ NRD } & \multirow[b]{2}{*}{$\Sigma$} & \multicolumn{3}{|c|}{ NMPS } & \multirow[b]{2}{*}{$\Sigma$} & \multirow{2}{*}{$\begin{array}{c}\% \\
\text { NMPS }\end{array}$} & \multirow{2}{*}{$\begin{array}{l}\% \\
\text { NMIf }\end{array}$} & \multirow{2}{*}{$\begin{array}{c}\% \text { PO } \\
(\mathrm{NMI}=2)\end{array}$} \\
\hline & $\mathrm{D}$ & G & Indét. & & $\mathrm{D}$ & G & Indét. & & & & \\
\hline Crâne & & & 0 & 0 & & & & 0 & & & 0,00 \\
\hline Dents supérieures & 0 & 0 & 0 & 0 & & & & & & & \\
\hline Maxillaire & & 0 & & 0 & & & & & & & \\
\hline Total mâchoire sup. & & & & 0 & & & & 0 & & & 0,00 \\
\hline Dents inférieures & 3 & 0 & 0 & 3 & & & & & & & \\
\hline Mandibule & 3 & 0 & 0 & 3 & & & & & & & \\
\hline Total mâchoire inf. & & & & & 2 & & & 3 & & 2 & 75,00 \\
\hline Dents indéterminées & & & 3 & 3 & & & & & & & \\
\hline Atlas & & & 1 & 1 & & & & 1 & & & 50,00 \\
\hline Axis & & & & & & & & 0 & & & 0,00 \\
\hline V. cervicales 3-7 & & & 1 & 1 & & & & 1 & & & 10,00 \\
\hline V. thoraciques & & & 1 & 1 & & & & 1 & & & 3,85 \\
\hline V. lombaires & & & 1 & 1 & & & & 1 & & & 8,33 \\
\hline V. caudale & & & 1 & 1 & & & & 1 & & & 5,00 \\
\hline Côtes & & & 2 & 2 & & & & 1 & & & 1,85 \\
\hline Scapula & & & 1 & 1 & & & & 1 & & & 25,00 \\
\hline Humérus & 1 & 1 & 0 & 2 & 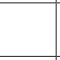 & & & 2 & & & 16,67 \\
\hline Radius/Ulna & 2 & 1 & & 3 & 2 & 1 & & 3 & & 2 & 50,00 \\
\hline Coxaux & & & & 0 & & & & 0 & & & 0,00 \\
\hline Fémur & 1 & 3 & & 4 & 1 & 2 & & 3 & & & 75,00 \\
\hline Patella & & & & 0 & & & & & & & 0,00 \\
\hline Tibia & 4 & 2 & & 3 & 1 & 1 & & 2 & & & 33,33 \\
\hline Fibula & & & 6 & 6 & & & 2 & 2 & & & 33,33 \\
\hline Carpiens / Carpe & 2 & & 1 & 3 & & & & 2 & & & 3,13 \\
\hline Tarsiens/Tarse & 0 & 0 & 0 & 0 & & & & 0 & & & \\
\hline Métacarpiens 3 \& 4 & & 1 & & 1 & & & & & & & \\
\hline \multicolumn{12}{|l|}{ Métacarpiens $2 \& 5$} \\
\hline Métatarsiens 3 \& 4 & 1 & 1 & & 2 & & & & & & & \\
\hline Métatarsiens 2 \& 5 & 1 & & & 1 & & & & & & & \\
\hline $\begin{array}{l}\text { Métapodes } 3 \& 4 \\
\text { indét. }\end{array}$ & & & 4 & 4 & & & & & & & \\
\hline $\begin{array}{l}\text { Métapodes } 2 \text { \& } 5 \\
\text { indét. }\end{array}$ & 1 & & 12 & 13 & & & & & & & \\
\hline Total Métapodes 3 \& 4 & & & & & & & & 2 & 1 & 3 & 18,75 \\
\hline Total Métapodes 2 \& 5 & & & & & & & 2 & & 6 & 7 & 43,75 \\
\hline Phalanges 1 (3 \& 4) & & & 3 & 3 & & & & & & 3 & 18,75 \\
\hline Phalanges 1 ( $2 \& 5)$ & & & 8 & 8 & & & & & & 7 & 43,75 \\
\hline Phalanges 2 (3 \& 4) & & & 4 & 4 & & & & & & 3 & 18,75 \\
\hline Phalanges 2 (2 \& 5) & & & 1 & 1 & & & & & & 1 & 6,25 \\
\hline Phalanges 3 (3 \& 4) & & & 4 & 4 & & & & & & 4 & 25,00 \\
\hline Phalanges 3 (2 \& 5) & & & 4 & 4 & & & & & & 4 & 25,00 \\
\hline Grands sésamoïdes & & & 6 & 6 & & & & & & 6 & 37,50 \\
\hline Petits sésamoïdes & & & 2 & 2 & & & & & & 2 & 25,00 \\
\hline
\end{tabular}

Tab. IV - Représentation des parties squelettiques des sangliers. NRD = nombre de restes déterminés ; NMPS $=$ nombre minimal de parties squelettiques ; NMIf = nombre minimal d'individus de fréquence ; $\% \mathrm{PO}=\%$ parties observées $/$ parties 


\section{Apport de l'étude faunique pour la caractérisation du site}

La faune issue du site de Warluis I est donc quasi-monospécifique, ce qui est singulier dans le panorama des corpus mésolithiques, plutôt caractérisés par une large gamme d'espèces. Ni la conservation différentielle, ni les caractéristiques environnementales n'expliquent cette configuration mono spécifique et l'absence de nombreuses portions de carcasses. En revanche, d'autres facteurs peuvent jouer sur la composition et la représentativité de cet échantillon faunique (et des échantillons en général), comme :

- la représentativité d'un secteur, à l'échelle de la structuration spatiale du site ;

- la nature même des activités pratiquées lors de l'occupation du site, notamment les modalités de traitement des gibiers ;

- la fonction du site à l'échelle du mode d'exploitation des territoires ;

- un mode de subsistance basé essentiellement sur le sanglier.

$\mathrm{Au}$ fur et à mesure des études conduites dans la région, une configuration récurrente se précise : les ensembles fauniques du début de la chronozone du Boréal comptent essentiellement du sanglier (BRIDault 1997, Coutard et al. 2010 ; Ducroce 2001, 2013), représentés par des restes de portions de carcasses de quelques individus chassés. Le spectre faunique de Warluis I ne reflète certainement pas la gamme des ressources potentielles offerte par ces milieux durant cette période. Cela est particulièrement patent concernant le chevreuil, autre gibier potentiel, sans nul doute présent dans l'environnement du site, étant donné qu'il est attesté à Warluis IIIb où il est daté de $8766 \pm 65$ BP (Erl-9384), dans la même fourchette chronologique que celle de l'occupation principale. En revanche, il est possible que le sanglier ait été une espèce particulièrement abondante durant cette période dans ces milieux de fond de vallée propices à son développement. Le sanglier a donc constitué (saisonnièrement ?) une ressource ciblée et son acquisition a pu influencer le choix dans l'implantation des campements.

\section{Les traces de combustion}

\section{Des traces d'activité anthropique}

Les centaines de sondages menés ces dernières années dans les vallées tourbeuses du nord de la France ont montré que des traces de feu matérialisées par quelques charbons sont toujours à mettre en relation avec une implantation humaine et donc un foyer plus ou moins bien conservé. La présence de quelques éléments brûlés épars est d'ailleurs un critère retenu pour justifier une augmentation de la densité des sondages qui, dans ce cas, débouche toujours sur la découverte d'une concentration. La forêt holocène de ces zones humides n'a rien à voir avec la forêt boréale ou méditerranéenne et les incendies naturels semblent exceptionnels. Les seuls contre-exemples sont des racines carbonisées d'arbre foudroyé. Cette observation a été faite sur une zone marginale du site voisin de Warluis II, mais les traces de combustion restent circonscrites à ces racines.

\section{Une probable structure de combustion démantelée}

Une structure de combustion est attestée par une zone fortement cendreuse mise en évidence au nord de la dépression. Elle est surtout soulignée par un sédiment avec des lits cendreux et des vestiges brûlés (restes osseux, charbons, noisettes et industrie lithique) qui témoigne de déplacements post-dépositionnels consécutifs au colmatage de la dépression.

\section{La signification des silex taillés chauffés}

Lefeun'a pasaltérétouslesélémentsdel'industrie lithique dans les mêmes proportions. Hormis deux fragments de nucléus "brûlés ", les nucléus, les tablettes et les pièces à crêtes ne révèlent pas de traces de feu. Les éclats et les produits laminaires sont aussi rarement « brûlés » (respectivement $3 \%$ et $0,6 \%$ ). Excepté une lamelle retouchée, les outils du fonds commun et les pièces « utilisées » ne révèlent pas d'altération thermique. Les microburins sont aussi rarement chauffés $(3,4 \%)$. En revanche, les armatures ont très souvent subi l'action du feu : $33,3 \%$ des pointes à base retouchée, 17,5\% des segments et $40,9 \%$ des fragments d'armature. On peut envisager la fabrication ou la réfection de traits près du foyer, ainsi que la chauffe de la colle avant l'enchâssement sur le trait. Lors de cette activité, les parties endommagées, y compris les fragments de microlithe, sont jetées dans le feu. La découverte de traces de colle (résine ?) sur les segments d'un autre site picard (Ducroce 2013) montre le recours à une telle substance pour préparer les armes de chasse.

\section{Les noisettes carbonisées}

Quelques centaines de fragments de coquille de noisettes ont été retrouvés dispersés sur toute la surface archéologique. Leur présence peut-elle être d'origine naturelle du fait de l'abondance des noisetiers à cette période ? Le sol a pu être pétri de ces coquilles de telle sorte que l'allumage d'un feu aurait eu toutes les chances de griller des coquilles. L'utilisation de branchages de noisetier comme combustible aurait pu également produire des carporestes carbonisés. Étant donné leur dispersion spatiale, l'hypothèse d'un phénomène peu localisé en relation avec une consommation de noisettes est privilégiée. Par comparaison avec d'autres gisements mésolithiques, notamment avec ceux où l'acquisition spécialisée de cette ressource est attestée (HoLst 2010), la quantité recueillie orienterait plutôt vers une consommation modeste. L'hypothèse 
d'une collecte occasionnelle et/ou individuelle de fruits frais à l'automne est vraisemblable et précise la saison d'occupation. Toutefois, on ne peut totalement exclure la consommation différée de graines stockées.

\section{Le rôle de la dépression centrale}

La dépression centrale au contour irrégulier est interprétée comme la résultante de fosses liées à la chute naturelle d'arbres (cf. supra). Tout indique qu'elle était encore marquée dans le paysage pendant l'occupation. Cette attraction des Mésolithiques pour les chablis est maintenant signalée par de nombreux chercheurs comme par exemple P. CROMbé (1993). Sur Warluis I, ces structures dendrogénétiques ont pu engendrer l'ouverture d'une clairière dans la corylaie, comme elles ont permis un accès aisé à une abondante matière première lithique. Ce sont deux paramètres évidemment attractifs.

Peut-on aussi envisager l'existence d'une structure d'habitat couverte sur cette dépression?

Depuis quelques années, les chercheurs européens proposent de plus en plus souvent d'assimiler ces fosses peu profondes à des emplacements de tentes. Plusieurs cas sont attestés comme, par exemple, à Howick dans le nord de la Grande-Bretagne (WADDINGTON 2007). Les structures les plus évidentes concernent la fin du Mésolithique scandinave avec des fosses et parfois du plancher conservé comme à Møllegabet II (SKAARUP \& GRøN 2004). La cuvette de Warluis I a un contour trop irrégulier pour envisager une importante modification anthropique. Cependant, il est possible que cette dépression d'origine naturelle ait subi quelques aménagements pour permettre un séjour un peu plus confortable.

\section{CONCLUSION}

L'implantation préhistorique de Warluis I était située dans une corylaie sur un sol sec de fond de vallée, à quelques dizaines de mètres d'un petit cours d'eau.

L'analyse critique a permis de définir un corpus de vestiges expurgé d'éléments diachroniques et daté directement de $8750 \pm 80$ BP (GrA-27997). Cet ensemble parait correspondre à un seul passage sur le site.

L'outillage lithique est attribuable au Beuronien à segments qui est une tradition mésolithique attestée dans tout le Bassin parisien et en Belgique, surtout documentée par de nombreux sites picards.

À Warluis I, l'activité la plus évidente est le débitage de nombreux blocs de matière première entretenir l'équipement de chasse. Cela n'en fait pas pour autant une halte de chasse, d'autant que l'analyse fonctionnelle montre un traitement des matières végétale et animale et qu'une structure de combustion est mise en évidence. Néanmoins, la prédation est ciblée sur le sanglier et les animaux abattus peuvent correspondre à un seul épisode de chasse d'une compagnie à la fin de l'hiver-début du printemps. Les indices de traitement de quelques carcasses de sanglier pointent à la fois des opérations de boucherie primaire (désarticulation de la tête et probablement des extrémités des pattes rejetées en connexion) ainsi qu'un traitement des carcasses plutôt expédient (fracturation d'un radius-ulna et d'un fémur sans désarticulation), qui ont eu lieu sur le site. L'exploitation de noisettes reste modeste et a pu constituer un appoint alimentaire. D'autres indicateurs plaident pour un séjour de courte durée, comme la brièveté d'utilisation des outils ou l'absence de témoignage du travail de l'os ou des peaux qui nécessite beaucoup de temps.

Une telle durée limitée n'a pas nécessité d'agencements élaborés du campement. L'aménagement s'est probablement limité à tirer parti d'une dépression préexistante idéalement placée sur le gîte de matière première à quelques dizaines de mètres d'un cours d'eau et dans une zone probablement giboyeuse. Une structure couverte associée à des lieux de couchages a pu être édifiée grossièrement sans laisser de traces tangibles.

Comme il a été discuté plus haut, Warluis I ne représente probablement qu'une portion d'un site un peu érodé sur ses marges ou caractérisé par la présence de plusieurs concentrations de vestiges relativement éloignées mais contemporaines. Dans cette hypothèse, on peut expliquer l'absence d'une partie des carcasses de sanglier par une dissociation spatiale des séquences de traitement et / ou de consommation du gibier à l'échelle d'un vaste site, voire par une redistribution des produits de la chasse, hors du site.

Plusieurs hypothèses sont envisageables pour interpréter la fonction d'un tel site à l'échelle de l'exploitation du territoire.

A - L'occupation principale de Warluis I peut être interprétée comme un secteur consacré à des activités limitées dans le temps au sein d'un vaste site de type résidentiel occupé relativement longtemps, avec, sur d'autres secteurs, des témoignages d'activités complémentaires.

B - Warluis I serait représentatif d'une unité d'un habitat résidentiel du Beuronien à segments avec pour caractéristique un spectre limité d'activités et un temps d'occupation assez bref. L'ensemble des activités indispensables à la survie du groupe serait réalisé au gré des différentes 
haltes. Dans cette hypothèse, les Mésolithiques exploiteraient leur territoire selon une forte mobilité résidentielle des groupes familiaux entre des sites de même configuration, comme cela a été proposé pour le Sauveterrien méridional (PHILIBERT 2004) contemporain du Beuronien à segments.

C- Enfin, Warluis I serait un campement occupé par une parte du groupe pour un temps limité. La chasse et la collecte seraient les activités principales. La traduction archéologique de ce type d'occupation serait identique à celle de l'hypothèse B. En outre, un tel camp à activité spécifique devrait théoriquement être connecté à un campement résidentiel étendu, occupé longtemps et consacré à de nombreuses activités. Hors, dans l'état actuel des recherches, ce type de site est inconnu dans le contexte culturel du Beuronien à segments.

Pour aller plus avant dans l'interprétation, il faut achever l'étude des sites déjà fouillés, notamment en Picardie, et également poursuivre les investigations sur le terrain. L'intérêt de gisements comme Warluis I est d'aboutir à un questionnement de type palethnologique et de dépasser la simple présentation des vestiges exhumés.

\section{BIBLIOGRAPHIE}

BLONDEAU Alphonse, CAVELIER Claude \& MONCIARDINI Christian (1970) - Carte géologique au $1 / 50000$ «Clermont » (XXIII), BRGM, Orléans.

BRIDAULT Anne (1994) - " Les économies de chasses épipaléolithiques et mésolithiques dans le Nord et l'Est de la France : nouvelles analyses », Anthropozoologica, 198, p. 55-67.

BRIDAULT Anne (1997) - « Chasseurs, ressources animales et milieux dans le Nord de la France de la fin du Paléolithique à la fin du Mésolithique » dans FAGNART Jean-Pierre \& THÉVENIN André (dir.) - Le Tardiglaciaire en Europe du nord-ouest. Actes du $119^{\circ}$ Congrès annuel des sociétés historiques et scientifiques (Amiens, 1994), éd. du C.T.H.S., p. 166-176

BRIDAULT Anne avec la coll. de Patricia CHIQUET (2000) - " L'exploitation des ressources animales à la Baume d'Ogens (Vaud, Suisse) » dans P. CROTTI (dir.), - MESO '97. Actes de la Table Ronde Épipaléolithique et Mésolithique (Lausanne, 21-23 novembre 1997), Cahiers d'archéologie romande n ${ }^{\circ}$ 81, p. 101-108.

BRIDAULT Anne, VIGNE Jean-Denis, HORARDHERBIN Marie-Pierre, PELLÉ Éric, FIQUET Pierre \& MASHKOUR Marjan (2000) - «Wild boar - Age at death estimates: the relevance of new modern data for archaeological skeletal material. 1, Presentation on the corpus. Dental and epiphyseal fusion ages» Ibex Journal of Mountain ecology, 5 - Anthropozoologica, 31, p. 11-18.

CASPAR Jean-Paul (1988) - Contribution à la tracéologie lithique du Néolithique ancien dans l'Europe Nord-Occidentale, Thèse de doctorat, Université catholique de Louvain, Louvain-la-Neuve, 2 vol., 194 p.
CHESNAUX Lorène (2013) - « Les microlithes du 62 rue Henry-Farman à Paris (15 ${ }^{\mathrm{e}}$ arrondissement) : des flèches diverses pour différents gibiers abattus en des lieux distincts ? " dans B. VALENTIN, B. SOUFFI, T. DUCROCQ, J.P. FAGNART, F. SEARA \& C. VERJUX (dir.) - Palethnologie du Mésolithique. Recherches sur les habitats de plein air entre Loire et Neckar, actes de la table-ronde internationale de Paris, 26 et 27 novembre 2010, Paris, Société Préhistorique Française, (Séances de la Société Préhistorique Française, 2-1), p. 119-132.

COLES Bryony (1998) - «Doggerland : A speculative survey ", Proceedings of the Prehistoric Society, 64, p. 45-81.

COUTARD Sylvie, DUCROCQ Thierry, LIMONDINLOZOUET Nicole, BRIDAULT Anne, LEROYER Chantal, ALLENET Gisèle \& PASTRE Jean-François (2010) " Contexte géomorphologique, chronostratigraphique et paléoenvironnemental des sites mésolithiques et paléolithiques de Warluis dans la vallée du Thérain (Oise, France)», Quaternaire, 21 (4), 357-384.

CROMBÉ Philippe (1993) - « Tree-fall features on final Palaeolithic and Mesolithic sites situated on sandy soils : how to deal with it », Helinium, 33, 1, p. 50-66.

DUCROCQ Thierry (1987) - «Quelques précisions sur la fabrication des armatures mésolithiques », Bulletin de la Société Préhistorique Française, 84, 2, p. 46-47.

DUCROCQ Thierry(1991) - « Le Mésolithique ancien et moyen du Bassin de la Somme (Nord de la France). Données typologiques et premiers éléments de chronologie ", Bulletin de la Société Préhistorique Luxembourgeoise, 12, p. 21-37.

DUCROCQ Thierry (1992) - «Une nouvelle occupation mésolithique datée dans le Nord de la France », Bulletin de la Société Préhistorique Française, 90, 3, p. 72-73.

DUCROCQ Thierry (2001) - Le Mésolithique du bassin de la Somme. Insertion dans un cadre morpho-stratigraphique, environnemental et chronoculturel. Publications du CERP, 7 , 255 p. , 200 fig. , 39 tabl.

DUCROCQ Thierry (2009) - « Éléments de chronologie absolue du Mésolithique dans le Nord de la France » dans CROMBÉ Philippe, Van STRYDONCK Mark, SERGANT Joris, BOUDIN Mathieu \& BATS Machteld - Chronology and evolution within the Mesolithic of North-West Europe. Cambridge Scholars Publishing, Newcastle, p. 345-362.

DUCROCQ Thierry (2010) - « Des traces discrètes d'occupations paléolithiques et mésolithiques dans le Marais de Warluis (Oise) : les sites VI et IX ", Revue Archéologique de Picardie, 2010, 1/2, p. 5-40.

DUCROCQ Thierry (2013) - « Le Beuronien à segments dans le nord de la France. Prémices d'une approche palethnologique » dans B. VALENTIN, B. SOUFFI, T. DUCROCQ, J.P. FAGNART, F. SEARA \& C. VERJUX (dir.) - Palethnologie du Mésolithique. Recherches sur les habitats de plein air entre Loire et Neckar, actes de la table-ronde internationale de Paris, 26 et 27 novembre 2010, Paris, Société Préhistorique Française, (Séances de la Société Préhistorique Française, 2-1), p. 189-206.

DUCROCQ Thierry, BRIDAULT Anne \& COUTARD Sylvie (2008) - « Le gisement mésolithique de Warluis : approche préliminaire "dans FAGNART Jean-Pierre, THÉVENIN André, DUCROCQ Thierry, SOUFFI Bénédicte\&COUDRETPaule (dir.), Le début du Mésolithique 
en Europe du Nord-Ouest, actes de la table-ronde (Amiens, 9-10 octobre 2004), Paris, Société Préhistorique Française, (Mémoire 45), p. 85-106.

DUCROCQ Thierry, BRIDAULT Anne, KETTERER Isabelle, LEROYER Chantal \& LIMONDIN-LOZOUET Nicole (2003) - Warluis, Le Marais de Merlemont - carrière Chouvet, secteurs I, II et III, rapport de fouilles, Afan/ Inrap, Service régional de l'Archéologie de Picardie, Amiens, $230 \mathrm{p}$.

FAGNART Jean-Pierre, COUDRET Paule \& SOUFFI Bénédicte (2008) - « Les occupations mésolithiques du gisement de Saleux » dans J.-P. Fagnart, A. Thévenin, T. Ducrocq, B. Souffi \& P. Coudret (dir.) - Le début du Mésolithique en Europe du Nord-Ouest, actes de la tableronde (Amiens, 9-10 octobre 2004), Paris, Société Préhistorique Française, (Mémoire 45), p. 107-133.

GOB André (1985) -Typologie des armatures et taxonomie des industries du Mésolithique au nord des Alpes. Cahiers de l'Institut Archéologique Liégeois, II, 79 p.

GRISELIN Sylvain, HAMON Caroline \& BOULAY Guy (2013) - «Fabrication et utilisation des outils prismatiques de type montmorencien : l'exemple du 62 rue HenryFarman à Paris $\left(15^{\mathrm{e}}\right.$ arrondissement)» dans B. VALENTIN, B. SOUFFI, T. DUCROCQ, J.P. FAGNART, F. SEARA \& C. VERJUX (dir.) - Palethnologie du Mésolithique. Recherches sur les habitats de plein air entre Loire et Neckar, actes de la table-ronde internationale de Paris, 26 et 27 novembre 2010, Paris, Société Préhistorique Française, (Séances de la Société Préhistorique Française, 2-1), p. 133-145.

GUERET Colas (2008) - Tout en souplesse! Approche fonctionnelle de l'outillage du Mésolithique moyen provenant du locus 295 de Saleux-Les Baquets (Somme), Mémoire de Master de l'Université de Paris 1.

HOLST Daniela (2010) - « Hazelnut economy of early holocene hunter-gatherers: a case study from mesolithic Duvensee, northern Germany », Journal of Archaeological Science, 37, p. 2871-2880.

JELGERSMA Saskia (1979) - « Sea-level changes in the north sea basin » dans OELE E. , SCHÜTTENHELM R.T.E. \& WIGGERS A.J. (éd.) - The Quaternary History of the North Sea, Uppsala, Univ. Soc. Upsaliensis pro geologia quaternaria (Acta Universitatis Upsaliensis, Symposium Universitatis Upsaliensis Annum Quingentesimum Celebrantis, 2), p. 233-248.

KEELEY Lawrence Harper (1980) - Experimental determination of stone tool uses : A microwear analysis, University of Chicago Press, 212 p.

KOZŁOWSKI Stefan Karol (1983) - Cultural differentiation of Europe from 10 th to 5 th millenium B.C. Warsaw University Press, 258 p. , 50 fig.

LANG Laurent \& SICARD Sandra (2008) - « Les occupations mésolithiques des Closeaux à RueilMalmaison (Hauts-de-Seine) » dans FAGNART Jean-Pierre, THÉVENIN André, DUCROCQ Thierry, SOUFFI Bénédicte \& COUDRET Paule (dir.) - Le début du Mésolithique en Europe du Nord-Ouest, actes de la table-ronde (Amiens, 9-10 octobre 2004), Paris, Société Préhistorique Française, (Mémoire 45), p. 65-83.

LEDUC Charlotte (2010) - «Stratégies d'acquisition et d'exploitation des ressources animales à partir d'un habitat maglemosien (Mésolithique ancien d'Europe du Nord) en contexte lacustre à Mullerup (Sjælland,
Danemark) » dans T. NICOLAS \& A. SALAVERT (dir.), - Territoires et économies, actes de la $2^{\mathrm{e}}$ Journée doctorale d'archéologie de l'université Paris 1 - Panthéon-Sorbonne (Paris, 2 juin 2007), Paris, Publications de la Sorbonne (Achéo. doct, 2), p. 47-75.

MAGNELL Ola (2005) - « Harvesting Wild Boar, a Study of Prey Choice by Hunters During the Mesolithic in South Scandinavia by Analysis of Age and Sex Structures in Faunal Remains ", Archaeofauna, 14, p. 27-41.

MUNAUT André-Valentin \& DEFGNÉE Anne (1997) - « Biostratigraphie et environnement végétal des industries du Tardiglaciaire et du début de l'Holocène dans le bassin de la Somme » dans FAGNART JeanPierre \& THÉVENIN André (dir.) - Le Tardiglaciaire en Europe du nord-ouest, actes du $119^{\mathrm{e}}$ Congrès annuel des sociétés historiques et scientifiques (Amiens, 1994), éd. du C.T.H.S., p. 27-37.

PELEGRIN Jacques (2000) - « Les techniques de débitage laminaire au Tardiglaciaire : critères de diagnose et quelques réflexions " dans VALENTIN Boris, BODU Pierre \& CHRISTENSEN Marianne (dir.) - L'Europe centrale et septentrionale au Tardiglaciaire, actes de la tableronde (Nemours, 13-16 mai 1997), Mémoires du Musée de Préhistoire d'Île de France, 7, p. 73-86.

PHILIBERT Sylvie (2002) - Les derniers « Sauvages », Territoires économiques et systèmes techno-fonctionnels mésolithiques, British Archaeological Reports International Series 1069, John et Erica Hedges Ltd editions, Oxford, 193 p.

PHILIBERT Sylvie (2004) - « Identity of the mediterranean Sauveterrian into techno-economic and social european Mesolithic » dans CROMBÉ Philippe \& VERMEERSCH Pierre (dir.) - Le Mésolithique, actes du XIVe Congrès de l'UISPP, section 7 (Université de Liège, Belgique, 2-8 septembre 2001), Oxford, Archaeopress, BAR International Series, 1302), p. 205-213.

PLISSON Hugues (1985) - « Contribution de la tracéologie à la localisation des aires d'activité et d'occupation », L'Anthropologie, 89, 4, p. 473-478.

REIMER Paula J., BARD Edouard, BAYLISS Alex, BECK J. Warren, BLACKWELL Paul G., BRONK RAMSEY Christopher, BUCK Caitlin E., CHENG Hai, EDWARDS R. Lawrence, GROOTES Pieter M., GUILDERSON Thomas P., HAFLIDASON Haflidi, HAJDAS Irka, HATTÉ Christine, HEATON Timothy J., HOFFMANN Dirk L., HOGG Alan G., HUGHEN Konrad A., KAISER Klaus Felix, KROMER Bernd, MANNING Sturt W, NIU Mu, REIMER Ron W., RICHARDS David, SCOTT E.Marian, SOUTHON John R., STAFF Richard A., TURNEY Christian S.M., VAN DER PLICHT Johannes (2013) - « IntCal13 and Marine13 radiocarbon age calibration curves, $0-50,000$ years cal BP ». Radiocarbon, 55, 4, p. 1869-1887.

ROZOY Jean-Georges (1969) - « Typologie de l'Epipaléolithique (Mésolithique) franco-belge. Réunion de 5 separata » Bulletin de la Société Préhistorique Française, 1966, 1967, 1968, 121 p. , 35 fig.

ROZOY Jean-Georges (1978) - Les derniers chasseurs. L'Epipaléolithique en France et en Belgique. Essai de synthèse. Bulletin de la Société Archéologique Champenoise, 3 vol. , $1256 \mathrm{p}$.

SKAARUP Jørgen et GRØN Ole (2004) - Møllegabet II. A submerged mesolithic settlement in southern Denmark. Langelands Museum, BAR International Series 1328, Oxford, Archaeopress, 199 p., 130 fig., 18 tabl. 
SOMMÉ Jean (1999) - « L'évolution de la plaine maritime de la mer du Nord (France) et la formation du Pas de Calais » dans Archéologie du littoral Manche-mer du Nord, Calais, Amis du vieux Calais (Bulletin des Amis du vieux Calais, 160-161-162), p. 430-441.

SOMMÉ Jean, MUNAUT André-Valentin, EMONTSPOHL Anne-Françoise, LIMONDIN Nicole, LEFEVRE David, CUNAT Nicole, MOUTHON Jacques \& GILOT Étienne (1992) - « Weichsélien ancien et Holocène marin à Watten (plaine maritime, Nord, France) ", Quaternaire, 3, 2, p. 87-89.

TARRÊTE Jacques (1977) - Le Montmorencien. Xe suppl. à Gallia Préhistoire, 216 p., 71 fig., 18 tabl., 8 pl.

TARRÊTE Jacques (1989) - « Le Montmorencien » dans J. -P. MOHEN (dir.) - Le Temps de la Préhistoire, p. 344-345.
TAUTE Wolfgang (1973) - « Neue Forschungen zur Chronologie von Spätpaläolithikum und Mesolithikum in Süddeutschland » dans Neue paläolithische und mesolithische Ausgrabungen in der Bundesrepublik Deutschland, Zum IX, INQUA-Kongress Neuseeland, p. 59-66.

Van ZEIST Wim et Van der SPOEL-WALVIUS MR (1980) - " A palynological study of the Late-Glacial and the Postglacial in the Paris Basin ». Paleohistoria, 22, p. 67-107.

VAUGHAN Patrick C. (1985) - Use-wear analysis of flaked stone tools, University of Arizona Press, Tucson, 204 p.

WADDINGTON Clive (ed.) (2007) - Mesolithic settlement in the north sea basin. A case study from Howick, North-East England. Oxbow Books, Oxford, 235 p.

\title{
Les auteurs
}

\author{
Thierry DUCROCQ \\ INRAP Nord-Picardie \\ 518, rue Saint-Fuscien \\ 80000 Amiens \\ thierry.ducrocq@inrap.fr
}

Anne BRIDAULT

CNRS, ArScAn UMR 7041,

Maison d'archéologie et d'Ethnologie,

21 allée de l'Université

92000 Nanterre

anne.bridault@mae.u-paris10.fr

Nicolas CAYOL

UMR 8215 « Trajectoires »

INRAP Nord-Picardie

Avenue du Parc

60400 PASSEL

nicolas.cayol@inrap.fr

Sylvie COUTARD

UMR CNRS 8591 - Laboratoire de Géographie Physique

INRAP Nord-Picardie

518, rue Saint-Fuscien

80000 Amiens

sylvie.coutard@inrap.fr

\section{Résumé}

La fouille préventive du gisement de Warluis I, dans la vallée du Thérain (Oise), a permis d'isoler une concentration de vestiges du Beuronien à segments datés de la deuxième moitié du huitième millénaire avant notre ère. Les Préhistoriques se sont installés sur un sol sec boisé à proximité d'un cours d'eau. Ils ont exploité sur place une matière première siliceuse abondante, ont collecté des noisettes et ont pratiqué une prédation ciblée sur le sanglier, probablement une compagnie (laie et ses petits). Le faible nombre d'animaux, l'absence de certaines parties squelettiques, la pauvreté typologique de l'outillage ainsi que sa courte durée d'utilisation, plaident en faveur d'un séjour de durée limitée.

Mots clés : nord de la France, plaine alluviale, Mésolithique, Beuronien à segments, sanglier, fonction des sites 
Abstract

Keywords : North of France, flood plain, Mesolithic, Beuronian with crescents, wild pig, function of the sites.

Zusammenfassung

Schlüsselwörter : 